\title{
APPLICATION STUDY OF WIND POWER TECHNOLOGY TO THE CITY OF HART, MICHIGAN
}

Progress Report
J. Asmussen
P. D. Fisher
G. L. Park
O. Krauss

December 31, 1975

Work Performed Under Contract No. E(11-1)-2603

Division of Engineering Research

Michigan State University

East Lansing, Michigan

\section{MASTER}

\section{ENERGY RESEARCH AND DEVELOPMENT ADMINISTRATION}

\section{Division of Solar Energy}




\section{DISCLAIMER}

This report was prepared as an account of work sponsored by an agency of the United States Government. Neither the United States Government nor any agency Thereof, nor any of their employees, makes any warranty, express or implied, or assumes any legal liability or responsibility for the accuracy, completeness, or usefulness of any information, apparatus, product, or process disclosed, or represents that its use would not infringe privately owned rights. Reference herein to any specific commercial product, process, or service by trade name, trademark, manufacturer, or otherwise does not necessarily constitute or imply its endorsement, recommendation, or favoring by the United States Government or any agency thereof. The views and opinions of authors expressed herein do not necessarily state or reflect those of the United States Government or any agency thereof. 


\section{DISCLAIMER}

Portions of this document may be illegible in electronic image products. Images are produced from the best available original document. 


\section{NOTICE}

This report was prepared as an account of wurk sponsored hy the United States Government. Neither the United States nor the United States Energy Research and Development Administration, nor any of their employees, nor any of their contractors, subcontractors, or their employees, makes any warranty, express or implied, or assumes any legal liability or responsibility for the accuracy, completeness or usefulncss of any information, apparatus, product or process disclosed, or represents that its use would not infringe privately owned rights.

This report has been reproduced directly from the best available copy.

Available from the National Technical Information Service, U. S. Department of Commerce, Springfield, Virginia 22161

Price: Paper Copy $\$ 5.50$ (domestic)

$\$ 8.00$ (foreign)

Microfiche $\$ 3.00$ (domestic)

$\$ 1.50$ (foreign) 
Progress Report

Energy Research and Development

Administration

Washington, D. C.

\section{APPLICATION STUDY OF WIND POWER TECHNOLOGY TO \\ THE CITY OF HART, MICHIGAN}

prepared by

Project Director: Dr. Jes Asmussen

Principal Investigator: Dr. P. D. Fisher

Principal Investigator: Dr. G. L. Park

Principal Investigator: Dr. O. Krauss

December 31, 1975

$\mathrm{E}(1.1-1)-2603$

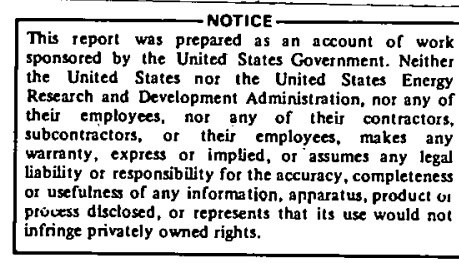

Division of Engineering Research

MICHIGAN STATE UNIVERSITY

East Lansing, Michigan 48824

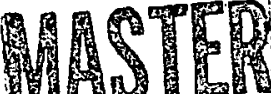




\begin{abstract}
This proposal seeks follow-on funding support for a Year II effort [Year I is under ERDA Grant E(1l-1)-2603] concerned with wind energy application to small municipal electric systems and rural electric cooperatives. A microcosmic approach is used as contrasted with the macrocosmic one of the national mission studies. It is proposed to: (1) go on with the study of the wind-hydro combination to achieve base-load or load-following capability, in addition to study of the fuelsaver mode of operation; (2) continue wind data development necessary in support of the effort; and (3) devise economic-and systems-models covering a number of operating modes. Emphasis is on technical feasibility and a systems study to define the economic potential of the various applications for several time-horizons. The information so developed will be generalized in order that it may find application elsewhere.
\end{abstract}




\section{TABIE' OF CONTENTS}

1. SUMMARY OF INTERIM REPORT

1.1. Wind Data Collection and Analysis

1.2. Hart Power Demand and Consumer Usage

1.3. Assessment

1.3.1. Wind Turbine Performance in the Hart Area

1.3.2. Assessment of Existing Transmission Line Grid

1.4. Hydro Assessment

1. 5. Preliminary Economics

1.6. The Environmental Impact of Wind Turbines and their Operation in the Hart Area

2. WIND DATA COLLECTION AND ANALYSIS

2. 1. The Availability and Application of NOAA and U. S. Coast Guard Wind Data

2.2. The Installation of Dedicated Field-recording Wind Sets

2. 3. Data Management and Data Reduction

2. 4. Preliminary Results of the Wind Assessment Study

2. 5. Wind Power Climatology of the Great Lakes Region:

A Preliminary Assessment

3. HART POWER DEMAND AND CONSUMER USAGE

3. 1. Characterization of Hart Power and Energy Demand 32

3. 2. Utilization and Consumption

4. ASSESSMENT

4. 1. Wind Turbine Performance in the Hart Area

4.2. Assessment of Existing Transmission Line Grid

5. HYDRO POWER ASSESSMENT

5. 1. Fuel-saver Mode of Operation

5.2. Wind Power as a Part of Baseload Capability

5.3. History and Capability of Present Hart Hydro

5. 4. Investigation of Hart Hydro Converted to Energy Storage Mode

5. 5. Hydro Inventory of the South Branch of the Pentwater 57

5. 5. 1. Estimate of Discharge, South Branch of Pentwater River 60

5.5.2. Survey of Hart Lake Storage Potential 61

5.5.3. Economic Cost of Hydro Storage and Generation Facility 63

5. 5. 4. Significance of the Wind-Power Hydro-Power Combination for Michigan

6. RESULTS OF THE PRELIMINARY ECONOMICS ANALYSIS - 67

6.1. Introduction $\quad 67$

6.2. Fuel Saver Economics $\quad 68$

6. 3. The Economics of a Baseload Wind Turbine-Hydro System 73

6.4. Benchmark Economics $\quad 73$

6.5. Energy Alternatives for the City of Hart 77 
7. THE ENVIRONMENTAL IMPACT OF WIND TURBINES AND OPERATION IN THE HART, OCEANA COUNTY, MICHIGAN AREA

7.1. Introduction

7.2. Five Provisional Wind Turbine Sites: A, B, C, D and E, Hart Area, Oceana County, Michigan

7.2.1. Site. A. Little Point Sable.

7.2:2. Site B. Taylor Road and 34th Street

7.2.3. Site C. Silver Hills Farm

7.2.4. Site D. Atop Hart Hill Just Off Tyler Road

7.2.5. Site E. 72nd Street North of Tyler Road

7.2.6. General Comments

7.3. The Impact Rating of the Five Sites

7. 4. Summary

8. SYSTEMS MODEL FOR THE HART POWER SYSTEM WITH WIND T URBINE

8. 1.: Need for Evaluation Model

8. 2. Choice of Parameters in Evaluation Model

8. 3. Model Structure 


\section{SUMMARY OF INTERIM REPORT}

The city of Hart, a small municipality of a pproximately 2, 500 people, is located in a high wind region eight miles east of Lake Michigan and is situated approximately midway between the two larger cities of Muskegon and Ludington. Hart derives its electric energy from a city owned municipal electric power system. This power system has a peak capacity of $4 \mathrm{MW}$ and depends almost entirely on diesel generation using gas and oil. The diesel plant is supplemented by a $300 \mathrm{k} \cdot \mathrm{W}$ hydro facility located at the outlet of Hart Lake. There is no spinning reserve. In effect it is supplied by a $5,000 \mathrm{~kW}$ interconnection to the Wolverine Electric Cooperative, a generation and transmission ( $G$ and $T$ ) Rural Electric Cooperative. The Hart Municipal System covers about three square miles surrounded by areas supplied by the system of the Oceana Electric Cooperative, a distribution rural electric cooperative.

The characteristics of (1) location in or near a high wind energy region (wind speeds average between 13 and $14 \mathrm{mph}$ on the lakeshore), (2) diesel generation of electricity, (3) the presence of a hydro facility and (4) a peak generation capacity of only $4 \mathrm{MW}$ all converge to make the city of Hart an interesting and promising application for wind energy conversion systems (WECS). The high wind energy in the Hart region indicates good economic potential for WECS applications. As costs of oil and natural gas continue to rise, the cost of generating electricity from diesel facilities becomes relatively more expensive. The hydro facility, modified and updated, may be utilized for energy storage to offset the intermittency and randomness of wind availability. Since the peak capacity of the Hart system is only $4 \mathrm{MW}$, a few $500 \mathrm{~kW}$ or 1. $5 \mathrm{MW}$ wind turbines can make significant impact on the total energy. generating system.

The research reviewed in this progress report has as its goal to study the technical and economic feasibility of a WECS for the city of Hart. By conducting this indepth study for Hart, it is felt an approach or methodology will be developed that can be generalized to other rural and small municipal applications. In addition, it is felt that general information important to other applications, i.e., the 
generic characteristics for small rural and municipal applications, will emerge from this study. A major question to be answered is: to what degree might it be possible, if at all, for a small municipality, such as Hart, to become energy-self-sufficient with respect to the electric power needs in a cost-effective manner and in what time frame?

The research in this grant is divided into a number of phases. They are:

Wind Data Collection and Analysis

Assessment of the Hart Power Demand and Consumer Usage

Assessment of: (1) Wind turbine performance in the Hart area

(2) Transmission line assessment

Hydro Assessment

Economics of WECS

Environmental impact of WECS in the Hart region

Development of a Systems Model for the Hart Power System

The progress of each of these project phases is reported in Sections 2-9 which follow. Conclusions of these phases are summarized below.

1.1. Wind Data Collection and Analysis

Initial efforts were directed towards the assembly, editing, and storage of selected historical wind data from the Coast Guard Stations along the Great Lakes shoreline of upper and lower Michigan. Three MSU established, permanent, continuous, field-recording wind stations were located in the Hart area. 1975 wind information was gathered and placed on computer tape from these MSU stations along with the 1975 wind data from the Ludington and Muskegon Coast Guard stations. This data collection phase of the project represented a significant initial effort and the processing of a few additional historical records and the incoming 1975 data continues at a moderate workload level. Since commencing this study, over 400,000 pieces of historical and 1975 wind data have been recorded on assessment forms and over 100,000 of these have received final editing and are available on computer tape. This stored information can be retrieved at will for the computer programs developed to process these wind data. 
Software has been written to operate on raw wind data and obtain:

1) average annual, monthly, and seasonal energy density;

2) wind speed and power distribution curves and velocity frequency curves by month and year;

3) wind roses and energy roses by month and year;

4) diurnal wind speed variation for month and year;

5) height corrected wind speeds.

By comparing 1975 wind data from Muskegon and inland MSU wind stations, an approximate relationship was established for apparent energy between these locations. This relationship was used to derive a 12 month estimate for the 1972 winds at the State Police Tower. It is recognized that the methods employed were only very approximate and that continuous wind monitoring into year II will provide several full years of wind information at inland locations.

Some important preliminary conclusions are:

1) The wind power densities along the coastal regions of Michigan correspond to an average annual wind power density of $225-375 \mathrm{~W} / \mathrm{m}^{2}$ at 10 meters. These densities, among the highest within the U.S., demonstrate that the coastal region of Michigan is an excellent area for wind turbine applications.

2) At all wind measuring stations, winter months are months of relatively high wind energy while summer months have relatively low wind energy. This fact suggests the possibility of using wind energy to replace oil, natural gas, and bottled gas for heating in the winter.

3) The yearly and monthly wind energy behavior along the coast from Ludington to Muskegon appears to be very similar (neglecting any terrain effects). Thus, the historical wind data from Ludington and Muskegon Coast Guard stations can be used with a high degree of confidence to provide historical wind information for the coastal region directly west of the city of Hart.

4) At a given height, wind energy is rapidly attenuated as one moves only a few miles inland from the coast. Preliminary estimates indicate that the wind energy in the city of Hart is over $50 \%$ lower than the wind energy along the coast, although Hart is only about eight miles from Lake Michigan.

1.2. Hart Power Demand and Consumer Usage

Twelve months of hour-by-hour total load and power generation by diesel, hydro and Wolverine have been card punched and are 
available for developing future load growth and economic predictions.

Attempts were made to break down consumer usage into pur pose and time-of-day and season. It was felt that this type of information would be helpful in determining how utilization practices might be adjusted to accommodate the availability of wind power. Few results have been produced to date and it may well take another year to produce tangible information.

1.3. Assessment

1.3.1. Wind Turbine Performance in the Hart Area

Using the histerical and 1975 wind information and the G.E. and Kaman $500 \mathrm{~kW}$ and 1. $5 \mathrm{MW}$ designs, the total energy, average power and down time were calculated for a number of different sites on the shore of the Great Lakes and at inland locations next to or in Hart.

Some preliminary conclusions are:

1) The $500 \mathrm{~kW}$ machines are superior to the $1.5 \mathrm{MW}$ machines in the Hart region. The $500 \mathrm{~kW}$ machines are favored over the 1.5 MW machine in both the fuel saver mode of operation and as part of a baseload with energy storage operation. That is, they have a higher plant factor and lower down time for both inland and coastal sites in the Hart region.

2) A large wind turbine of $1 \mathrm{MW}$ or more which is designed for yearly average wind speeds of $14-15 \mathrm{mph}$ appears to be in the region. Applications for this machine would be more numerous than the G.E. and Kaman 1.5 MW designis.

3) The annual energy output for each machine next to the city of Hart is over $50 \%$ less than the energy output on coastal sites. This conclusion must be verified with more complete inland wind measurements.

1.3.2. Assessment of Existing Transmission Line Grid

The transmission grids of the Wolverine Electric Cooperative and Oceana Electric Cooperative were assessed for their capacity.

The important conclusions are:

1) The $69 \mathrm{~kW}$ Wolverine network has the capacity to transfer power equal to the entire Hart peak demand. Thus, this network can easily handle energy from both $500 \mathrm{~kW}$ and 1. $5 \mathrm{MW}$ wind turbines.

2) The three phase Oceana distribution network can only handle outputs from the $500 \mathrm{~kW}$ and 1. $5 \mathrm{MW}$ machines for distances of less than two miles. However, $200 \mathrm{~kW}$ machines, e.g., the Plum Brook machine, can be tied directly into the threephase Oceana grid. 
3) For most sites $500 \mathrm{~kW}$ and 1. $5 \mathrm{MW}$ machines would have to be tied directly into the $69 \mathrm{kV}$ Wolverine network.

\subsection{Hydro Assessment}

The Hart hydro facility was investigated for it potential use as the energy storage reservoir for a wind-hydro baseload electric generating system. This hyd ro facility is typical of most such generating units in Michigan in that it is operated as a flowthrough system with little or no capacity for storage. Thus, the Hart Lake basin was surveyed to determine the energy storage potential of the lake area. Also, the month by month waterflow in the Pentwater River was estimated and a cost estimate in $\$ / \mathrm{kW}$ covering the modification and expansion of the hydro facility was established. The conclusions are:

1) The height of Hart Lake can be increased 6 feet without encountering any major problems. The energy stored in this water increase would allow a $1,000 \mathrm{~kW}$ system to run for at least 38 hours.

2) Water discharge estimates indicate that on the average, twice as much water flows in the Pentwater River than is presently used to generate electricity by the Hart Hydro facility.

3) The expansion of the hydro facility would cost $\$ 800 / \mathrm{kW}$.

This hydro assessment is presently being generalized in order to develop the generic technical and economic characteristics at such wind-hydro energy delivery systems. Preliminary surveys indicate that, assuming a 50-50 match of wind power and hydro-power, more than $1,000 \mathrm{MW}$ could be derived from wind-hydro combinations in Michigan. This would be all baseload generation, obviously requiring no fossil fuels.

\section{5. Preliminary Economics}

The economics of WECS as fuel savers or as part of a hydro baseload electric generating facility were investigated. In general, the economics strongly favor lakeshore locations over inland city of Hart locations. These preliminary economics indicate that WECS as fuel savers or as baseload are both competitive now (or will be shortly as fuel prices rise) with the present Hart diesel generating facility.

The energy cost differences $(\$ / \mathrm{kWh})$ between the $500 \mathrm{~kW}$, and 
1. $5 \mathrm{MWG}$. E. and Kaman designs are not substantial. Since the $500 \mathrm{~kW}$ machine has the technical advantage of having less down time than the 1. $5 \mathrm{MW}$ machine, it appears that a system of $500 \mathrm{~kW}$ machines may be the best solution for wind turbines in the Great Lakes region.

Some energy generation alternatives open to Hart were reviewed. Research continuing into year II will compare these and other energy alternatives open to the city of Hart with the costs of "fuel saver and baseload WECS." The economics will be generalized to a class of small cities similar to Hart.

1.6. The Environmental Impact of Wind Turbines and Their Operation in the Hart Area

Five sites were rated as to the potential environmental impact of wind turbine installations. It is felt that wind turbines will have very few environmental problems. Certain types of impacts such as bird kill and of E-M interference are somewhat speculative and must be investigated by more indepth studies. 1

The major problem with wind turbines may be one of aesthetics or visual pollution. This may be the case with sites along the coast of Michigan. For example, it has been shown in this progress report that wind energy is significantly higher on the lake and coast than even a few miles inland. Because of the low down time and high plant factor the $500 \mathrm{~kW}$ designs are favored over the $1.5 \mathrm{MW}$ designs in the Lake Michigan area. Thus, even for a small application like the city of Hart, several or more lake sites spread over tens of miles would be desirable. However, the lakeshore is a scenic and a recreation area and to find environmentally acceptable sites accessible to the appropriate transmission lines may prove difficult. Thus, the siting constraints, indicate the need in the Great Lakes Region for a large machine of $1 \mathrm{MW}$ or more with a high plant factor and a low down time.

\section{WIND DATA COLLECTION AND ANALYSIS}

Measurements to determine wind behavior, particularly as they relate to wind power studies, can be classified according to one or more of the following principal objectives:

(a) those measurements which provide data so that the 
probable annual energy output of a particular wind energy conversion system, located at or near the site of the measuring station, can be predicted;

(b) those measurements whicil are required to furnish information on the wind structure under different climatic, topographic, seasonal, and diurnal conditions, at or near the site of interest;

(c) those measurements which provide raw data that are needed in special studies which permit system designers to develop an optimum wind energy conversion system for the site or region of interest.

Each of these wind measurement objectives is being met for the Great Lakes Region through the wind data collection and analysis portion of the Michigan State University wind research project. Although the MSU project, as a whole, focuses on the small municipal. power system in Hart, Michigan, the generic characteristics of the wind in the Great Lakes Region are being emphasized. These generic results then in turn are being applied to the city of Hart's small municipal power system study.

2. 1. The Availability and Application of NOAA and U.S. Coast Guard Wind Data

In our consideration of the methods to be used in collecting wind data, we recognized from the outset the fact that much valuable infor mation on wind speeds and directions already exists in records of NOAA and the U.S. Coast Guard. For obvious reasons, wind data obtained by these sources have not been based on the requirements for a wind energy conversion system (WECS). Instead, they are, in the main, related to the general wind regime for districts surrounding observation stations, and thus are not necessarily located at particularly windy sites. Nevertheless, they provide reasonably reliable long-term records. We decided not to neglect them because they provide important benchmark data.

After careful thought, we decided that meteorological data for NOAA and the U.S. Coast Guard Stations in the Great Lakes Region can be put to advantage. Both historical and current wind data from the se sources are used for the following:

(a) As a basis for wind surveys indicating the areas in the 
Great Lakes Region where the highest wind speeds are likely to be found;

(b) As an indication of the direction of the prevailing wind since a knowledge of this is important when selecting wind power sites;

(c) As a measure of the constancy, or variability, of the annual mean wind speed from year to year;

(d) As an indication of the annual wind regime derived from the values of monthly mean wind speeds for an area;

(e) As a measure of the diurnal variations in wind speed to be expected at different seasons of the year;

(f) As a guide for determining the probability of the occurrence of various maximum wind speeds or calm spells;

(g) As benchmark data used in correlation studies with data derived from wind recording instruments which are to be placed for short time periods at potential wind power generation sites.

Michigan, which has over 3000 miles of shoreline on five of the six Great Lakes, is particularly well situated for being the "laboratory" in which winds in the Great Lakes Region are studied. Furthermore, Michigan has in its favor the fact that there are twenty-nine ${ }^{2}$ NOAA and U.S. Air Force meteorological stations and more than a half dozen U.S. Coast Guard Stations within its boundaries, all which routinely record wind speed and direction information. (See Figure 1). 2.2. The Installation of Dedicated Field-recording Wind Sets Unfortunately, not all of the wind data required for making an effective evaluation of wind behavior in the Great Lakes Region can be obtained from these NOAA, U.S. Air Force, and U.S. Coast Guards Stations. The deficiencies in the data derived from these stations, particularly as they relate to wind power studies are as follows:

(a) The recordings are not made continuously but rather typically every one-to-four hours. As a result, the data obtained at these stations is not useful in determining the short-term dynamic characteristics of the wind, e.g., the power spectra of the wind speed and the short-term variations in the wind direction for various wind speeds;

(b) Two or more wind recording instruments are never placed at the same station for the purpose of understanding how 
wind speed and wind direction vary in the short-term or the long-term with height. Also, data for horizontal shear determinations are never collected;

(c) Many of the permanent wird recording stations are in relatively sheltered areas. Wind records at these locations are often not indicative of the wind energy potential in the area;

(d) The permanent wind recording stations are not situated in an array that would permit one to determine how the winds are attenuated as they move inland from one of the Great Lakes.

To augment the standard meteorological stations, five sets of field-recording wind sets (R.M. Young Company Model 6404) were purchased and installed. With these instruments, wind speed and direction are continuously and simultaneously recorded on a two-pen, strip-chart recorder.

One wind vane and three-cup anemometer set was placed 110 feet above the coast of Lake Michigan atop the Little Point Sable Lighthouse. This lighthouse is strategically located on the shore of Lake Michigan approximately 20 miles from the Ludington Coast Guard Station, 25 miles from the Muskegon Coast Guard Station, and only seven miles from the city of Hart (see Figures 1 and 2). A second field-recording wind set was mounted at a height of 30 meters on a State Police communication tower just south of the city of Hart (see Figure 2). This tower was chosen because it sits on a promising $320 \mathrm{ft}$. hill and also is almost straight inland from the Little Point Sable Lighthouse. The third field-recording wind set was placed on the Pro Gas tower at 30 meters, in the city of Hart. The fourth and fifth wind sets either mounted on one of the two towers already mentioned in order to gather spatial gradient information on the winds, or they are mounted on a portable tower. The portable tower is used to determine the attenuation of wind speed with distance as the wind moves in off Lake Michigan. Also, it will be used as a prospecting tool in the search for suitable high-wind locations in the Hart region.

Wind data will be recorded continuously for at least two years, and will be correlated with the Ludington and Muskegon Coast Guard data and will also serve as benchmark wind data for other wind data 


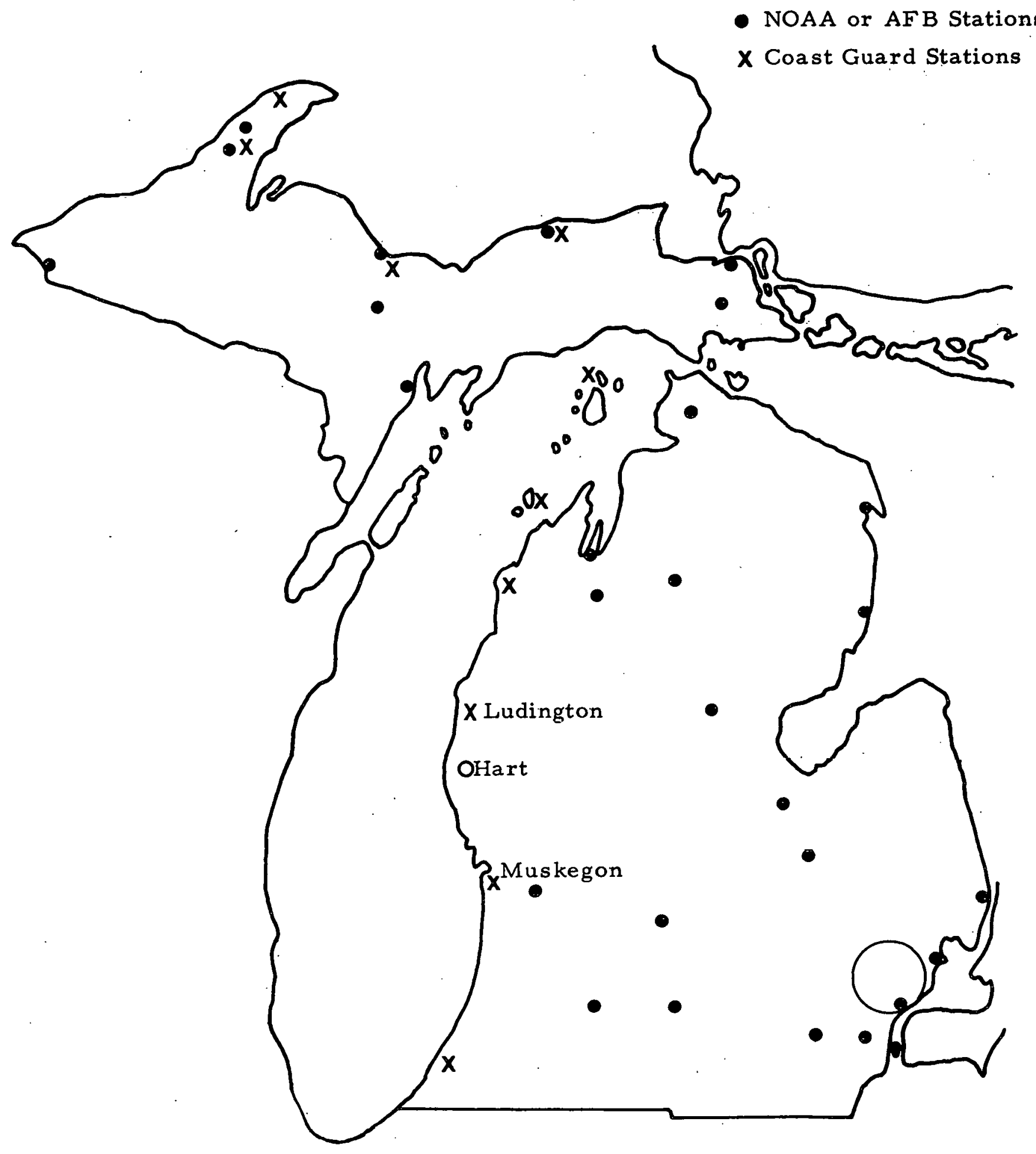

Figure 1. Map of Michigan showing the location of the existing NOAA, U. S. Air Force, and U. S. Coast Guard wind recording stations. 


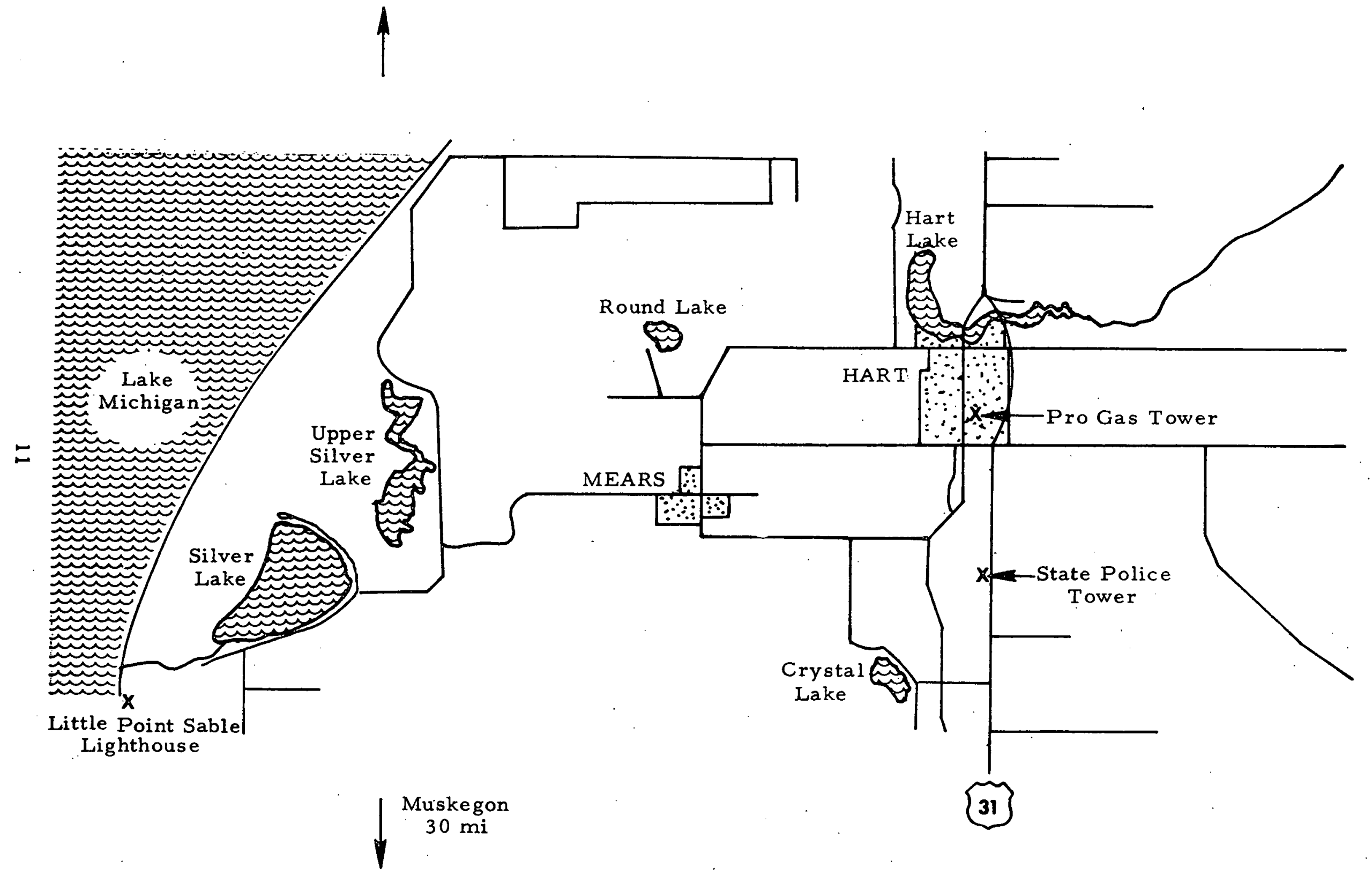

Figure 2. Map of the Hart region showing the location of the dedicated field recording wind sets. 
collected in the Great Lakes Region and city of Hart region since it will be the first processed continuous wind data known to be available on the entire Lake Michigan shoreline. It is worth noting that the Hart area is very similar topographically to much of the Great Lakes Region; therefore, the results of this wind study should be of general use throughout the Region.

\subsection{Data Management and Data Reduction}

With a simple calculation, it can be seen that if only hourly data from all of the possible wind data sources within the State of Michigan were collected, there would be over one-half million data items annually. Because of this, data must be carefully selected, collected, organized, maintained, and disseminated; otherwise, inefficiency and chaos will result.

Basically, we obtain raw wind data from tables prepared by the National Weather Service, from tables prepared by the U.S. Coast Guard, and from the strip charts derived from our dedicated fieldrecording wind sets. A typical table from the Coast Guard and a typical strip-chart recording are shown in Figures 3 and 4, respectively. (Note: The data from the Coast Guard is in knots)

Each wind recording station is given a unique "Station Code." Hourly data are then transferred from the raw tables and charts onto "Wind Energy Assessment Forms" (See Figure 5). The data are now essentially in a card-image format. From the forms, computer cards are punched and the data are entered into the computer-based data management system where it is stored on magnetic tape. Specialized wind data, e.g., data which are derived from the continuous strip charts and relate to short-term wind phenomena, are entered into the computer in a similar manner.

All data is maintained on the computer in such a manner that researchers have easy access to any type of raw-data listing that might be required. Also, the data may be massaged in any number of ways in order to get useful data summaries, or selected portions of the data base might be moved directly into one of the power system models for simulation purposes. 


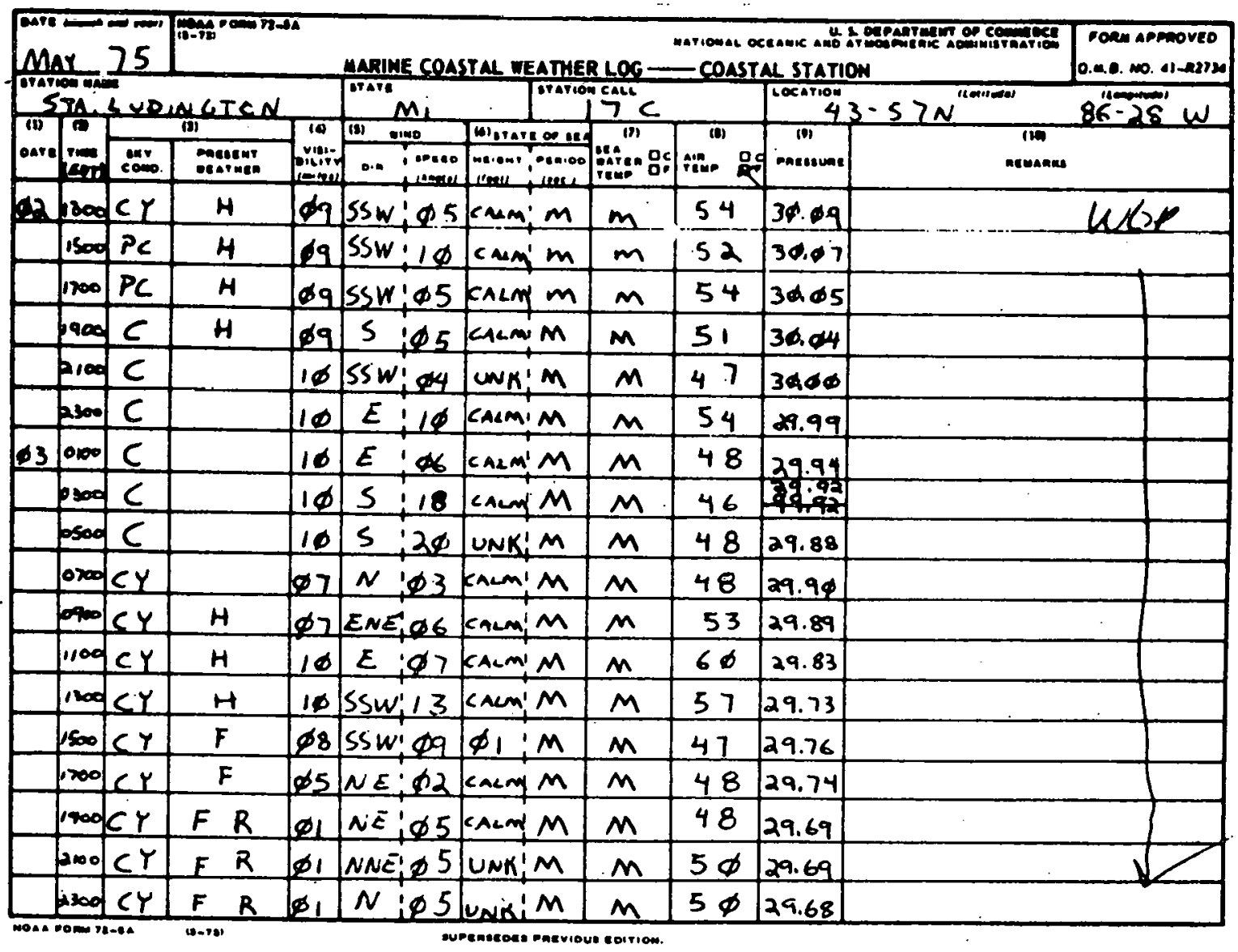

Figure 3. Typical meteorological chart completed by the U. S. Coast Guard.

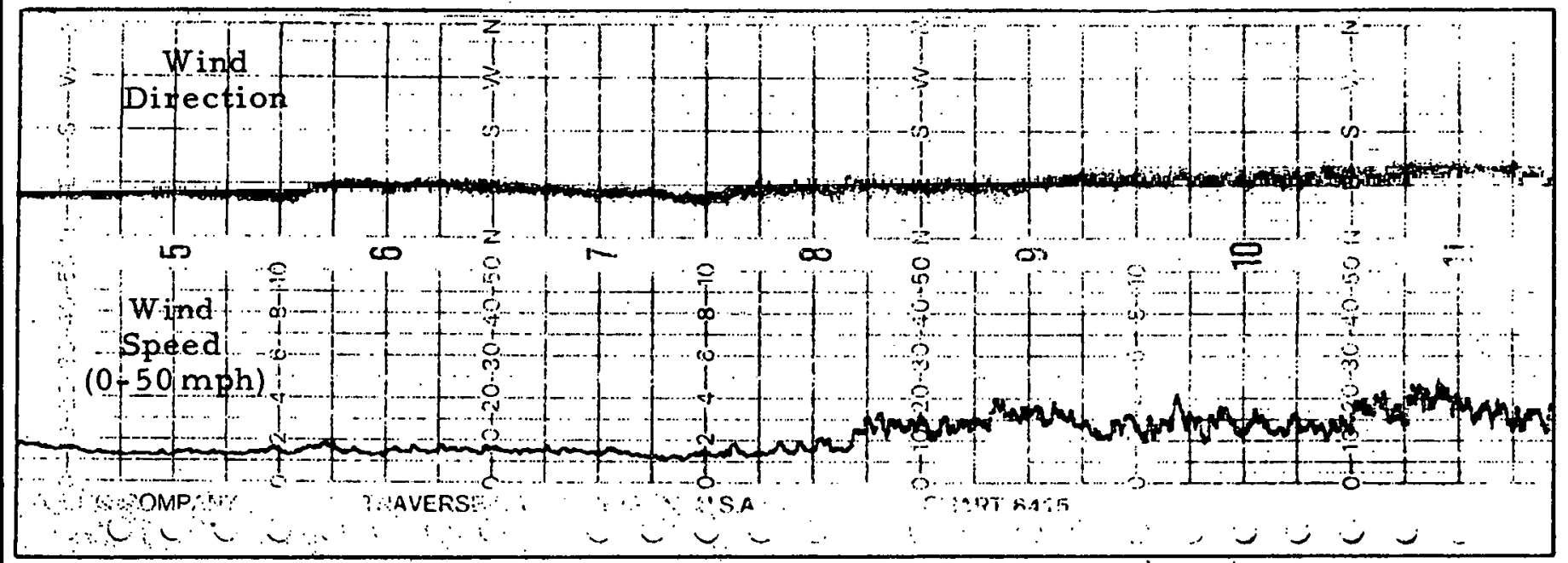

Figure 4. Typical output from one of the dedicated fieldrecording wind sets. 
Page No. 2

WIND ENERGY ASSESSMENT FORM (WE- 2)

MICIUIGAN ST ATF, UNIV ERSITY

WATl 3/19/75_ PIATION NO._HTSPOI STATION LOCATION STATE POLICE

\begin{tabular}{|c|c|c|c|c|c|}
\hline \multirow{2}{*}{$\begin{array}{l}\text { IIM I: } \\
\text { OF" } \\
\text { IIAY }\end{array}$} & \multicolumn{3}{|c|}{ WIND SPEEU (MPH) } & \multirow{2}{*}{$\begin{array}{c}\text { DIRECTION } \\
\left(\div 15^{\circ}\right)\end{array}$} & \multirow{2}{*}{ COMMENTS } \\
\hline & AVCi & MAX & MIN & & \\
\hline $1: 00$ & 5 & 6 & 4 & 6 & \\
\hline $2: 00$ & 3 & 5 & 2 & 6 & \\
\hline $3: 00$ & 2 & 4 & 0 & 0 & \\
\hline $4: 00$ & 3 & 4 & 2 & 0 & \\
\hline $5: 00$ & 5 & 8 & 2 & 20 & \\
\hline $6: 00$ & 9 & 12 & 6 & 18 & \\
\hline $7: 00$ & 6 & 8 & 5 & 19 & \\
\hline $8: 00$ & 7 & 10 & 5 & 18 & \\
\hline $9: 00$ & 8 & 12 & 4 & 19 & \\
\hline $10: 00$ & 7 & 10 & 4 & 19 & \\
\hline $11: 00$ & 7 & 10 & 5 & 18 & \\
\hline $12: 00$ & 10 & 14 & 6 & 19 & \\
\hline 13:00 & 8 & 12 & 5 & 19 & \\
\hline $14: 00$ & 12 & 16 & 7 & 19 & \\
\hline $15: 00$ & 12 & 17 & 7 & 19 & \\
\hline $16: 00$ & 7 & 12 & 3 & 19 & \\
\hline $17: 00$ & $7:$ & 11 & 3 & 18 & \\
\hline $18: 00$ & 8 & 12 & 4 & 18 & \\
\hline $19: 00$ & 10 & 14 & 7 & 18 & \\
\hline $20: 00$ & 8 & 11 & 5 & 19 & \\
\hline $21: 00$ & 8 & 13 & 3 & 20 & \\
\hline $22: 00$ & 8 & 12 & 3 & 2 & \\
\hline $23: 00$ & 5 & 10 & 0 & 14 & \\
\hline $24: 00$ & 7 & 10 & 3 & 14 & . \\
\hline
\end{tabular}

DAILY AVERAGE (MPH)

7

Name: Betty Shanahan

Date: 21 April 1975

Figure 5. Example of a completed "Wind Energy Assessment Form." 
2.4. Preliminary Results of the Wind Assessment Study

Immediately upon receiving notification that we were awarded the Grant (February 1975), three of the field-recording wind sets were purchased. These were installed at th 2 three permanent wind recording sites by April 1, 1975. The fourth wind set and the portable tower were put in the field around August i, 1975. The fifth wind set.was obtained from an existing MSU weather station on Beaver Island. Several minor problems were encountered with the wind recording instruments; namely, the strip-chart paper bound several times in the recorders with approximately a $10 \%$ loss of data resulting. At the time of this report, all useful data through October 1, 1975, has been extracted from the strip charts and put on the computer. Also, immediately upon receiving notification of the Grant, we asked for and received permission from the District Commander of the U.S. Coast Guard to have Ludington and Muskegon Coast Guard Station personnel send us copies of their wind data logs at the end of each month. This information is now on the computer up to October 1, 1975. In addition to these wind data sources, we initiated a project to incorporate selected wind data contained on National Weather Service magnetic tapes into our Great Lakes Region wind power study. This data is currently being entered on our computer and anàlyzed.

Table 1 summarizes both the 1975 and historical wind data by year and station that has been gathered to date by this project. As indicated in Table 1, six years of historical data have been processed and have been given final editing and stored on magnetic tape. Six months (March-October) of 1975 wind data from five (Ludington, Muskegon, Little Sable, State Police, and Pro Gas) wind measuring stations in the Hart region has also been processed, edited and placed on computer tape. Also included are nine more years of wind data that have been key punched on computer cards and an additional eleven years of historical wind data which has been recorded only on assessment. forms. It is expected that these 20 years of wind data will be edited and placed on computer tape by the end of the first year of this project.

Software packages have been written which enable a researcher to obtain for each station monthly and yearly average velocities, 
TABLE 1

Historical Wind Data

STATION Recorded on Assessment Forms \begin{tabular}{lllll}
68 & 69 & 70 & 71 & 72 \\
\hline
\end{tabular}

Muskegon

Ludington

Point Betsie

Grand Marais

Lansing Shoals

๙ . St. Joseph

Eagle Harbor 1971

Hancock Portage 1971

Manitou 1971

Marquette 1971

Passage Isle 1971

Rock of Ages 1971

Muskegon 3/75-10/75

Ludington 3/75-10/75

Pro Gas 3/18/75-10/21/75

State Police 3/18/75 - 10/2/75

Lighthouse $3 / 18 / 75-10 / 2 / 75$

$\begin{array}{lllll}x & X & x & x & X\end{array}$

$\mathrm{X} \quad \mathrm{X} X$

$\mathrm{X} X \mathrm{X}$

$\mathrm{X}, \mathrm{X} \mathrm{X}$

$\mathrm{X} x$

$\mathrm{X} \quad \mathrm{X}$

$\mathrm{X}$

$\mathrm{X}$

$\mathrm{X}$

$\mathrm{x}$

$\mathrm{X}$

$\mathrm{X}$

1975 Wind Data

$x$

$x$

$\mathrm{x}$

$\mathrm{X}$

$\mathrm{X}$

$\mathrm{X}$

$\mathrm{X}$

\begin{tabular}{|c|c|c|c|c|c|c|c|c|c|}
\hline \multicolumn{5}{|c|}{$\begin{array}{c}\text { Computer } \\
\text { File }\end{array}$} & \multicolumn{5}{|c|}{$\begin{array}{l}\text { File } \\
\text { Edited } \\
\end{array}$} \\
\hline 68 & 69 & 70 & 71 & 72 & 68 & 69 & 70 & 71 & 72 \\
\hline & & $\mathrm{X}$ & $\mathrm{X}$ & $\mathrm{X}$ & & & & & $\mathrm{X}$ \\
\hline & & $\mathrm{X}$ & $\mathrm{X}$ & $\mathrm{X}$ & & & & & $\mathrm{X}$ \\
\hline & & $X$ & $X$ & $X$ & & & & & $\mathrm{X}$ \\
\hline & & & $\mathrm{X}$ & $\mathrm{X}$ & & & & & $X$ \\
\hline & & & & $\mathrm{X}$ & & & & & $\mathrm{X}$ \\
\hline
\end{tabular}

$\mathrm{X}$

$\mathrm{X}$

$\mathrm{X}$

$\mathrm{X}$
X $\mathrm{X}$ $\mathrm{X}$

$\mathrm{X}$

$\mathrm{X}$ 
velocity-frequency curves, speed and power duration curves by month and year, monthly, seasonal, or annual energy density and/or power density, and wind rose and energy rose curves by month and year. An additional computer program automatically corrects wind speed for any height using the appropriate vertical wind profile correction formula. 2 Figures 6 through 14 display the outputs of these software packages for Muskegon 1972 wind data. Each year of final edited wind data indicated in Table 1 can be processed yielding the appropriate duration curves, wind roses, etc. The yearly average wind speeds indicated in Figure 15 are examples of these computer calculations. When the data collection and analysis phase of the wind power study reach the appropriate point in time, a technical report will be issued. This report will summarize all of our wind data from each station as well as all of the conclusions which can be drawn from the data.

Despite the fact that much of the data is very preliminary, we are using it as a data base to provide key information needed to predict the probable energy output and economics of known and planned wind energy conversion systems. Also, from the preliminary data, we are now able to draw several very general conclusions concerning Great Lakes wind power climatology. In the next section, we will present these conclusions and also provide a sampling of 1975 wind data which has been collected and analyzed to date.

2.5. Wind Power Climatology of the Great Lakes Region: a Preliminary Assessment

The Great Lakes appear to have a profound effect on the winds in the region. At inland locations and sheltered meteorological stations along the coastlines, average annual wind speeds are in the 8-to-ll MPH range. 4 This corresponds to an average annual wind power density of $100-150 \mathrm{~W} / \mathrm{m}^{2}$ at 10 meters. Since most of the meterological stations are either inland or sheltered, any national wind power survey would rate the Great Lakes Region as only "moderate" as far as wind power is concerned. This is in fact the exact conclusion drawn by J.W. Reed ${ }^{5}$ in his study entitled "Wind Power Climatology of the United States".

As shown in Figure 15 wind data from U.S. Coast Guard 
VRLOCIILS IIV KNOTS

HE IUHI CURKLLIEU FKUM $21.3 \mathrm{M}$ TO $10.0 \mathrm{M}$ (HEIGHT CUKKECTION EXP= .IG)

\begin{tabular}{|c|c|c|c|c|c|c|c|c|c|c|c|c|c|c|}
\hline$t L$ & UTAL & AIV & $F E H$ & MAR & $A P K$ & MAY & JUN & JUL & AUG. & PEP & XT & vur & DEC & $t L \otimes \infty$. \\
\hline $\begin{array}{l}0 \\
1 \\
2 \\
3 \\
4 \\
5 \\
6 \\
7 \\
8 \\
99 \\
10 \\
11 \\
12 \\
13 \\
14 \\
15 \\
16 \\
17 \\
18 \\
19 \\
20 \\
31 \\
22 \\
23 \\
24 \\
25 \\
26 \\
27 \\
28 \\
29 \\
30 \\
31 \\
32 \\
33 \\
34 \\
35 \\
36 \\
37 \\
38 \\
39 \\
40 \\
41 \\
42 \\
43 \\
44 \\
45 \\
46 \\
47 \\
48 \\
49\end{array}$ & 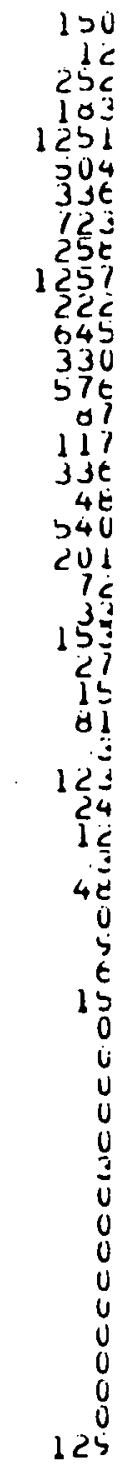 & $\begin{array}{c}0 \\
0 \\
10 \\
12 \\
42 \\
42 \\
12 \\
24 \\
12 \\
42 \\
24 \\
66 \\
24 \\
40 \\
12 \\
10 \\
30 \\
0 \\
06 \\
54 \\
24 \\
0 \\
40 \\
0 \\
0 \\
24 \\
0 \\
36 \\
0 \\
0 \\
0 \\
24 \\
0 \\
0 \\
6 \\
6 \\
0 \\
0 \\
0 \\
0 \\
0 \\
0 \\
0 \\
0 \\
0 \\
0 \\
0 \\
0 \\
0 \\
0 \\
0 \\
0 \\
0\end{array}$ & $\begin{array}{r}12 \\
0 \\
18 \\
120 \\
120 \\
78 \\
24 \\
72 \\
36 \\
84 \\
12 \\
30 \\
12 \\
24 \\
12 \\
24 \\
30 \\
50 \\
12 \\
12 \\
0 \\
10 \\
0 \\
0 \\
0 \\
0 \\
18 \\
0 \\
0 \\
0 \\
6 \\
0 \\
0 \\
0 \\
0 \\
0 \\
0 \\
0 \\
0 \\
0 \\
0 \\
0 \\
0 \\
0 \\
0 \\
0 \\
0 \\
0 \\
0 \\
0 \\
0\end{array}$ & $\begin{array}{r}30 \\
0 \\
24 \\
12 \\
72 \\
36 \\
18 \\
96 \\
12 \\
120 \\
18 \\
66 \\
36 \\
54 \\
0 \\
0 \\
12 \\
36 \\
18 \\
0 \\
18 \\
18 \\
6 \\
0 \\
12 \\
18 \\
18 \\
0 \\
6 \\
0 \\
0 \\
0 \\
0 \\
0 \\
0 \\
0 \\
0 \\
0 \\
0 \\
0 \\
0 \\
0 \\
0 \\
0 \\
0 \\
0 \\
0 \\
0 \\
0 \\
0 \\
0\end{array}$ & $\begin{array}{r}30 \\
0 \\
0 \\
12 \\
84 \\
72 \\
10 \\
84 \\
18 \\
126 \\
12 \\
42 \\
48 \\
42 \\
12 \\
24 \\
40 \\
6 \\
12 \\
6 \\
6 \\
6 \\
6 \\
0 \\
0 \\
0 \\
0 \\
0 \\
0 \\
0 \\
0 \\
0 \\
0 \\
0 \\
0 \\
0 \\
0 \\
0 \\
0 \\
0 \\
0 \\
0 \\
0 \\
0 \\
0 \\
0 \\
0 \\
0 \\
0 \\
0 \\
0 \\
6\end{array}$ & $\begin{array}{r}24 \\
0 \\
0 \\
24 \\
114 \\
54 \\
66 \\
72 \\
60 \\
96 \\
24 \\
54 \\
42 \\
54 \\
0 \\
0 \\
6 \\
12 \\
12 \\
6 \\
0 \\
8 \\
0 \\
0 \\
0 \\
0 \\
0 \\
0 \\
0 \\
0 \\
0 \\
0 \\
0 \\
0 \\
0 \\
0 \\
0 \\
0 \\
0 \\
0 \\
0 \\
0 \\
0 \\
0 \\
0 \\
0 \\
0 \\
0 \\
0 \\
0 \\
0 \\
24\end{array}$ & $\begin{array}{r}10 \\
0 \\
18 \\
24 \\
120 \\
30 \\
30 \\
54 \\
10 \\
102 \\
30 \\
30 \\
60 \\
12 \\
60 \\
6 \\
6 \\
12 \\
12 \\
00 \\
0 \\
0 \\
0 \\
0 \\
0 \\
0 \\
0 \\
0 \\
0 \\
0 \\
0 \\
0 \\
0 \\
0 \\
0 \\
0 \\
0 \\
0 \\
0 \\
0 \\
0 \\
0 \\
0 \\
0 \\
0 \\
0 \\
0 \\
0 \\
0 \\
0 \\
0 \\
0 \\
0 \\
0 \\
0 \\
0 \\
12\end{array}$ & $\begin{array}{r}0 \\
6 \\
54 \\
12 \\
156 \\
42 \\
36 \\
42 \\
18 \\
96 \\
6 \\
60 \\
24 \\
00 \\
12 \\
6 \\
24 \\
40 \\
42 \\
0 \\
0 \\
8 \\
0 \\
0 \\
0 \\
0 \\
0 \\
0 \\
0 \\
0 \\
0 \\
0 \\
0 \\
0 \\
0 \\
0 \\
0 \\
0 \\
0 \\
0 \\
0 \\
0 \\
0 \\
0 \\
0 \\
0 \\
0 \\
0 \\
0 \\
0 \\
42\end{array}$ & $\begin{array}{r}0 \\
6 \\
42 \\
24 \\
108 \\
30 \\
42 \\
60 \\
6 \\
46 \\
12 \\
60 \\
30 \\
60 \\
0 \\
6 \\
48 \\
0 \\
30 \\
6 \\
0 \\
8 \\
0 \\
0 \\
0 \\
0 \\
0 \\
0 \\
0 \\
0 \\
0 \\
0 \\
0 \\
0 \\
0 \\
0 \\
0 \\
0 \\
0 \\
0 \\
0 \\
0 \\
0 \\
0 \\
0 \\
0 \\
0 \\
0 \\
0 \\
0 \\
12\end{array}$ & $\begin{array}{r}0 \\
0 \\
39 \\
27 \\
117 \\
30 \\
24 \\
54 \\
24 \\
93 \\
24 \\
54 \\
39 \\
54 \\
12 \\
3 \\
21 \\
13 \\
59 \\
4 \\
0 \\
3 \\
9 \\
3 \\
0 \\
0 \\
0 \\
3 \\
0 \\
0 \\
0 \\
0 \\
0 \\
3 \\
0 \\
0 \\
0 \\
0 \\
0 \\
0 \\
0 \\
0 \\
0 \\
0 \\
0 \\
0 \\
0 \\
0 \\
0 \\
0 \\
0 \\
6\end{array}$ & $\begin{array}{r}0 \\
0 \\
24 \\
21 \\
108 \\
33 \\
12 \\
60 \\
27 \\
93 \\
6 \\
45 \\
18 \\
36 \\
15 \\
42 \\
40 \\
48 \\
33 \\
6 \\
12 \\
45 \\
3 \\
6 \\
18 \\
33 \\
12 \\
3 \\
0\end{array}$ & $\begin{array}{r}0 \\
0 \\
y \\
12 \\
87 \\
30 \\
24 \\
57 \\
15 \\
141 \\
33 \\
40 \\
21 \\
33 \\
12 \\
9 \\
33 \\
12 \\
39 \\
27 \\
12 \\
6 \\
0 \\
3 \\
0 \\
15 \\
0 \\
15 \\
6 \\
0 \\
0 \\
0 \\
0 \\
0 \\
0 \\
0 \\
0 \\
0 \\
0 \\
0 \\
0 \\
0 \\
0 \\
0 \\
0 \\
0 \\
0 \\
0 \\
0 \\
0 \\
0 \\
y\end{array}$ & $\begin{array}{r}0 \\
0 \\
0 \\
3 \\
63 \\
21 \\
30 \\
48 \\
12 \\
168 \\
21 \\
54 \\
24 \\
45 \\
0 \\
6 \\
30 \\
78 \\
78 \\
24 \\
12 \\
0 \\
9 \\
0 \\
3 \\
6 \\
0 \\
21 \\
9 \\
0 \\
3 \\
18 \\
0 \\
6 \\
0 \\
9 \\
0 \\
0 \\
0 \\
0 \\
0 \\
3 \\
0 \\
0 \\
0 \\
0 \\
0 \\
0 \\
0 \\
0 \\
0 \\
12\end{array}$ & $\begin{array}{l}68 \\
74 \\
79 \\
85 \\
91 \\
97\end{array}$ \\
\hline
\end{tabular}

Figure 6. Velocity frequency data for Muskegon 1972. 


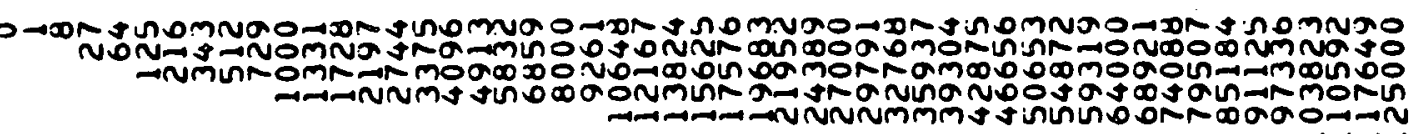

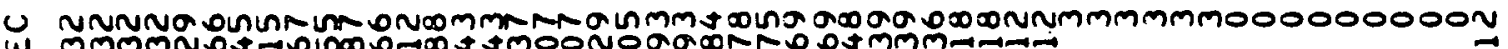

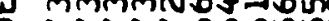

Z Z=تNOMTM

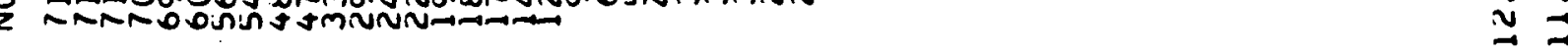

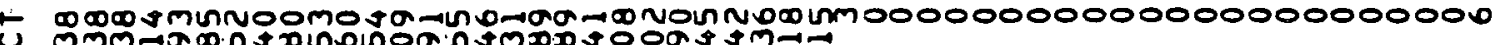

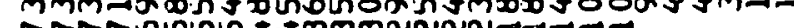

?

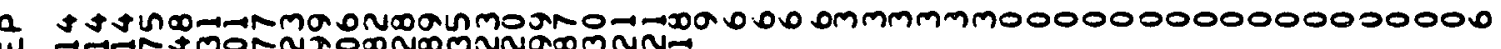

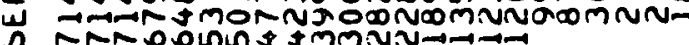

$\because \because$

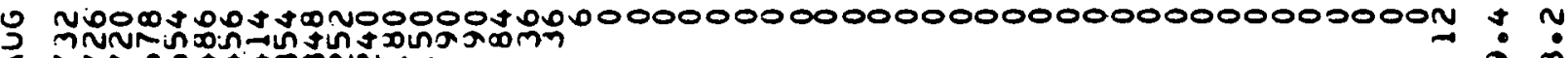

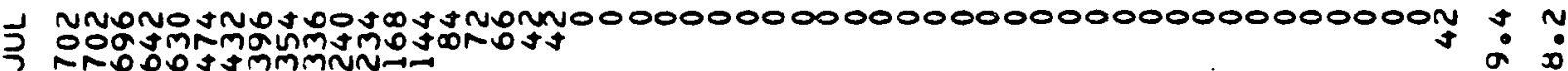

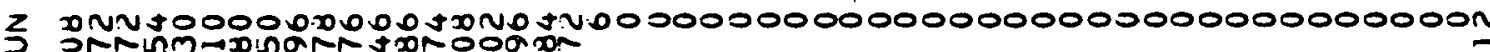

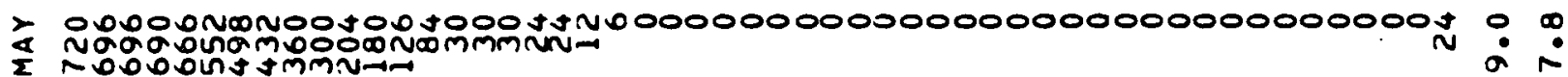

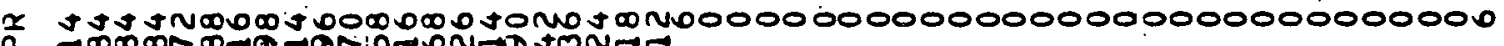
!)

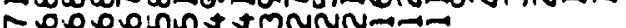

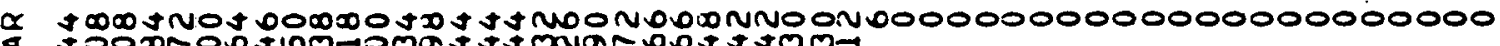
:

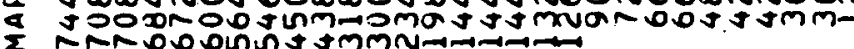

$\pm 0$ 苟

$\stackrel{\infty}{*}$

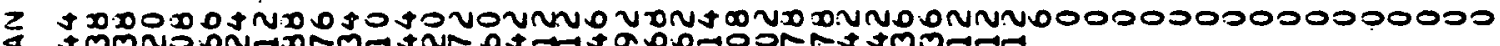

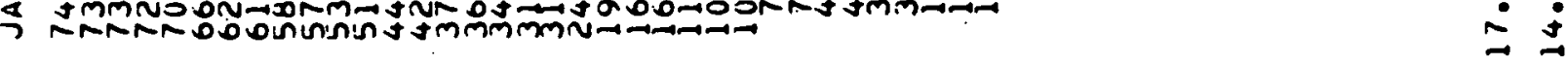

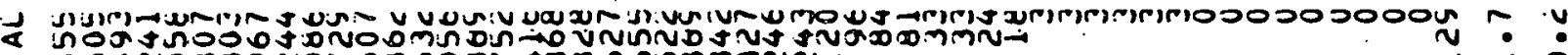

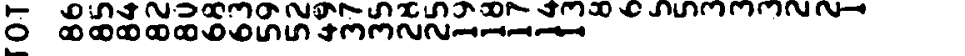




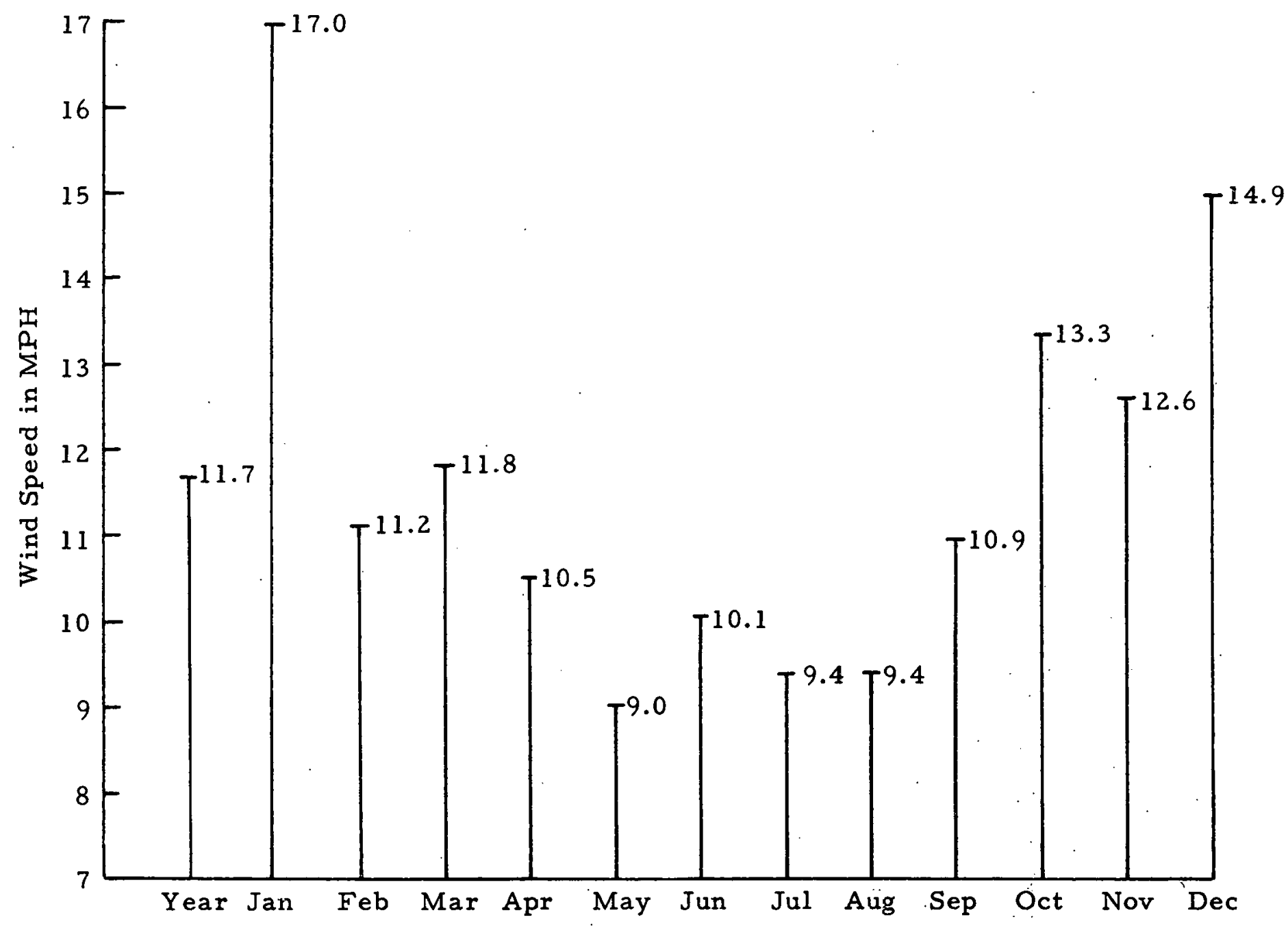

Figure 8.

Yearly and Monthly Average Wind Speeds at 10 Meters for Muskegon, 1972 
Avg. wind Avg. wind

speed mph speed kns

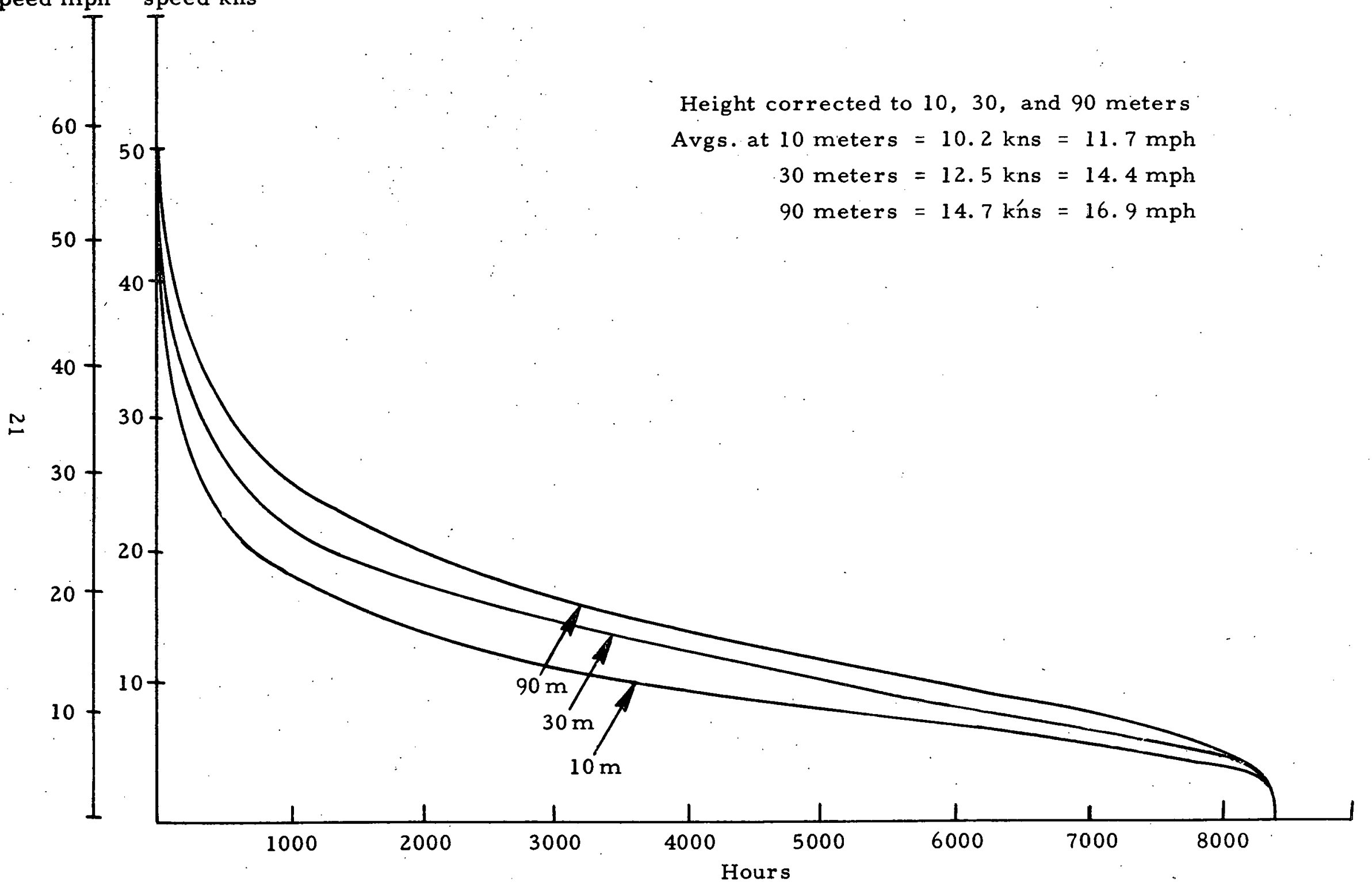

Figure 9. Wind Speed Duration for Muskegon, 1972 


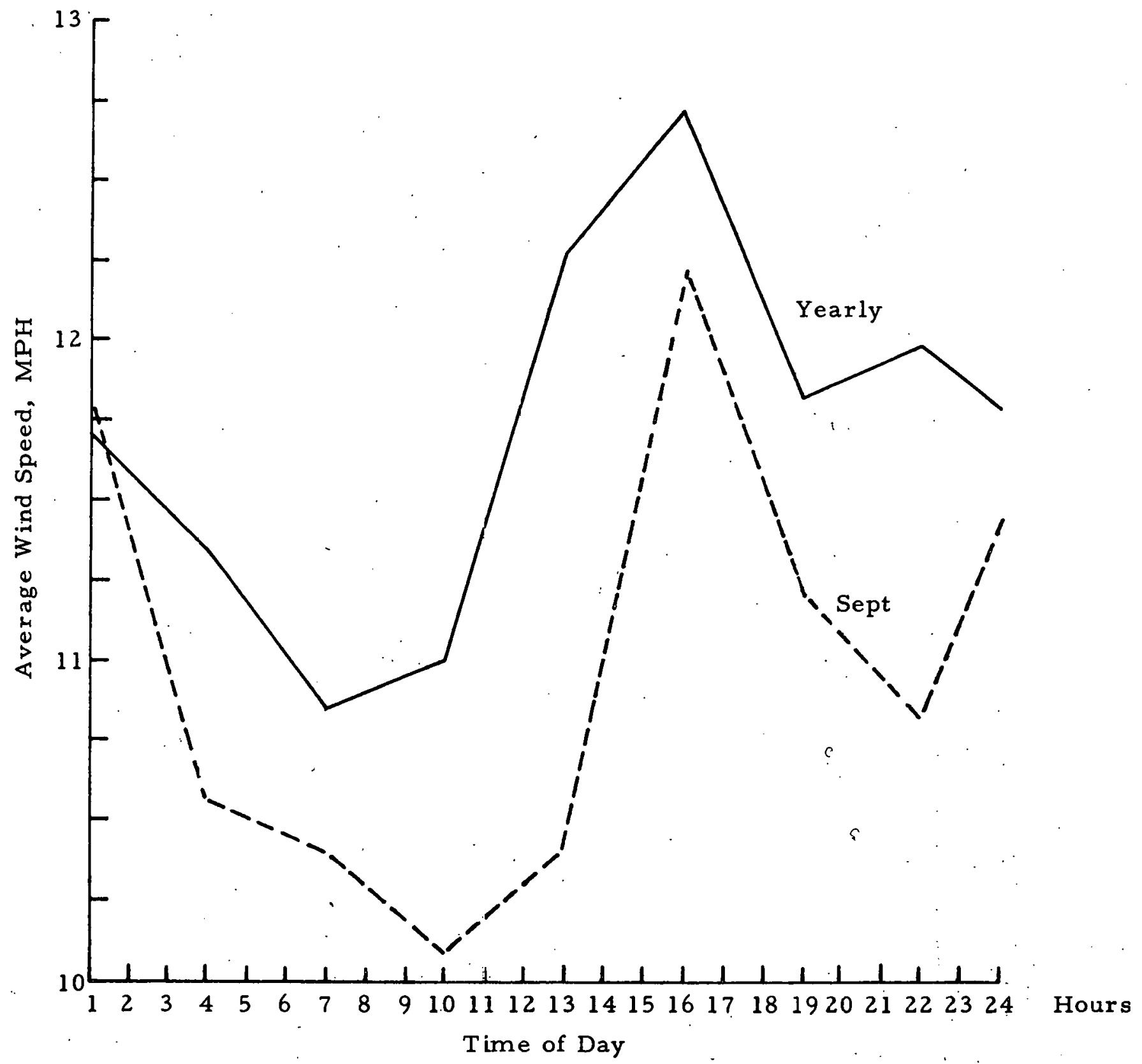

Figure 10. Diurnal Variations at 10 Meters for Muskegon, 1972 


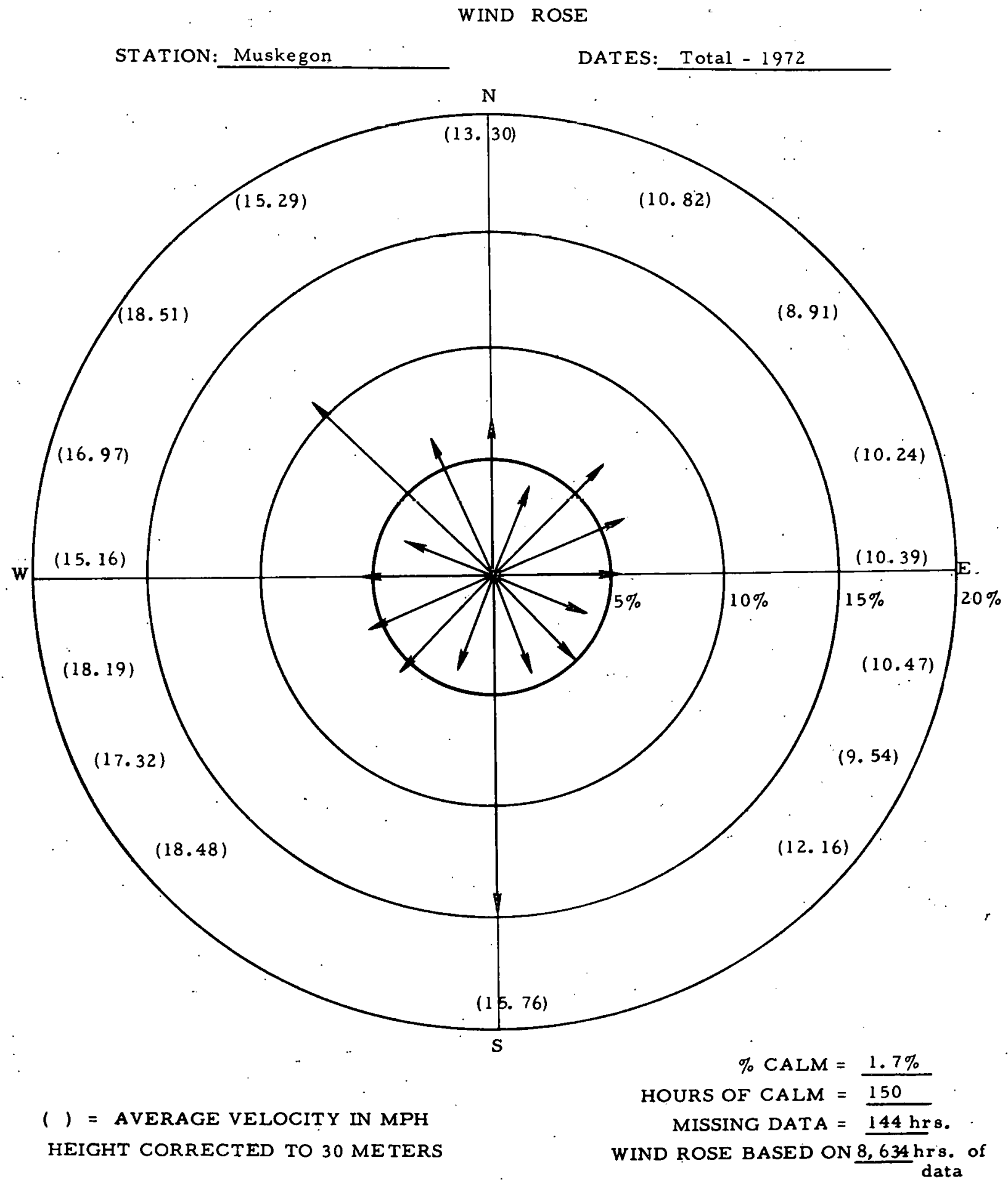

Figure 11. Muskegon 1972 annual wind rose. 


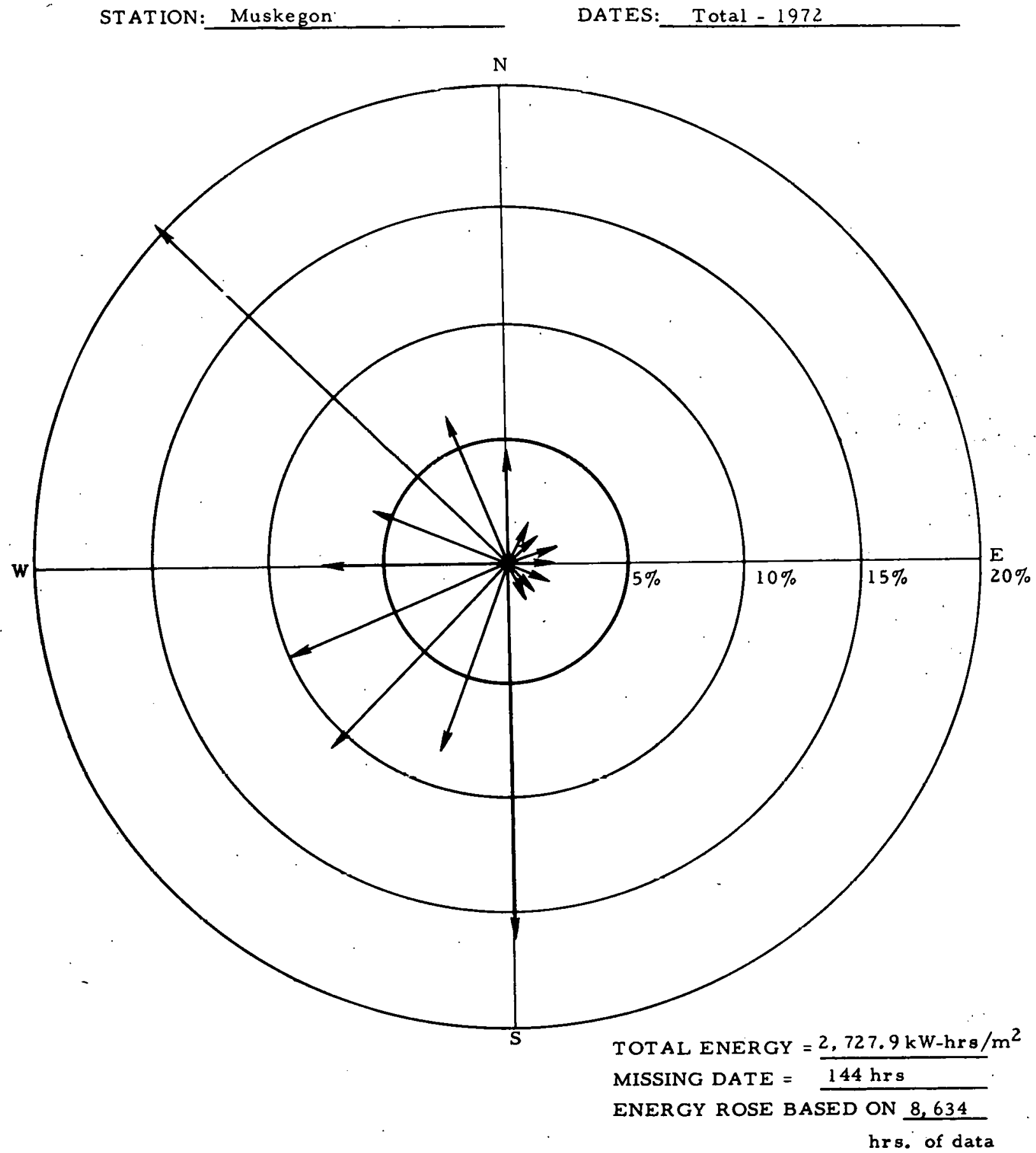

Figure 12. Muskegon 1972 annual energy rose. 


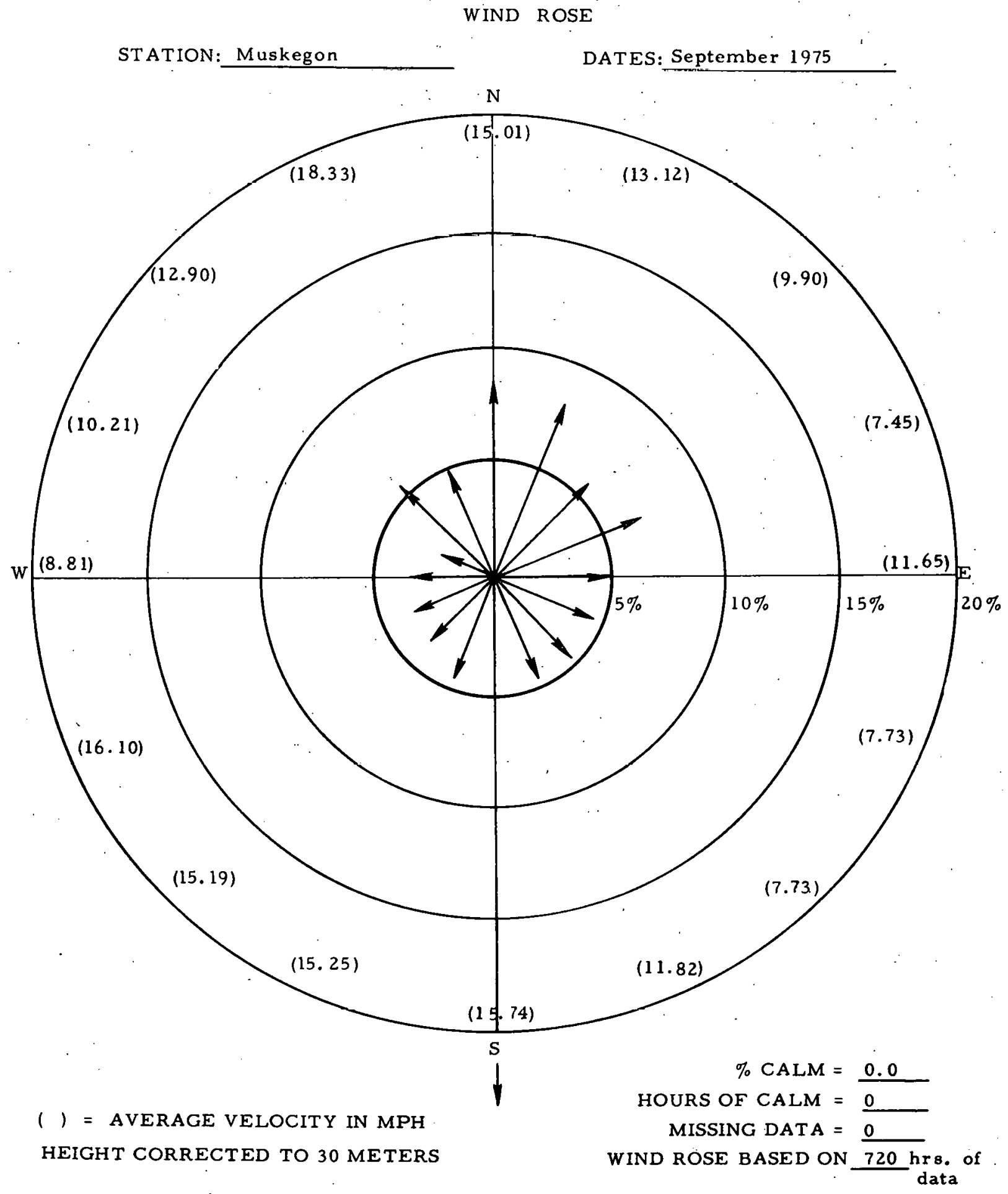

Figure 13. Muskegon September 1975 wind rose. 


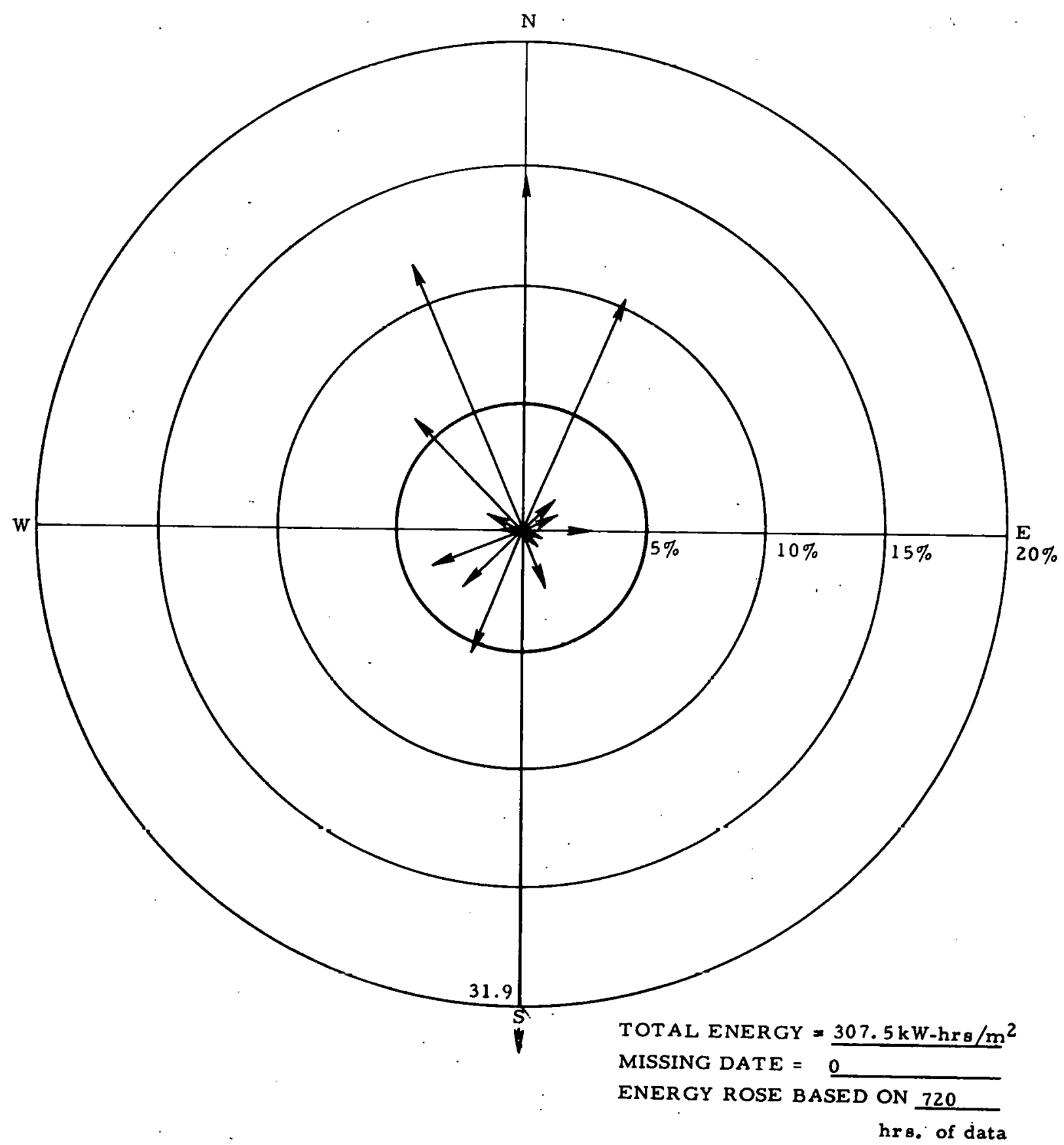

Figure 14. Muskegon September 1975 energy rose. 
stations indicates that average annual wind speeds of between 13 and $18 \mathrm{MPH}$ are the norm at or near the Great Lakes shoreline. These winds correspond to an average annual wind power density of 225-375 $\mathrm{W} / \mathrm{m}^{2}$ at 10 meters. These wind power densities rank amongst the highest within the U.S. ${ }^{6}$ and demonstrate that the coastal region of Michigan is an excellent area for wind turbine applications.

The monthly average wind speeds shown in Figure 8 clearly show that the winter months, October through March are months of high wind energy while the summer months of June through August have low wind energy. Each wind measuring station in the Great Lakes region has a similar seasonal wind pattern. This fact suggests the possibility of using wind energy to replace oil, natural gas, and bottled gas for heating in the winter.

Prevailing winds in the region are westerly. During the summer months, winds are predominantly southwesterly as the "Bermuda High Pressure Center" pushes into the Southeastern United States. During the winter months, the prevailing winds are West to Northwest, but change quite frequently for short periods into the other directions. These changes are due to the interaction of maritime-polar or continental polar air with maritime-tropical air.

The Great Lakes Region, particularly the western and upper portions of the region, resides on the fringe of the Midwest tornado belt. The lower frequency of tornadoes occurring in this region is due to the colder water of the Great Lakes during the spring months, a prime period for tornado activity. Since 1900, for example, only two tornadoes are known to have touched down in Oceana County, the county in which the city of Hart, Michigan is located. 4

Examples of computer processed 1975 wind data are shown in Table 2 and Figures 16 and 17. Several conclusions are apparent from this information. A comparison of the monthly wind speed averages in Table 2 for Ludington, Muskegon and Little Foint Sable Lighthouse and a comparison of their diurnal variations in Figure 16 shows that, although these three stations are separated by 50 miles along the coast of Lake Michigan, they consistently show very similar wind energy behavior. Thus, if the wind energy is well known by month and 
TABLE 2

1975 WIND DATA

Average Velocity in MPH at $30 \mathrm{~m}$.

\begin{tabular}{|c|c|c|c|c|c|c|c|c|}
\hline & March & April & May & June & July & August & Sept. & Yearly Average \\
\hline $\begin{array}{l}\text { Muskegon } \\
\text { Average Velocity }\end{array}$ & 14.0 & 13.4 & 10.9 & 12.7 & 11.7 & 11.3 & 12.6 & 12.37 \\
\hline $\begin{array}{l}\text { Ludington } \\
\text { Average Vel ocity }\end{array}$ & 15.3 & 13.7 & 10.8 & 12.6 & 11.7 & II. 7 & 12.9 & 12.61 \\
\hline $\begin{array}{l}\text { Light House } \\
\text { Average Velocity }\end{array}$ & & 13.3 & 10.9 & " & $*$ & * & 12.4 & \\
\hline $\begin{array}{l}\text { State Police } \\
\text { Average Velocity }\end{array}$ & & II.I & * & 10.1 & 8.8 & 7.7 & $7: 1$ & 9.65 \\
\hline $\begin{array}{l}\text { Pro Gas } \\
\text { Average Velocity }\end{array}$ & & * & 8.5 & 10.1 & 8.1 & 9.0 & * & \\
\hline
\end{tabular}

* Not sufficient data for one month average. 


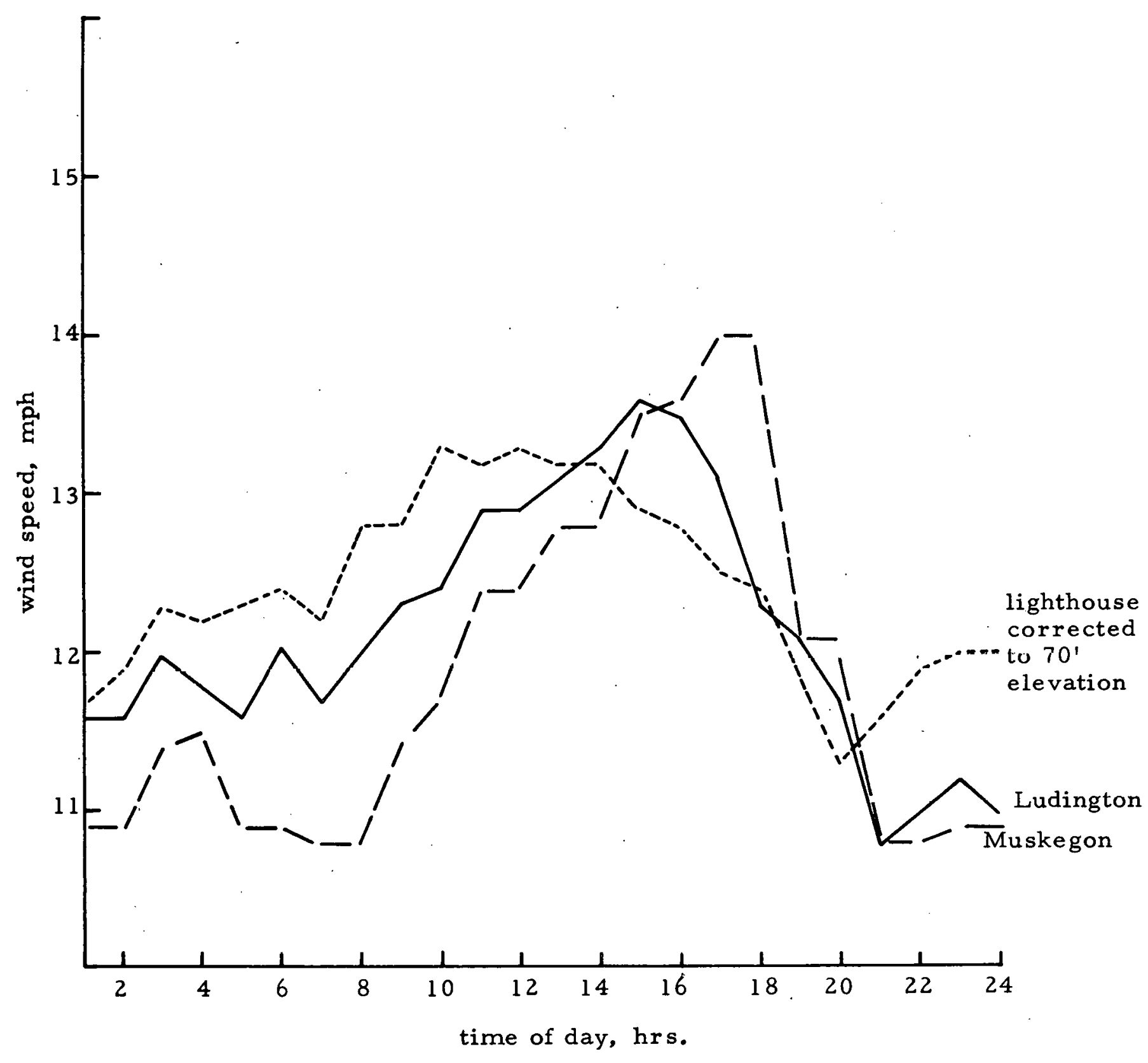

Figure 16. Diurnal variations for Ludington, Muskegon and the Little Point Sable lighthouse. 
year at a particular position on the coast, it can be assumed to be known with a high degree of accuracy (neglecting local topographic effects that would be caused by hills and dunes adjacent to the coast) any where along this 50 mile coastal region. Furthermore, this implies that the historical wind data from both the Ludington and Muskegon Coast Guard Stations can be used to provide historical wind information for the coastal region west of the city of Hart.

Figure 17 displays the diurnal wind variations for Little Point Sable Lighthouse, State Police Tower and Pro Gas wind stations. The attenuation of wind energy due to the characteristics of the terrain is clearly indicated by the $13.4 \mathrm{mph}$ average wind speed at Little Point Sable Lighthouse vs: the 11.1 and 9.1 averages for the State Police and Pro Gas wind measuring stations respectively. Thus, even though the State Police wind station is 320 feet above the lake level, the attenuation of wind energy is significant. This difference between shoreline wind speeds and wind speeds at inland locations is consistent with the results from the historical wind data. An important question is raised by this fact and must be answered by our study: How rapidly is the wind attenuated as it moves inland off of the Great Lakes?

\section{HART POWER DEMAND AND CONSUMER USAGE}

3. 1 Characterization of Hart Power and Energy Demand Since the goal of the project is to determine the feasibility of future implementation of wind power in the Hart area, it is necessary to predict the total load as it grows over the prediction time horizon. The total load at any time includes the sum of losses in transmission and distribution as well as consumer load. As indicated in the next section, the features of the load demanded by consumers will be analyzed separately from the total load so that predictions can be corrected for anticipated changes in consumer load behavior and substitution effects between natural gas and electricity. Nevertheless, one input to any feasibility evaluation of wind power is total load pre dicted on an hourly basis. Since this total load is equal to the sum of power generated by diesel and hydro alternators in Hart, plus that 
supplied by Wolverine, operating logs with this data can be used as an historical base. Twelve months of such data has now been card-punched and a typical graph of this total load (called total indicated kilowatts) is shown in Figures 18 and 19. Notice the consistent nightly minimum of about $1100 \mathrm{~kW}$ and the daily peaks ranging from 2300 to $3000 \mathrm{~kW}$. This data is typical of most weeks except during the peak season of the local canneries in June, August and September. This historical data will be used to find a probabilistic demand model for the future with a load increase averaging about $7 \%$ per year--a value predicted by the Hart management which is lower than the short-term historical data indicates. Corrections to this load growth estimate will be made from the consumer usage study and the corrected estimates used as input to the economic evaluation model discussed in Sections 7 and 9 of this report.

\subsection{Utilization and Consumption}

The energy shortage is dominantly a shortage of gas and oil. These are the fuels heavily relied upon by Hart, directly and indirectly. To solve the problem, a shift to other energy sources is indicated. One such source is presumed to be wind power. How to apply it costeffectively, thereby reducing the consumption of precious gas and oil, is, of course, the subject of the present study.

Application of wind power to small electric systems, and the utilization of wind power otherwise, can take several directions: (1) utilization of wind energy as a fuel saver, (2) wind energy combined with an energy storage system forming a base load operation, (3) changes in consumer utilization practices, i.e. demand, to accommodate, at least in part, variations in wind availability. Option (3) might include energy storage at the consumer level. It might also include a switch in space and water heating fuels from oil and gas to wind-generated electricity.

Options (1) and (2) assume that the market demand for electricity will be met by the supplier, when and if such demand arises. Option (3) would require societal and/or institutional changes related to living habits and life styles, economic and human values, commercial and industrial processes, and a host of other characteristics of a community. In order to determine how such change might be brought 


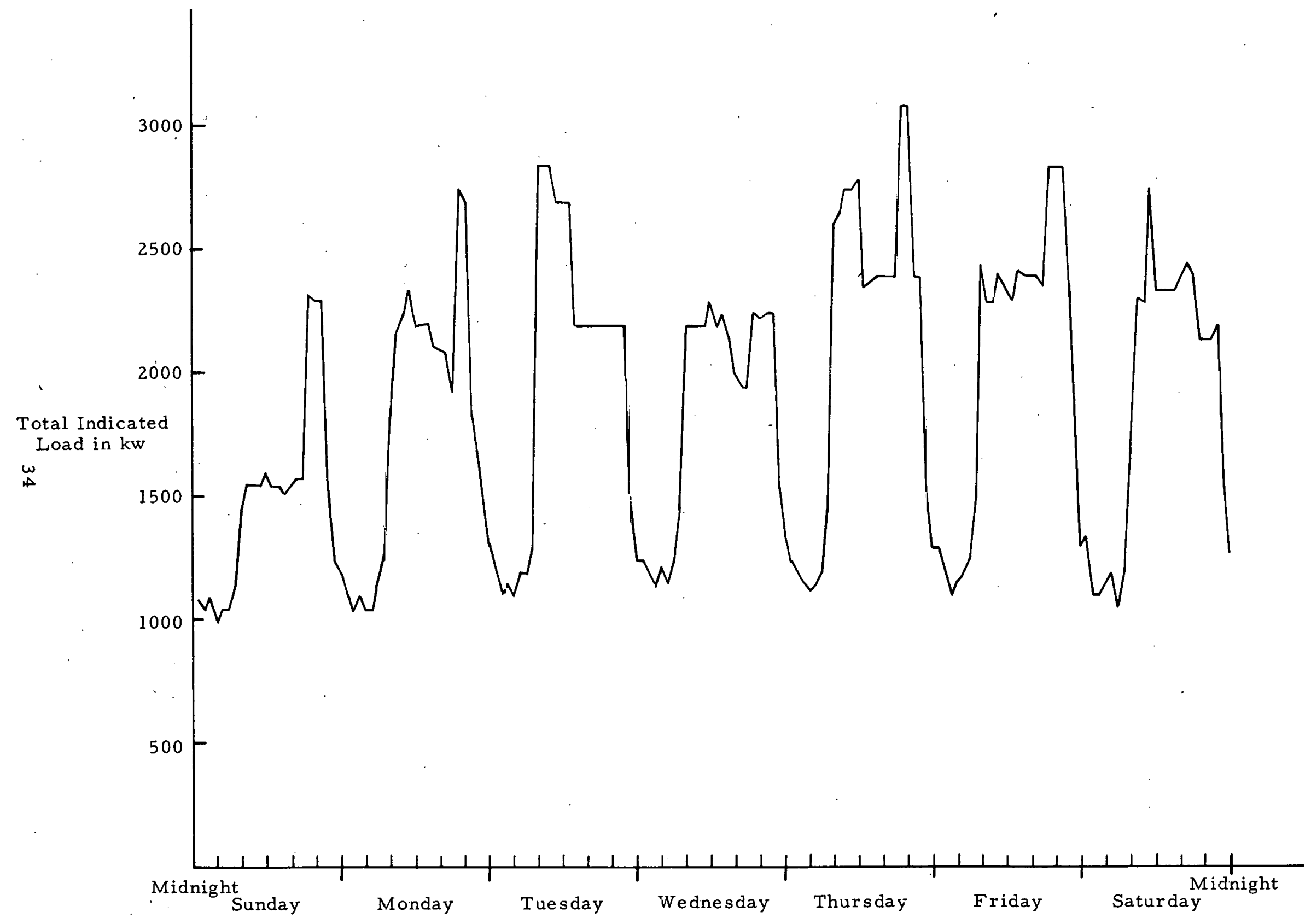

Figure 18. Typical Hart Load Profile (Week of January 6-12, 1974). 


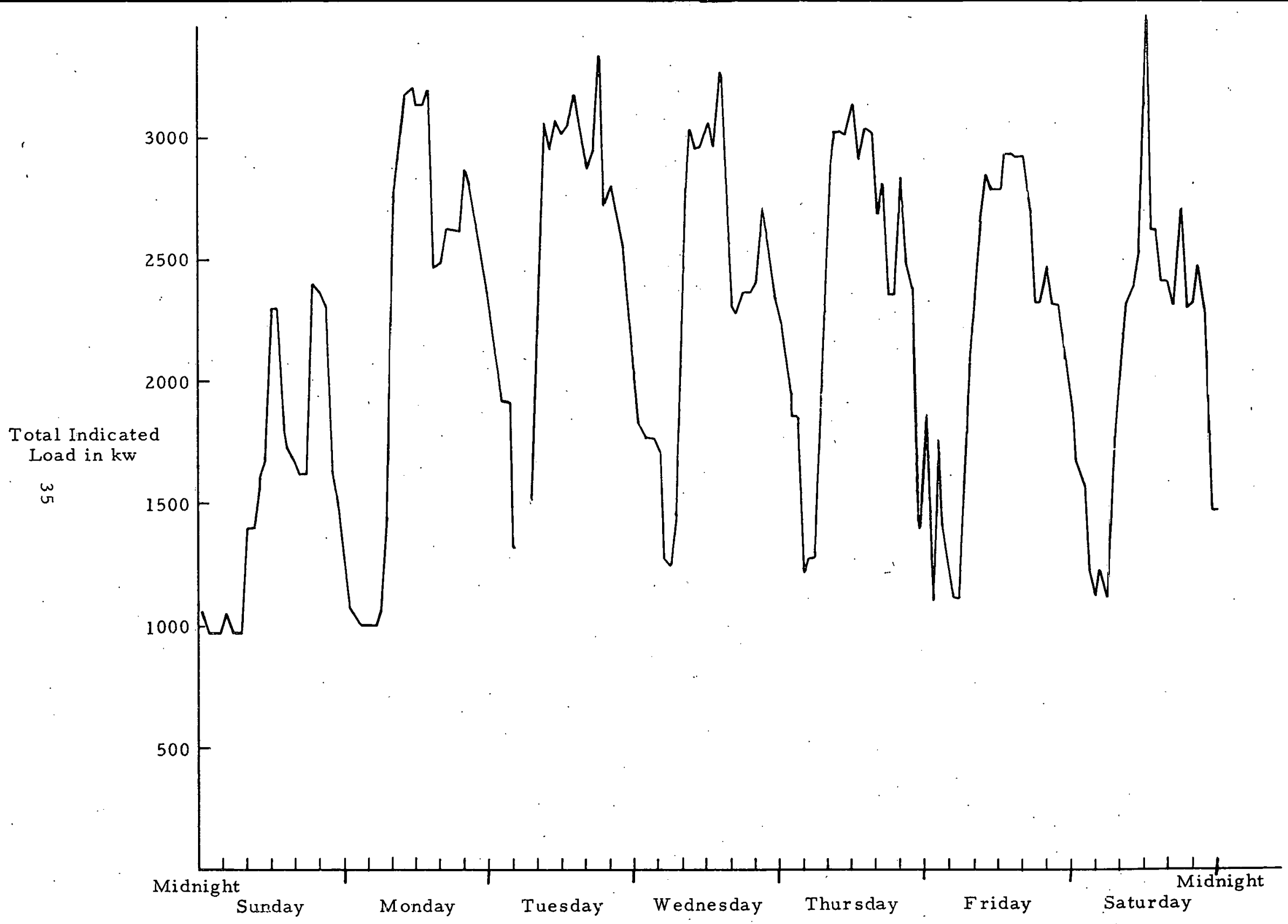

Figure 19. Typical Hart Load Profile (Week of October 6-12, 1974). 
about, that is, changes which would accommodate the nature of wind power, requires information. Unfortunately, there is little such information readily available.

Ideally, the information needed is time-continuous wind-power data, and individual time-continuous consumption data with time intervals on the order of minutes. The wind data situation is dealt with in Section 2 of this work. Utility-energy consumption data is available only in a macro sense. With respect to the Hart system, there is information on hourly electricity send-out, daily, monthly, and yearly aggregates. Similar information is available for natural gas. Monthly billings tell one about monthly consumption by individual users, and these users can be categorized. The following tables serve to illustrate the type of information available.

August 10, 1975 to September 10, 1075

Table 3, Hart Electric System, Deliveries by Category

(Fruit) Industry

Commercial

Offices

Light Industry and Farming

Residential

Utilities, Water and Sewage

Grocery Markets

Other Retail Stores

Restaurants

Bars

Motels

Gas Stations

Schools

Medical Care

Public Grounds

Miscellaneous
$32.9 \%$

4.8

2.6

1.7

21.2

14.4

6.9

2.0

1.3

.8

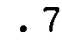

.3

2. 1

5.3

1.1

$\frac{1.9}{100.0 \%}$

Total delivery for the period $=1,573,478 \mathrm{kWh}$.

Source: Billings for the period 
TA.BLE 4

Michigan Consolidated Gas Company

Natural Gas Deliveries by Categories

October 1, 1974 to September 30, 1975

\section{Type of Customer}

Residential (a)

Residential Heating

Commercial ${ }^{(c)}$

Commercial Heating

Industrial $(e)$

Inter ruptible ${ }^{(f)}$ (b)

$$
\begin{gathered}
.3 \% \\
31.0 \\
2.6 \\
31.2 \\
2.0 \\
32.9 \\
\hline 100.0 \%
\end{gathered}
$$

Total deliveries for the period $=292,842$ million Btu

(a) - generally cooking and water -heating

(b) - generally cooking, water-heating, and heating: Heating is generally $75 \%$ of the consumption

(c) - generally commercial cooking; laundromats, and non-heating com-. mercial uses

(d) - generally commercial and industrial heating, including residential apartment buildings

(e) - industrial processing without stand -by (other fuels) capability

(f) - industrial processing with stand -by capabilities (City of Hart electric plant)

Source: Michigan Consolidated Gas Company

Of note is that natural gas consumption is roughly the equivalent of five times the energy value of the consumption of electric energy. 
As already indicated, this type of information is inadequate for determining how wind power availability might be related to total demand, or how utilization practices might be adjusted to accommodate the availability of wind power, adjusted in a reasonably cost-effective and socially acceptable manner. The literature was reviewed to determine whether any past consumption studies could be used to construct the needed detailed consumption profiles. The outcome was negative. Admittedly, a more intensive search might alter this judgement.

The problem centers on the indeterminate nature of the demand variations which are illustrated by Table 5, Baseload, Peakload, and Ratio, Hart Electric System 1974, and Figure 19, Daily. Demand Variations, Hart Electric System, week of October 6-12, 1975.

Table 5

Baseload, Peakload, and Ratio

Hart Electric System 1974

$\begin{array}{llll}\text { Month } & \text { Baseload } & \text { Peakload } & \text { Ratio (Peak/Base) } \\ \text { January } & 768 & 3,050 & 4.0 \\ \text { February } & 920 \text { highest } & 2,490 & 2.7 \text { minimum } \\ \text { March } & 820 & 2,450 & 3.0 \\ \text { April } & 770 & 2,260 \text { lowest } & 2.9 \\ \text { May } & 800 & 2,390 & 3.0 \\ \text { June } & 820 & 2,290 & 2.8 \\ \text { July } & 730 & 3,410 & 4.7 \\ \text { August } & 820 & 3,350 & 4.1 \\ \text { September } & 580 & 3,280 & 5.7 \text { maximum } \\ \text { October } & 860 & 3,550 \text { highest } & 4.1 \\ \text { November } & 700 & 2,980 & 4.3 \\ \text { December } & 530 \text { lowest } & 2,940 & 5.5\end{array}$

Source: Hart Electric Plant Daily Log Sheets for 1974.

The information presented in Table 5, and Figure 19, explains the difficulties one encounters in attempting to match wind power availability with the actual utilization of the kind of energy wind power could supply. It is of note that the peak/base ratio of the Hart system must be considered abnormally high.

The ideal way to approach the problem would be to instrument and continuously meter representative samples of actual consumption. 
However, it was felt that this was too costly and time-consuming, without knowing whether the return on the effort could be sufficiently productive and worthwhile. Further analysis is to verify this assumption.

A two-part decision.was made to (1) survey the residential sector by means of a user questionnaire included with one mailing of the monthly electric bills, and (2) to obtain information from the other sectors by means of personal interviews to collect pertinent informa tion. A sample of the residential user survey questionnaire can be found in the appendix.

About $60 \%$ of the residential questionnaires have been returned and are yet to be processed. Some random sample interview data of commercial users has also been collected, but has yet to be analyzed and suitably organized.

In summary, because of the unknowns and complexities involved in the questions raised, it may well take another year to produce tangible information useful in terms of the particular objective, that is, to spell out how consumption might be accommodated to the availability of wind energy. It all depends on whether the information can be developed at all without too costly methods and tools:

\section{ASSESSMENT}

4.1. Wind Turbine Performance in the Hart Area

In order to effectively use wind energy, two different types of modes of operation are available for WECS: (1) WECS as fuel savers and (2) WECS as part of base load of electric system operation. The first of these requires that wind systems be tied directly into existing electric power grids. In general, energy delivered in this manner requires conventional spinning reserve capacity and would be worth the cost of fuel saved in a conventional plant and must compete with any other "dump" energy such as excess energy from a plant which normally is not fully utilized a round the clock. Wind systems operating as part of a base load require an adequate energy storage system to be available on demand whenever a wind lull period is present. If energy storage is present, then the energy generated by wind power can be used on demand and the same reserve requirements would exist as for conventional power plants. 
For the purpose of WECS design and economics, it is necessary to calculate energy output and average power output per month and year for different wind turbine designs and wind turbine sites. It is also necessary to determine the frequency of occurrence and the length of time of periods when the wind turbines are not in operation. Each of these calculations is dependent on the region's wind characteristics and on individual wind turbine characteristics. Example calculations of energy, average power and down period diuration for the G. E. and Kaman Wind turbine designs are presented in this section. Historical wind data from the Muskegon and Ludington Coast Guard Stations (Note the conclusion in section 2.5 that the winds along the Lake Michigan shore west of Hart are very similar to the winds at Muskegon and Ludington) and the 1975 wind data gathered by the MSU wind stations in the Hart region is used as the input wind information.

Tables 6 through 9 show example calculations of the total energy and average power for the $500 \mathrm{~kW}$ and $1.5 \mathrm{MW} \mathrm{G.E.} \mathrm{and} \mathrm{Kaman}$ machines located at a number of different sites on the shore of Lake Michigan and at inland locations in the vicinity of Hart. These calculations were carried out by numerically integrating actual power duration curves or velocity frequency curves using the best wind turbine informa tion available from the final G.E. and Kaman presentations.

Historical wind information was employed in all the calculations except for those shown in Table 7 for the State Police tower south of the city of Hart. Since a full year of wind information was not available yet from the ongoing MSU wind measurements, the velocity frequency curve for a full year had to be estimated. An approximated velocityfrequency curve was found by using the April - Sept. 1970 wind informa tion to provide a relationship between the energy at Muskegon and the State Police tower. For example, it was found that the energy at the State Police tower was less than one-half of the energy on the Lake Michigan shore. Using this information, the 1972 Muskegon velocity frequency curve was modified, i.e., "shifted" to the State Police tower.

Two wind turbine models were employed. Whenever actual machine characteristics vs. wind speed. were available, they were numerically integrated together with the power duration/frequency speed curves. When detailed machine models were not supplied, the 
machine efficiently was assumed to be independent of wind speed for wind speeds between"cut-in" and "rated." While cut-in, rated, average, etc. wind speeds are referenced at $30 \mathrm{ft}$., when making energy and power calculations, the wind speeds could be corrected for height, (h), over the diameter of the wind turbine blade. A height variation of $(\mathrm{h})$ 0.16 was used for lake and lakeshore regions while a height variation of (h) 0.28 was assumed for the wind variation for sites located several miles or more from the lakeshore.

If wind machines are to be used as part of a base-load operation, energy must be available to users on demand. In order to determine the energy storage requirements of a WECS with energy storage, it is necessary to know the frequency at which a wind turbine is closed down and the length of time for each of these down periods. In this report the turning off or closing down of a wind machine is called "down time" and the length of time of such an occurrence is called "down period." The down time and down period include the time when the winds are equal to or above the machine cut-off wind speed as well as when the wind conditions are below the cut-in. wind speed. That is, a down period equals the number of consecutive hours the wind speed is less than cut-in or greater than or equal to the cut-off velocity. Thus, the down period is a function of site wind characteristics and the characteristics of the wind turbine configuration selected.

A software package was developed to compute the frequency down period duration curve from the wind turbine and the wind characteristics. Figure 20 shows the frequency of the down period durations for the G.E. $500 \mathrm{~kW}$ and $1500 \mathrm{~kW}$ machines using Ludington 1972 wind data. The $500 \mathrm{~kW}$ machine is down a total of 1972 hours for the year and has only one down period in excess of 36 hours (actually this down period is in excess of 50 hours). In comparison, the larger $1500 \mathrm{~kW}$ machine is down a total of 3640 hours for the year and has 27 down periods in excess of 36 hours ( 8 of these are in excess of 50 hours). Thus, if the larger machine is part of a base load system, it would require a significantly larger energy storage system than an equivalent system of smaller widely separated wind turbines.

More specifically, one 1.5 MW machine on the lakeshore will produce on the average $400 \mathrm{~kW} / \mathrm{hr}$ over a year. (See Table 6) Two 
TABLE 6.

AVERAGE POWER OUTPUT AND ANNUAL

ENERGY OUTPUT FOR G.E. AND KAMAN WIND TURBINES

Wind Data - Muskegon 1972 - Average velocity $=11.7 \mathrm{mph}$ at 30 feet

\begin{tabular}{l|c|c|c}
\multicolumn{1}{c|}{ Machine } & $\begin{array}{c}\text { Annual } \\
\text { Energy Output }\end{array}$ & $\begin{array}{c}\text { Average } \\
\text { Power Output }\end{array}$ & $\begin{array}{c}\text { Plant } \\
\text { G.E. } 500 \mathrm{~kW}\end{array}$ \\
\hline G.E. I.5 MW & $2.04 \times 10^{6} \mathrm{kWh}$ & $235 \mathrm{~kW}$ & 0.47 \\
\hline Kaman $500 \mathrm{~kW}$ & $3.41 \times 10^{6} \mathrm{kWh}$ & $394 \mathrm{~kW}$ & 0.26 \\
\hline Kaman I.5 MW & $1.30 \times 10^{6} \mathrm{kWh}$ & $150 \mathrm{~kW}$ & 0.30 \\
\hline
\end{tabular}


TABLE 7:

AVERAGE POWER OUTPUT AND ANNUAL

ENERGY OUTPUT FOR G.E. AND KAMAN WIND TURBINES WIND DATA-STATE POLICE TOWER (I972 estimate)

Annual

Average

Plant

\begin{tabular}{l|c|c|c}
\multicolumn{1}{c|}{ Machine } & Pnergy Output & $114 \mathrm{~kW}$ & 0.23 \\
\hline G.E. $500 \mathrm{~kW}$ & $1.00 \times 10^{6} \mathrm{kWh}$ & $130 \mathrm{~kW}$ & 0.09 \\
\hline G.E. I.5 MW & $1.14 \times 10^{6} \mathrm{kWh}$ & $63 \mathrm{~kW}$ & 0.126 \\
\hline Kaman $500 \mathrm{~kW}$ & $.55 \times 10^{6} \mathrm{kWh}$ & $80 \mathrm{~kW}$ & 0.05 \\
\hline Kaman I.5 MW & $.70 \times 10^{6} \mathrm{kWh}$ & & \\
\hline
\end{tabular}


TABLE 8.

AVERAGE POWER OUTPUT AND ANNUAL ENERGY

OUTPUT FOR G.E. W IND TURBINES

ALONG THE COAST OF LOWER MICHIGAN

Wind data - 1972 Historical Coast Guard Data

\begin{tabular}{l|l|c|c|c}
\multirow{2}{*}{ Location } & \multicolumn{2}{c|}{$500 \mathrm{~kW}$ G. E. } & \multicolumn{2}{c}{ I.5 MW G. E. } \\
\cline { 2 - 5 } & $\begin{array}{c}\text { Annual Energy } \\
\mathrm{kW}-\mathrm{Hr}\end{array}$ & $\begin{array}{c}\text { Average Power } \\
\mathrm{kW}\end{array}$ & $\begin{array}{c}\text { Annual Energy } \\
\mathrm{kW}-\mathrm{Hr}\end{array}$ & $\begin{array}{c}\text { Average Power } \\
\mathrm{kW}\end{array}$ \\
\hline Muskegon & $2.0 \times 10^{6} \mathrm{kWh}$ & $235 \mathrm{~kW}$ & $3.41 \times 10^{6} \mathrm{kWh}$ & $394 \mathrm{~kW}$ \\
\hline $\begin{array}{l}\text { Ludington } \\
\text { Lansing Shoals }\end{array}$ & $2.2 \times 10^{6} \mathrm{kWh}$ & $253 \mathrm{~kW}$ & $3.46 \times 10^{6} \mathrm{kWh}$ & $396 \mathrm{~kW}$ \\
\hline
\end{tabular}


TABLE 9.

AVERAGE POWER OUTPUT FOR I. 5 MW

G.E. Wind Turbine Machine

Wind Data: Muskegon 1972

Cut in Velocity $=11.4 \mathrm{mph}$ Diameter $=190$ feet Rated Velocity $=22.5 \mathrm{mph}$

All wind velocities given are at 30 feet

\begin{tabular}{|c|c|c|c|c|c|c|c|c|c|c|c|c|c|}
\hline & Jan & Feb & Mar & April & May & June & July & August & Sept & Oct & Nov & Dec & $\mathrm{Yr}$ \\
\hline $\begin{array}{l}\text { Average } \\
\text { Velocity } \\
\text { (mph) }\end{array}$ & 17.0 & 11.2 & 11.8 & 10.5 & 9.0 & 10.0 & 9.4 & 9.4 & 10.9 & 13.3 & 12.6 & 14.9 & 11.7 \\
\hline Average & & & & & & & & & & & & & \\
\hline $\begin{array}{l}\text { Output } \\
\text { Power } \\
\text { kW }\end{array}$ & 793 & 369 & 382 & 298 & 166 & 304 & 249 & 254 & 353 & 536 & 442 & 555 & 394 \\
\hline
\end{tabular}




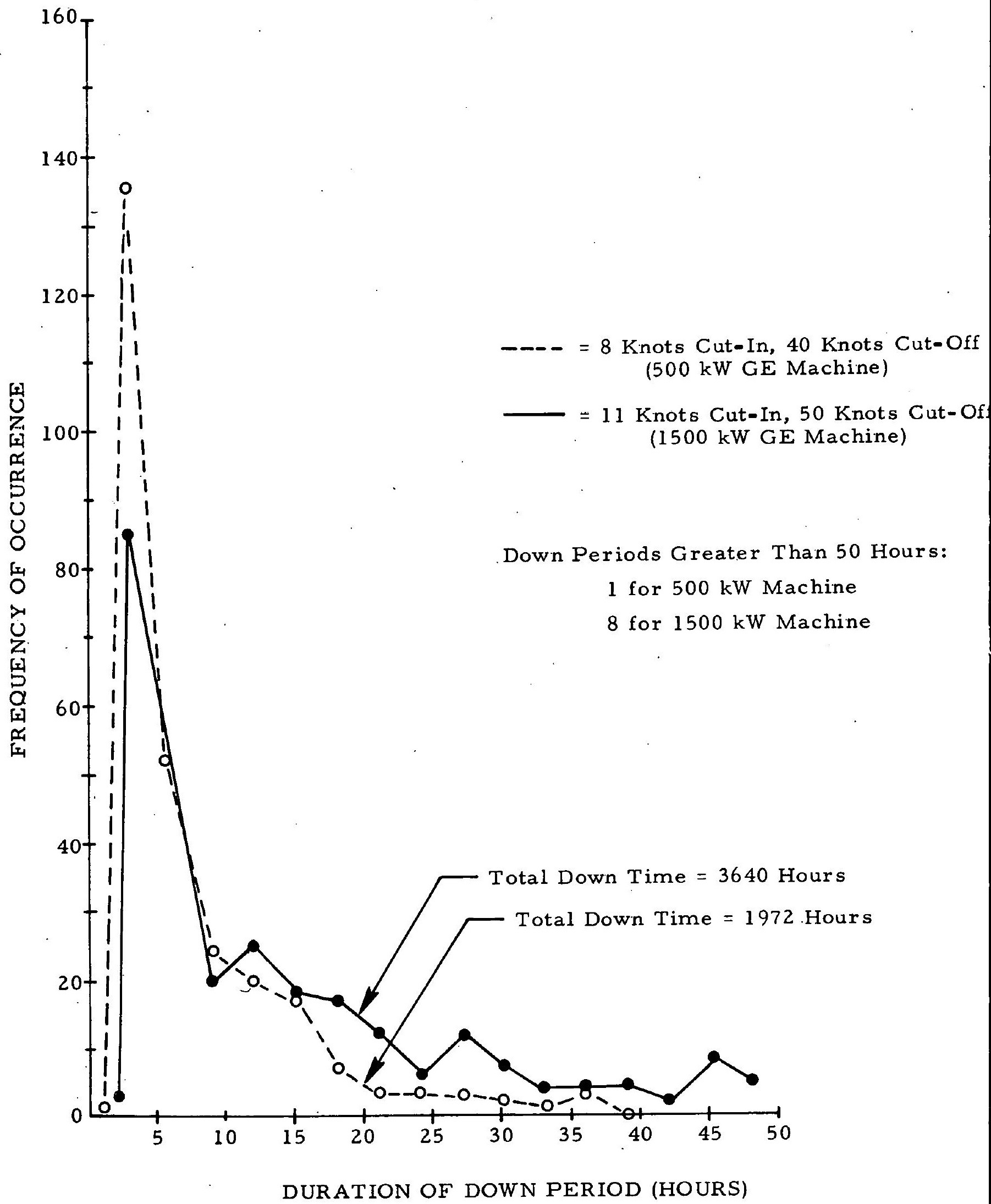

Figure 20. Down period duration curves for G. E. wind turbines. 
$500 \mathrm{KW}$ machines are equivalent to slightly more than one $1.5 \mathrm{MW}$ machine since together they produce an average power output of $500 \mathrm{~kW} / \mathrm{hr}$ per year. If one operates these two systems as fuel savers, the large machine would have a slight economic advantage since its cost is $\$ 500 / \mathrm{kW}$ or $\$ 750,000 \mathrm{vs}$. the two smaller machines which cost $\$ 1,000 / \mathrm{kW}$ or a total of $\$ 1,000,000$.

However, if these two systems are operated as part of a base load system the optimum economic design probably will be different. One would expect that the two $500 \mathrm{~kW}$ machines operating together will have less than the 1972 hour of down time of a single machine. This is particularly true if the two turbines were separated along the coast by tens of miles. 7

Thus, the energy storage requirements of the two smaller machines are expected to be much less than the energy storage system for the large machine. (3640 hours of down time) It may be possible, that even though the two $500 \mathrm{~kW}$ wind turbines cost $\$ 250,000$ more than the large 1. $5 \mathrm{MW}$ turbine, that total capital investment for wind turbine plus storage system is less for the system comprising smaller machines than may be the case for the larger machine. In addition, a system made up of several turbines has the advantage of better probable reliability over a single large unit.

Another conclusion is apparent. The 1.5 MW machine, which has been designed for optimum operation in locations where the average wind speed is $18 \mathrm{mph}$ at 30 feet, does not perform efficiently on the Lake Michigan shore, except in the Lansing Shoals location. Lansing Shoals is probably representative of many other over-water locations and not coastal locations. It does not perform optimumiy, not only as part of a base load system, but also as a fuel saver, since the average wind speeds are generally less than $15 \mathrm{mph}$. It is believed that a 1. $5 \mathrm{MW}$ machine designed for an average wind speed of $15 \mathrm{mph}$ would perform more economically as a fuel saver and if it had a low.cut in velocity, would also require less energy storage for operation as a part of a base load system.

At a given height, the attenuation of the wind energy is significant as it passes from lakeshore sites to inland sites as evidenced by Figure 17 in Second 2 and by Tables 6 and 7 . Based on the preliminary 
yearly wind energy estimates, finding economic inland sites near the city of Hart does not appear promising. Also, since the G.E. wind turbine design has lower rated and cut-in wind speeds than the Kaman designs, G.E. performs better both on the lakeshore and at inland sites.

These conclusions are preliminary. Further study is required to determine the optimum design criteria. For example, the following questions must be answered: (1) how many, what size, and where should the wind turbines be located, (2) how large a base load system of hydro plus wind can be constructed, (3) how should it be operated; by month and by day and (4) does a mix of large and small wind tur bines providing for both fuel saver and base load operation make sense? These and other points are discussed in Section 10: Future work.

4.2. Assessment of Existing Transmission Line Grid

It is unlikely that possible high-wind generation sites will be close to or within the Hart electric system distribution area. Thus, it was necessary to assess the capabilities of the existing transmission lines in the high-wind areas surrounding Hart, see map in Figure 21. If these lines lacked the capacity to carry wind-generated electricity, costs of new transmission lines would be part of total system cost, a probable negative. An area of about 100 square miles was evaluated, this area is marked on the map. Most of this area is serviced by the Oceana Electric Cooperative which, like the Hart, purchases energy from the Wolverine $G$ and $T$ Cooperative. Thus, Oceana and Hart are interconnected via Wolverine. Oceana's lines are both three phase at $12.5 \mathrm{kV}$ and single phase at $7.2 \mathrm{kV}$. Most of the lines serving the high-wind shoreline areas are $7.2 \mathrm{kV}$ single phase. The Wolverine Electric Cooperative has a $69 \mathrm{kV}$ three-phase "backbone" system passing through the middle of the area with three substations feeding Oceana and Hart.

A set of lines, marked on the map, was assessed for ampacity and voltage drop. The lower-voltage distribution lines chosen emanated from the substations and fed load in areas that were thought to be high-wind regions. This choice was made in the summer of 1975 


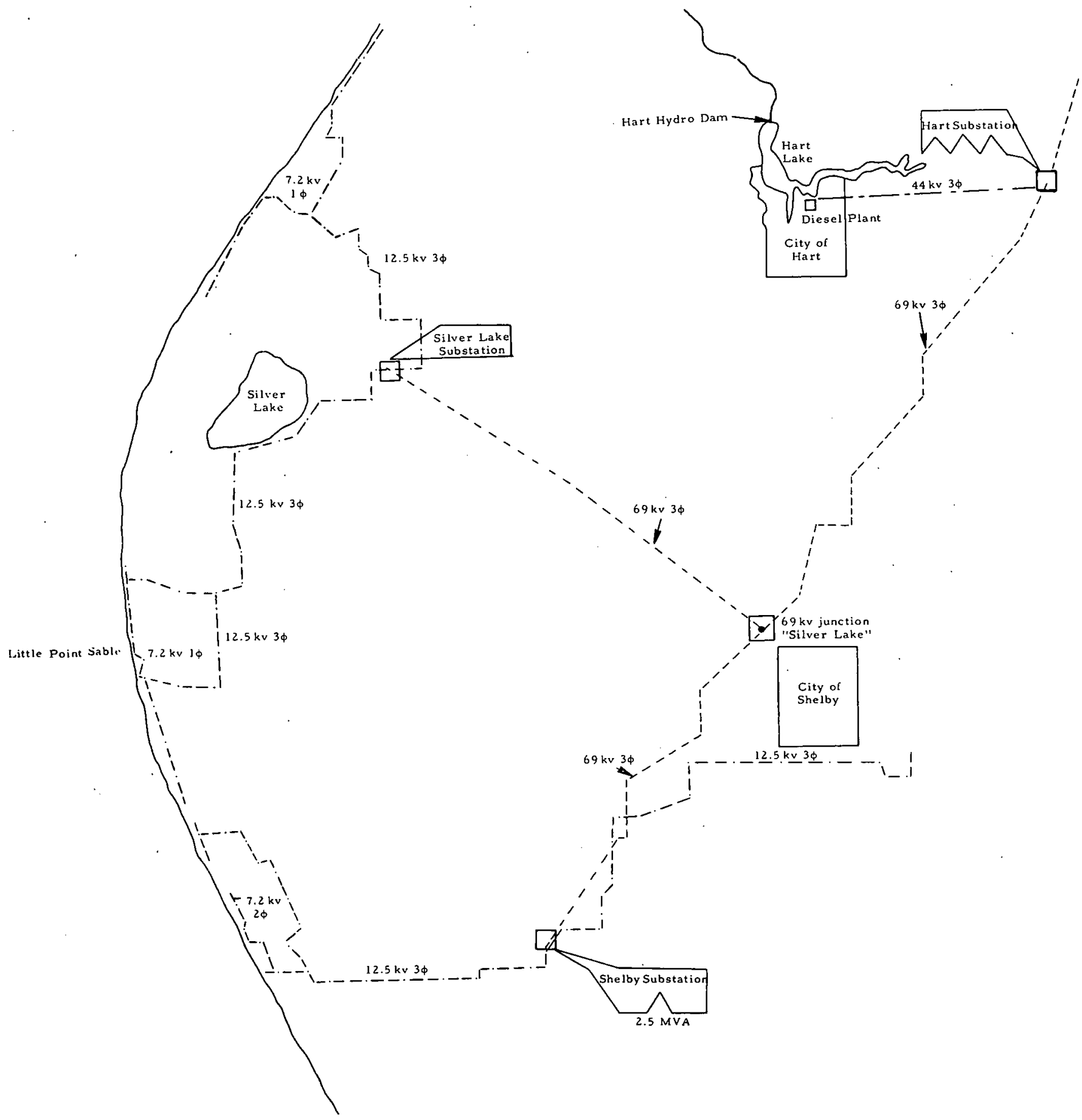

Figure 21. Transmission lines.in Oceana County, Cceana and Wolverine Cooperatives. 
before appreciable wind data had been gathered. The length and configuration of a selection of these lines is shown in Figures 22 through 24. The impedance and ampacity (allowable current before thermal damage) of each section was calculated and then a table of power capacity versus voltage drop was computed--with a power factor assumption of 0.8 . The results for three-phase distribution lines is given in Figure 25 which indicates, for example, that a line ten miles long will have a voltage drop of $5 \%$ when $134 \mathrm{~kW}$ is transferred. The single-phase lines were immediately omitted because the voltage drop was prohibitive at substantial power levels. If these distribution rightof-ways were to be used to feed power into Hart via Oceana and Wolverine, it would be necessary to string additional wires and convert them to three-phases lines. Similar calculations were completed for the $69 \mathrm{kV}$ Wolverine grid.

For example, the line from the Shelby substation at the southern end of the test area to the Hart substation has a capacity of 7 MVA with a $2 \%$ voltage drop--more than adequate for a $1.5 \mathrm{MW}$ wind station. This is $7 \mathrm{MVA}$ and exceeds present scheduled power transfer by several MVA.

\section{Conclusions:}

The $69 \mathrm{kV}$ Wolverine network has the capacity to transfer power equal to the entire Hart peak demand while the three-phase Oceana distribution network could handle several wind stations on modified lines, of a capacity up to several hundred $\mathrm{kW}$. The $500 \mathrm{~kW}$ G.E. and Kaman machines would be tied into short sections 2 miles or less of the Oceana distribution network and the 1. $5 \mathrm{MW}$ wind turbines must be tied directly into the $\mathrm{kW}$ Wolverine network. The calculations leading to these conclusions are available (they were done by visiting Professor Julius Preminger while at MSU--an experienced power engineer) but are not included in this progress report.

\section{HYDRO POWER ASSESSMENT}

5.1. Fuel-Saver Mode of Operation

"Fuel-saver" mode of wind power systems is being shown applicable to small electric systems such as the Hart system. This is primarily because present generation relies mostly on natural gas and/or 
Figure 22. $69 \mathrm{kV}$ lines considered (sketch) in Hart area.

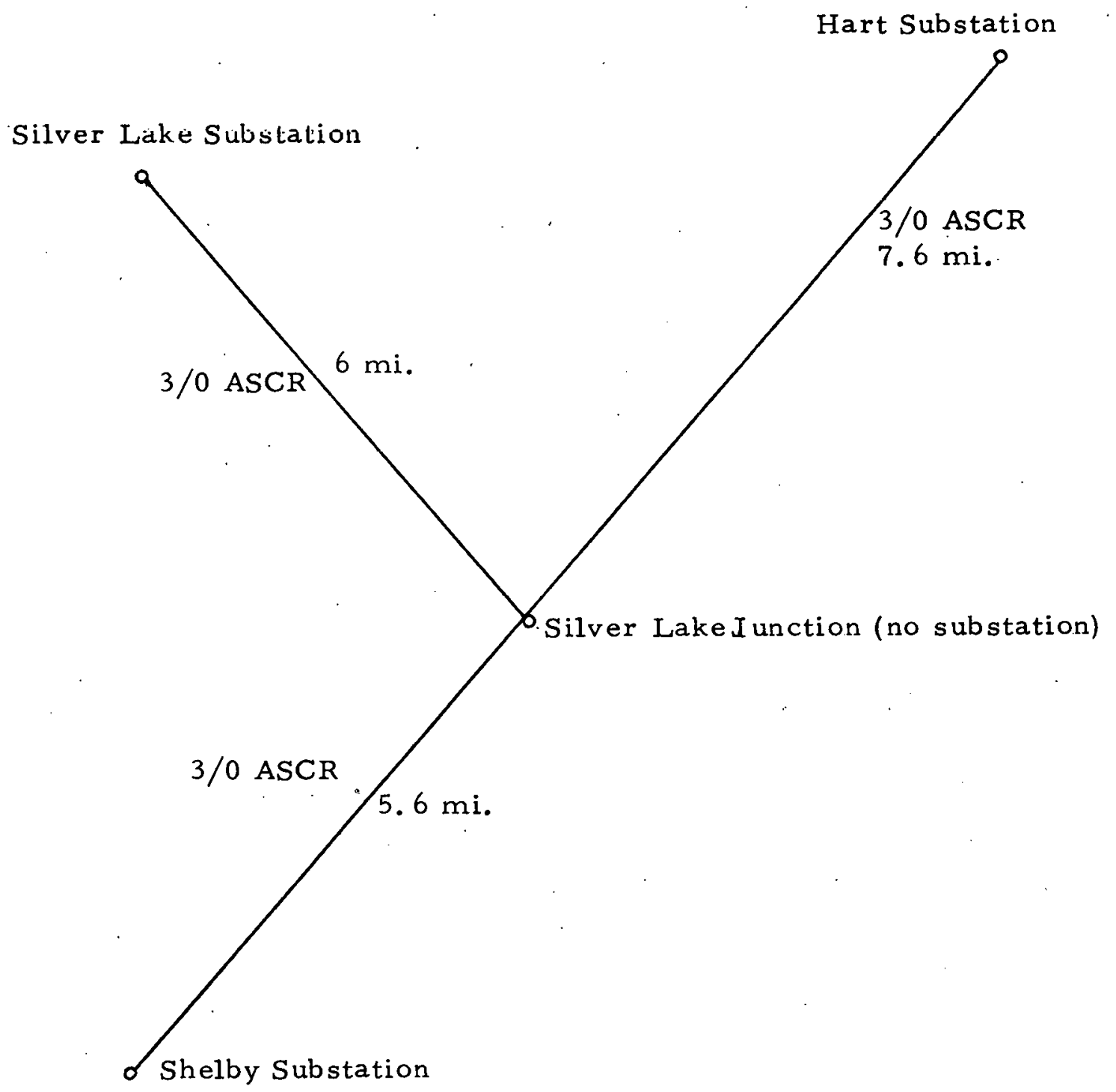

All lines are of $3 / 0$ ASCR conductor. 
A. Lines originating from SILVER LAKE SUBSTATION

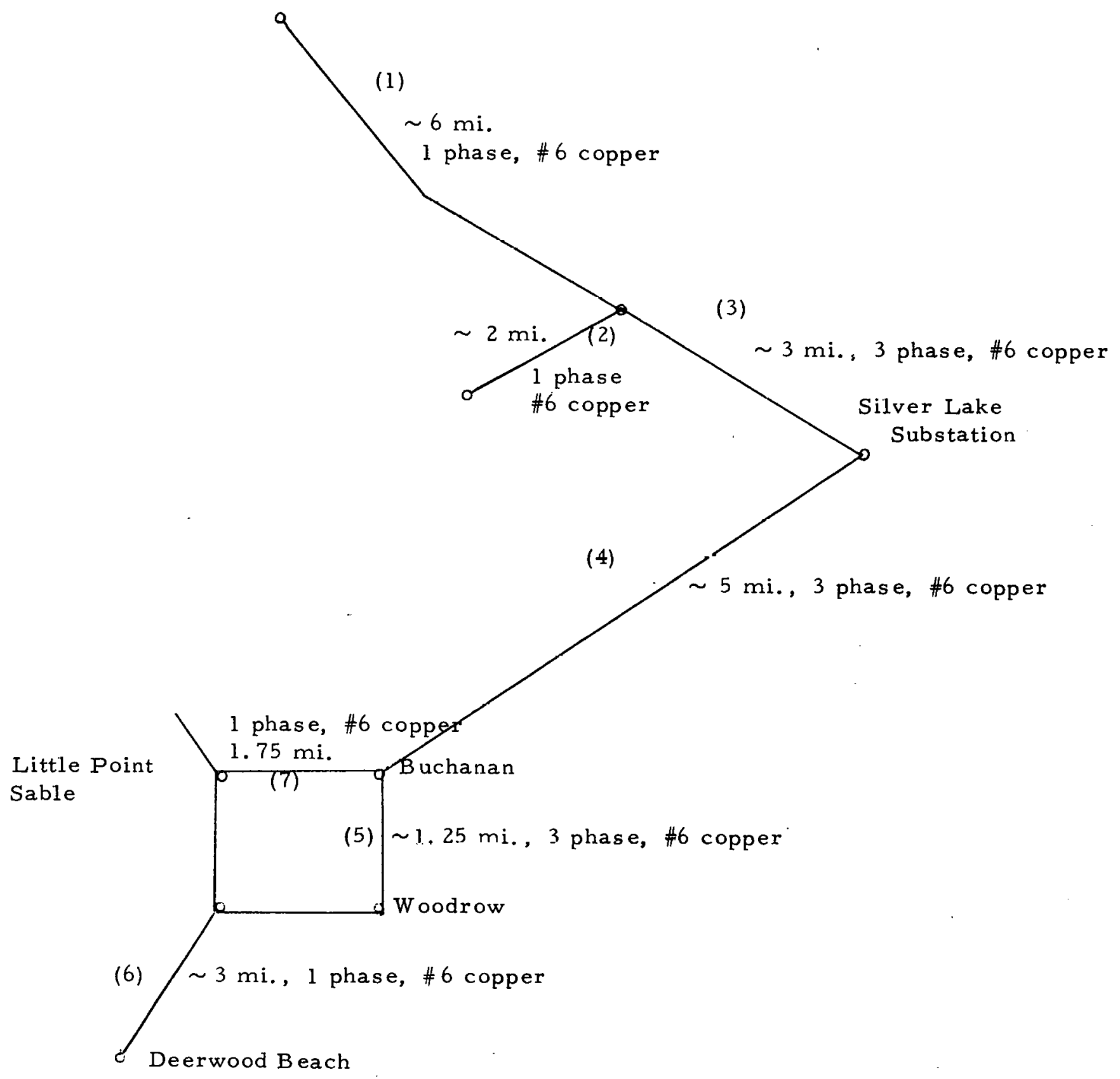

Figure 23. Sketch of $12.5 / 7.2 \mathrm{kV}$ lines considered. 
B. Lines originating from SHELBY SUBSTATION

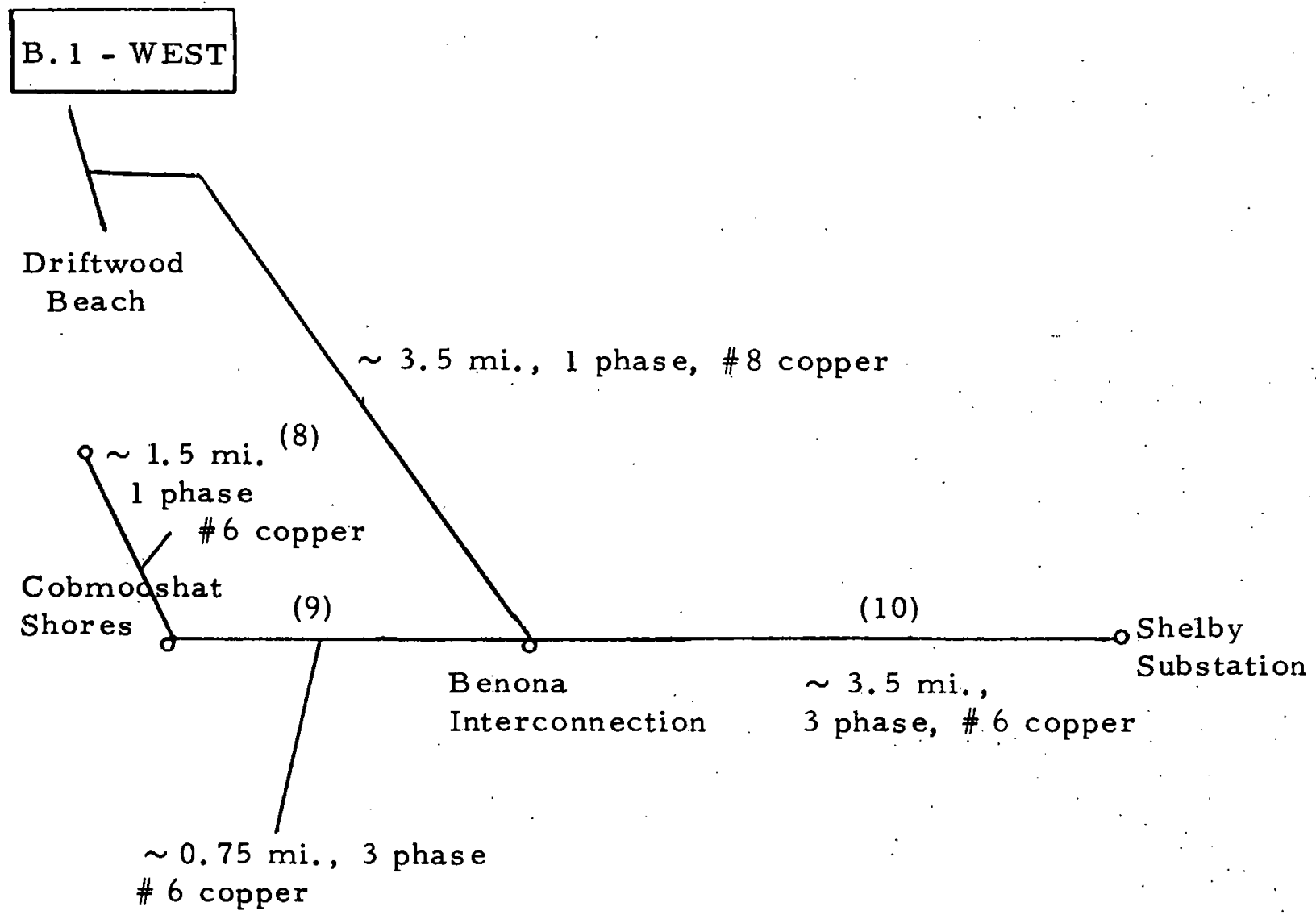

Figure 24. 
TABLE: Transferred power in $\mathrm{kw}$ for a 3 phase \# 6 copper line assuming $P . F .=0.8$ and $12.5 / 7.2 \mathrm{kV}$, as a function of voltage drop in $\%$ and distance in miles.

\begin{tabular}{|c|c|c|c|c|c|c|}
\hline & & 2 & 4 & 6 & 8 & 10 \\
\hline$\%$ & 2 & 269 & 135 & 90 & 68 & 54 \\
\hline & 5 & 667 & 334 & 222 & 167 & 134 \\
\hline & 10 & 1334 & 667 & 443 & 333 & 269 \\
\hline
\end{tabular}

The capacity limit for \#6 copper conductors is $110 \mathrm{~A}$, so for this case the ampacity limit of the considered line $S=\sqrt{3} \cdot 12.5 \cdot 110=\cong 2300 \mathrm{kVa}$ is overruled by the voltage drop limitations.

Figure 25. Voltage drop table for Hart area distribution lines. 
diesel oil for fuel. The cost of these fuels, which are expected to continue their rapid advance in price, are likely to favor capital invest ment in wind power facilities. This holds as long as no new capital facilities for system expansion are required, i.e., as long as existing plant satisfies current demand. However, this does not entirely hold true for Hart, nor does it for similar situations, small municipal and rural electric systems, which are faced with an annual load growth in the $5 \%$ to $7 \%$ range. Such load growth cannot be accommodated with wind power facilities operating in the "fuel saver" mode.

5.2 Wind Power as a Part of Base Load Capability

Energy for the Hart municipal electric system is normally supplied from three sources: (1) diesel power using either oil or gas as a fuel, (2) the Wolverine Rural Electric Cooperative, which also generates using oil or gas as a fuel, and also purchases a part of its requirements from large utilities, and (3) hydro generation using the South Branch of the Pentwater River. Hart, as is the case with most other utilities, is in need of additional generating capability, or additional supply from external sources, where the same problem prevails. One alternative is to use the Hart hydroelectric facility in combination with a wind power system. The mode of operation would have to be so arranged that the hydro facility is used during periods when the wind falls below a certain energy level.

5.3 History and Capability of Present Hart Hydro

The Hart hydro was built in 1926 by damming the South Branch of the Pentwater River, which flows westerly into Lake Michigan at Pentwater, about 10 miles from the Hart hydro dam. The impoundment created Hart Lake with a surface area of about 240 acres at an elevation of about 622 feet above sea level. The head so obtained is about 32 feet, which means that the tailwater is at an elevation of about 590 feet. Lake Michigan's normal elevation is about $578 \mathrm{ft}$.

As with most of the several hundred hydros which operated in Michigan at one time--now approximately 100 operating-- they were built in "waterwheel" fashion, i.e. "flowthrough", with no significant storage capacity. In other words, the impoundments were created 
simply to gain head (*). Therefore, the Hart Lake impoundment has almost no storage capacity, other than the storage contained in the lake, which is necessary to maintain the $32 \mathrm{ft}$. head.

When there is excess water, the "waste gates" are opened far enough to prevent raising the level of Hart Lake appreciably above the $622 \mathrm{ft}$. elevation. As will be shown later, about one-half of the annual discharge does not generate power.

Generating capability is relatively small, although it did satisfy the needs of the city of Hart initially, from 1927 to 1934 . The two wheels originally installed have a name plate rating of $300 \mathrm{~kW}$. The U.S. Geological Survey rated this installation (in 1958) at $270 \mathrm{~kW}$, and determined an efficiency factor of between $70 \%$ and $76 \%$ depending on the state of the facility. The probable average efficiency is $73 \%$, which is 10 to 15 percentage points below what a modern installation would be. A four year assessment of the 1971-1974 experience indicates that the average power output from the hydro facility is $94 \mathrm{~kW}$. 5.4 Investigation of Hart Hydro Converted to Energy Storage Mode Using the Hart hydro as an energy storage reservoir would call for a substantial increase in impoundment capacity, as well as an expansion of hydro generating capability to fall into line with wind power generating capability. For example, if a base load wind-hydro combination power capability were $1000 \mathrm{~kW}$, the hydroelectric capability would need to be $1000 \mathrm{kw}$.

Not considering pumped storage at this point of the investi gation, the basic limitation imposed on such a scheme is the volume of water flowing in the river system under study. Volume is referred to as discharge.

Investigation disclosed that longitudinal discharge data for the Pentwater was never collected and therefore, not available. To make an estimate of the hydro-storage potential of Hart Lake, it became

(*) A listing of hydro impoundments in Michigan is maintained by the Michigan Water Resources Commission, Department of Natural Resources, Lansing, Michigan. Pond averages, not including Lake Superior, range upward to 18,770 acres; heads range from 608 feet to 6 feet. A listing of more detail can also be found in HYDROELECTRIC POWER RESOURCES OF THE UNITED STATES, Developed and Undeveloped, Federal Power Commission, Washington, December 1972 . 
necessary to learn about the discharge characteristics of the South Branch of the Pentwater.

5.5 Hydro Inventory of the South Branch of the Pentwater Watershed, and Storage Capability of Hart Lake Enlarged The hydrogeneration records tell us how much hydroelectric power was produced, see Table 10.

TABLE 10. Four-Year Production at the Hart Hydroelectric Plant (in $1,000 \mathrm{kWh} / \mathrm{mo}$ )

\begin{tabular}{lllll}
\multicolumn{4}{c}{$\begin{array}{l}\text { year } \\
\text { Average }\end{array} \quad 1973 \quad 1972$} & Avera
\end{tabular}

\begin{tabular}{lrrrrr}
\hline Jan & 1 & 100 & 124 & 149 & 120 \\
Feb & 115 & 86 & 101 & 102 & 104 \\
Mar & 185 & 146 & 158 & 165 & 136 \\
Apr & 166 & 135 & 129 & 128 & 88 \\
May & 111 & 101 & 111 & 138 & 94 \\
June & 91 & 53 & 88 & 77 & 133 \\
July & 46 & 42 & 48 & 54 & 52 \\
Aug & 47 & 56 & 59 & 49 & 86 \\
Sept & 39 & 52 & 48 & 43 & 59 \\
Oct & 51 & 86 & 73 & 64 & 94 \\
Nov & 79 & 93 & 90 & 84 & 106 \\
Dec & 137 & 94 & 101 & 85 & 89 \\
& & & & & \\
\hline
\end{tabular}

This information in turn tells us how much water was used for generation. However, no records have been kept on the discharge through the waste gates.

The discharge through the two wheels can be estimated:

$Q=\frac{11.8 \times 2 \times 135}{32 \times .73}=136.4 \mathrm{ft} .3 / \mathrm{sec}$ (at 1.0 governor setting) where 
$Q$ is the discharge in $\mathrm{ft} .3 / \mathrm{sec}$.

\section{8 is a constant}

32 is the head in $\mathrm{ft}$.

.73 is the probable efficiency

(from HYDRAULICS HANDBOOK, D. V. Davis and K. E. Sorenson, Handbook of Applied Hydraulics, McGraw-Hill, New York, 1969, pp. 29-11 and pp. 24-27)

Actual production experience reflects an annual discharge through the wheels of:

$$
1,103,000 \times \frac{136.4}{270} \times 60 \times 60=2.0 \times 10^{9} \mathrm{ft}^{3}
$$

where

$1,103,000$ is the 4 year average annual production in $\mathrm{kWh}$ (see Table 20) 136.4 is $Q$

270 is the wheel rating in $\mathrm{kW}$ as rated by the U.S. Geological Survey Estimated total discharge (method used for estimating is described in the following):

Estimated annual discharge $=116.25 \times 60 \times 60 \times 24 \times 365=$ $3.7 \times 10^{9} \mathrm{ft} .{ }^{3}$

where

116.25 is the estimated $Q$ for the South Branch of the Pentwater.

The above shows that the present hydrogenerating capability at Hart is twice the production. It further shows that water availability on an annual basis is almost twice the production. This is due mainly to lack of hydro storage capacity.

Three tasks were performed and will be described in the following: (1) an estimate of the discharge of the Pentwater South Branch was made, (2) Hart Lake was surveyed to determine by how much the storage capacity could be increased, i.e., how much the level could be raised, before encountering very costly and perhaps insurmountable difficulties, and (3) a cost index and guidelines for use in economic cost estimates covering hydrostorage expansion was established. 
TABLE 11 Estimated Stage Discharge for South Branch of Pentwater River at Hart Hydro (in $\mathrm{ft}^{3} / \mathrm{sec}^{\mathrm{s}}$ using Watershed Area Ratios from above Table A 1.)

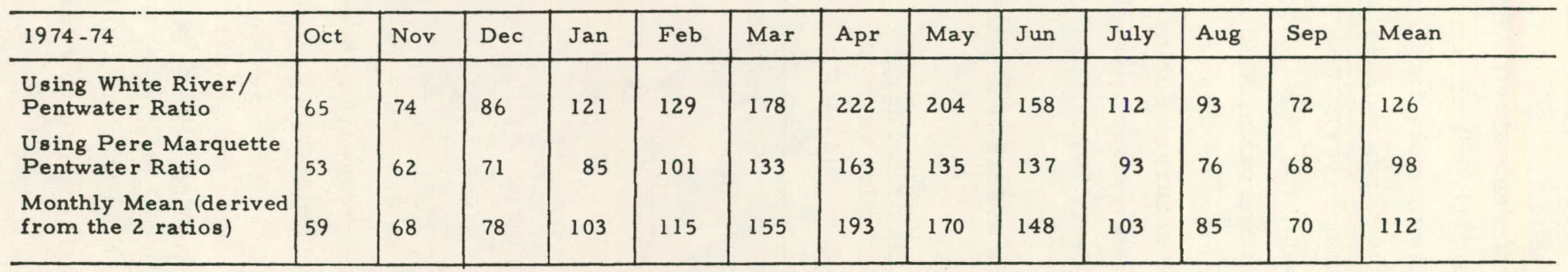

ACCURACY $=$ Better Than $\pm 20 \%$

TABLE 1\% Stage Discharge (in $\mathrm{ft}^{3} / \mathrm{sec}$ ) / Watershed Area (in $\mathrm{mi}^{2}$ ), Comparison between White, Pere Marquette and South Branch Pentwater Rivers.

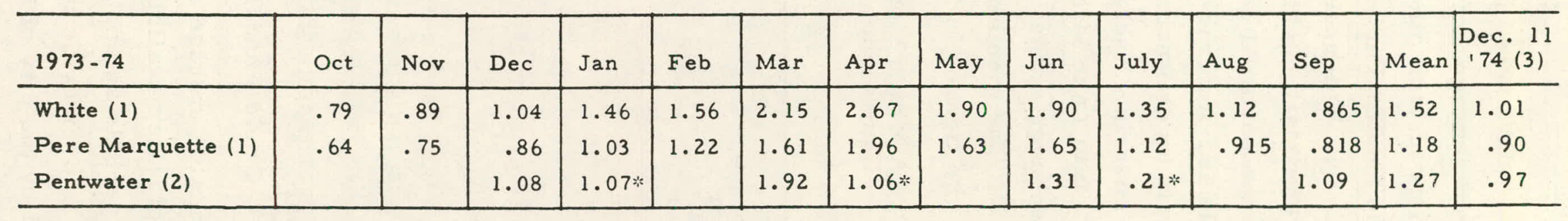

* probably inaccurate due to ice or hydro operation

(1) For location of stage discharge recorders and other pertinent data, see information published by the U.S. Geological Survey

(2) Crest stage indicator located $.8 \mathrm{mi}$ below Hart hydro dam, read by eye about once per month, therefore, infrequently data is not considered reliable. Readings were begun in Dec. 1973.

(3) Inserted to show comparison with Dec. 1973 data. 
5.5.1. Estimate of Discharge, South Branch of Pentwater River Two sources of information - - unfortunately not entirely independent of each other - - were used to obtain the monthly and annual discharge for the Pentwater South Branch (watershed area $=83 \mathrm{mi}^{2}$, see Table 11, Watershed, South Branch of Pentwater River). One source was the correlation with the two adjacent watersheds, the Pere Marquette River to the north $\left(709 \mathrm{mi}^{2}\right)$ and the White River to the south, (380 $\mathrm{mi}^{2}$ ) see Table 12, Watersheds, Lower Peninsula of Michigan. The other source was an estimate made by the U.S. Geological Survey during 1972-73 covering discharge from the entire Pentwater River watershed $\left(177 \mathrm{mi}^{2}\right.$ ) into Lake Michigan, reduced on a ratio basis ( $83 \mathrm{mi}^{2}$ ) to a stage discharge at the Hart Hydro.

The monthly figures so arrived at were averaged which gives us the figures in Table 13 .

Table 13. Average Monthly Stage Discharge and Electric Energy Equivalent at Hart Hydro

\begin{tabular}{lcc}
$\begin{array}{c}1972-72 \\
\text { Month }\end{array}$ & $\begin{array}{c}\text { Average Monthly Discharge } \\
\text { at Hart Hydro }\end{array}$ & $\begin{array}{c}\text { Electric Energy } \\
\text { Equivalent }\end{array}$ \\
\hline October & $82 \mathrm{ft}^{3} / \mathrm{sec}$ & $162 \mathrm{~kW}$ \\
November & 85 & 168 \\
December & 91 & 180 \\
January & 142 & 281 \\
February & 124 & 246 \\
March & 158 & 313 \\
April & 157 & 311 \\
May & 159 & 315 \\
June & 137 & 271 \\
July & 100 & 198 \\
August & 86 & 170 \\
September & 74 & 146 \\
& $116 \mathrm{ft}^{3} / \mathrm{sec}$. & $230 \mathrm{~kW}$
\end{tabular}

Given suitable storage capacity, the above roughly represents the amount of water available for compensating for wind power variation and lull periods as applicable to the city of Hart. Note that the $230 \mathrm{~kW}$ average is over twice the actual average power performance now being achieved by the city of Hart. 


\subsubsection{Survey of Hart Lake Storage Potential}

The dam, the hydro plant, and the entire shoreline of Hart Lake were inspected and surveyed. Arbitrary increases of the Hart Lake level in one $\mathrm{ft}$. increments were considered starting with the above normal level of $622 \mathrm{ft}$. asl. The effect on shoreline land and property was noted and mapped, see Figure 26, MAP OF HART LAKE.

It was found that $628 \mathrm{ft}$. is a threshold to a series of additional problems and costs. For example, the Mill Pond, fed by Russell Creek, is now controlled to about $628 \mathrm{ft}$. asl. Below 628 this part would be unaffected but going higher would involve more shoreline, many more properties. The Mill Pond is the city's swimming hole.

Since wind data was being assembled concurrently with this investigation, and wind deficiency information was not yet available, an assumption had to be made, namely that the available South Branch discharge would preclude a storage scheme larger than a $6 \mathrm{ft}$. increase in lake level would provide. It goes without saying, that this assumption will be carefully checked out.

An up to $6 \mathrm{ft}$. increase was examined in terms of one $\mathrm{ft}$. increments. No matter how much the level is raised, there are some basic and major costs, replacement of the bridge and approaches crossing Hart Lake, for example. Granted, the bridge is old and will have to be replaced anyway. The cost of land flooded as the lake level rises is nominal when compared with the problem of compensating riparian owners for affecting the shoreline and the variation in lake level. Another illustration, environmental and societal issues have to be faced with any increase. Hart Lake is used for sport fishing, therefore, this aspect must be investigated in more detail if economic justification can be established.

The city of Hart for itself owns or controls a substantial part of the Hart Lake shoreline. The private riparian rights situation will have to be investigated in more detail by researching the title records, plat dedications, and tax assessment rolls.

The map of Hart Lake was redrawn to show areas which would flood by an increase in level up to $6 \mathrm{ft}$, (see Fi gure 26, Map of Hart Lake). The incremental increase of lake area was determined as $300,000 \mathrm{ft}^{2}$ 

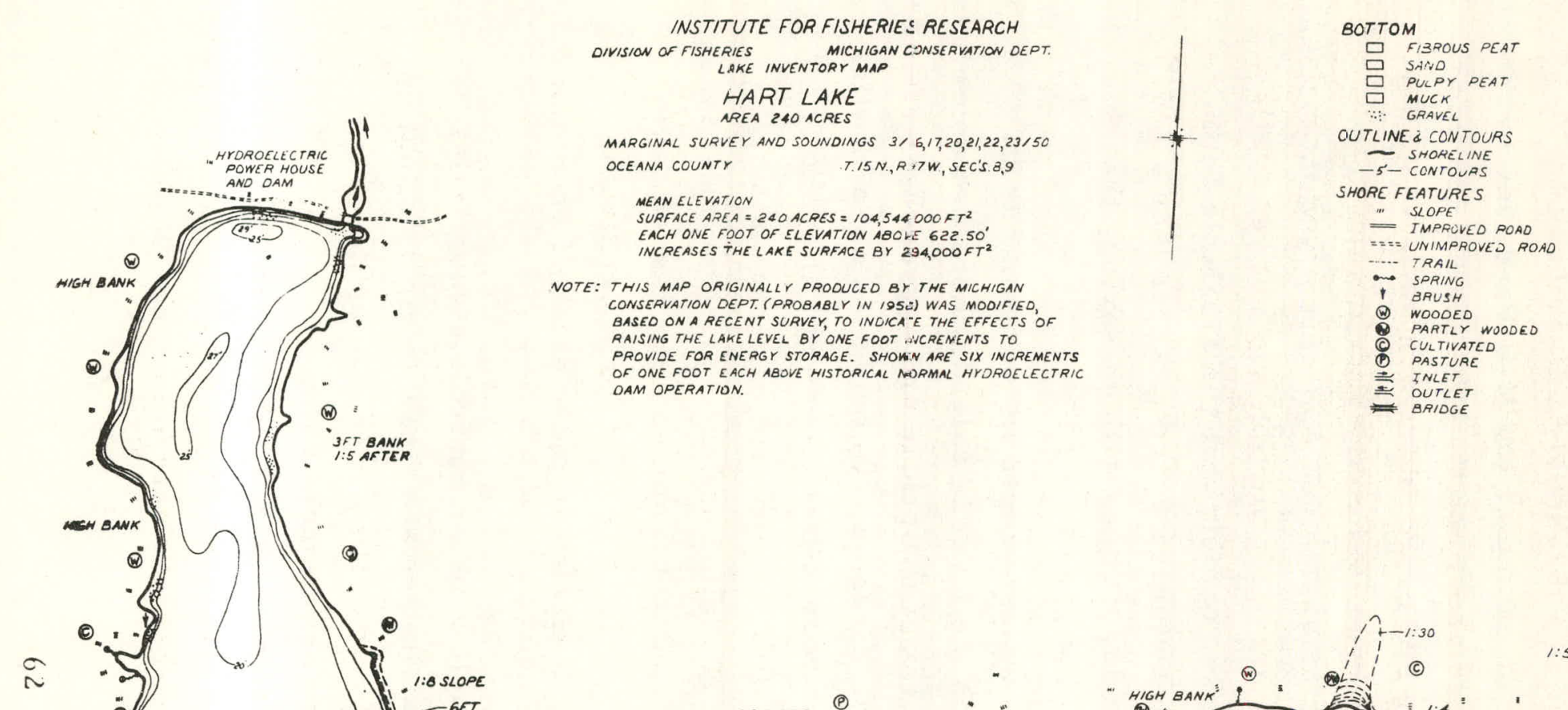

$\approx$

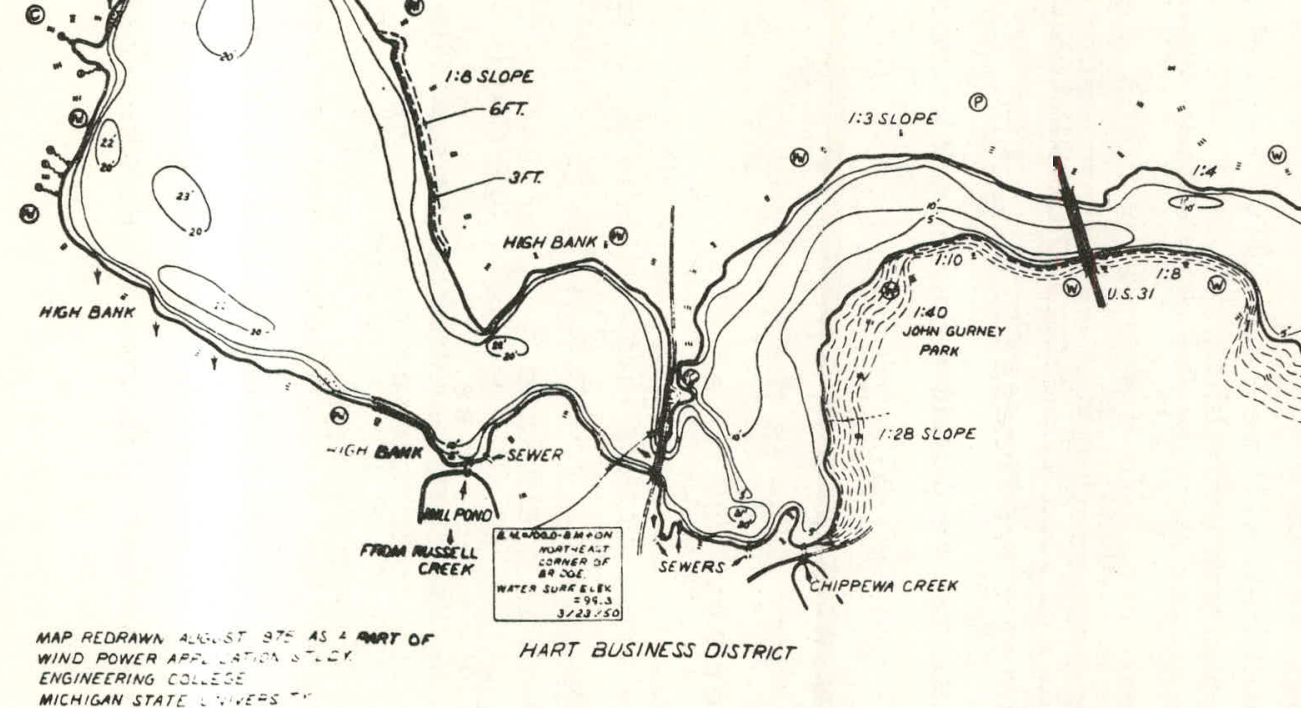

Figure 26. Map of Hart Lake (revised to show flooding if lake level were raised by $l^{\prime}$ increments). 
per $\mathrm{ft}$. of increase in level. In other words, $6 \mathrm{ft}$. of lake level increase would consume about 40 acres of land.

At normal ( $622 \mathrm{ft} \mathrm{asl),} \mathrm{the} \mathrm{lake} \mathrm{surface} \mathrm{is} 10,500,000 \mathrm{ft}^{2}$ or 240 acres (the Water Resources Commission, Michigan Department of Natural Resources as of $11 / 14 / 67$ lists the impoundment area of Hart Lake as 400 acres).

A.t a mean surface of 260 acres and $6 \mathrm{ft}$. of storage depth, storage capacity of Hart Lake is

$$
(10,500,000+900,000) \times 6=68,400,000 \mathrm{ft}^{3}
$$

One $\mathrm{ft}^{3} / \mathrm{sec}$. of discharge at $32 \mathrm{ft}$ head will produce roughly $2 \mathrm{~kW}$. Therefore, the storage capacity contained in $6 \mathrm{ft}$. would be $136,800,000 \mathrm{~kW}$.

$$
\begin{aligned}
& \frac{136,800,000}{3,600}=38,000 \mathrm{kWh} \text { of storage capacity } \\
& \text { or a } 1000 \mathrm{~kW} \text { system could run for } 38 \text { hours, not considering }
\end{aligned}
$$
the inflow.

When considering the inflow, the following water conservation equation would apply:

$$
\begin{aligned}
& -R_{1} t+R_{2} t=h\left(10.5 \times 10^{6}\right) \quad \text { for } 0 \leq h \leq 1 \mathrm{ft} \\
& -R_{1} t+R_{2} t=h\left(10.5 \times 10^{6}\right)+\left(.3 \times 10^{6}\right)(h-1) \text { for } 1 \leq h \leq 6 \mathrm{ft} \\
& h \text { expressed in } \mathrm{ft} .
\end{aligned}
$$

$\mathrm{R}_{1}$ is volume outflow in $\mathrm{ft}^{3} / \mathrm{sec}$.

$\mathrm{R}_{2}$ is volume inflow in $\mathrm{ft}^{3} / \mathrm{sec}$.

This is the equation which will have to be related to a wind power availability equation in order to optimize a system. It must be remembered that the $6 \mathrm{ft}$. lake elevation increase used in the fore going is a rbitrary and subject to change up or down as the wind -hydro system is optimized. Optimization of the system would seek to (1) utilize as nearly as possible all of the water available, and (2) to improve hydro generation efficiency, as operated in conjunction with a wind power system.

5. 5. 3. Economic Cost of Hydro Storage and Generation Facility Economic Cost factors are:

(1) hydro generating machinery 
(2) turbine gallery and building

(3) dam

(4) bridges and roadways

(5) lakeshore

For rough or preliminary estimating purposes, the following cost indexes may be applied:

(1) To increase hydro generation capacity would cost $\$ 100$ to $\$ 150 /$ installed $\mathrm{kW}$ (source: James Leffel and Co.).

(2) The turbine gallery and building part would cost between $\$ 1.50$ to $\$ 3.00 / \mathrm{ft}^{3}$ of building volume (source: Bechtel Corp.).

(3) Work on dam comes in three parts:

(a) concrete work at hydro inlet, gates, etc., estimate is $\$ 20 / \mathrm{yd}^{3}$ of concrete (source: Bechtel Corp.).

(b) earthfill $\$ 1 / y^{3}$, see attached analysis for earthfill requirements at va rious lake levels (source: Engineering News Record).

(c) spillway if necessary (there is no spillway now), $\$ 20 / \mathrm{yd}^{3}$ if concrete work in place (source: (Bechtel Corp.).

(4) Modification of the US-31 highway bridge would require about $\$ 10,000$. The old bridge $32^{\prime} \times 88^{\prime}$ which is about worn out, would take $\$ 85,000$ for bridge replacement plus $\$ 60,000$ for the approaches $=$ $\$ 145,000$ (source: Michigan Department of Highways and Transportation).

(5) The map of Hart Lake was redrawn, see Figure 26, to show flooding of land at various lake levels. Land flooded by the increase in lake level elevation would. cost $\$ 200 / a c r e$. Lake frontage is now appraised at $\$ 70 /$ linear ft (source: Hart City Assessor). Buildings and structures affected are few and less then $\$ 100,000$ would be required to compensate. 
Steep bank property owners may have to be compensated by a nominal amount. This has to be investi gated further when doing economic impact and attitude study.

If desired, an independent appraisal by a qualified consulting engineering firm can be had for about $\$ 2,000$ (contact Gerald $R$. Bacus, Fargo Engineering in Chicago).

Environmental factors have not yet been accounted for. An impact assessment would require a certain amount of survey work among property owners and local citizens. Perhaps this could be combined with the attitude studies concerning wind power utilization (University of Illinois). Hart Lake is now used for sport fishing which is another factor to be considered.

To bring the above into focus, assume a $1,000 \mathrm{~kW}$ hydrostorage and generating installation:

\begin{tabular}{lr} 
Hydro machinery & $\$ 150,000$ \\
Turbine building & 200,000 \\
Dam & 100,000 \\
Roads and Bridges & 175,000 \\
$\begin{array}{l}\text { Land and buildings } \\
\text { compensation }\end{array}$ & 200,000 \\
\hline & $\$ 825,000$
\end{tabular}

As of now, the above is no more than an indication of a cost target. Once the wind data has been brought down to where it can be used for system optimization, a more reliable estimate can be made. The figures presented tend to encourage continuing the investigation and a comparison with alternatives.

5. 5. 4: Significance of the Wind-Power Hydro-Power Combination for Michigan

There are several hundred hydro sites in Michigan. According to the Federal Power Commission, 83 are now operating. Some of the hydro-impoundments have been abandoned, some are now in use for other purposes, and 32 are listed as "undeveloped". The 1967 listing of the Water Resources Commission, Michigan Department of Natural Resources, ${ }^{(*)}$ shows a much larger number. Many of these (*) Unpublished Departmental paper 
sites are in areas of low density distribution of electricity, mostly rural electric and small municipal electric systems. Moreover, many are located in or adjacent to regions with annual wind speed averages of $14 \mathrm{mi} / \mathrm{hr}$ or even higher, regions where the seasonal demand for lighting, space-heating and water-heating tends to match seasonal wind patterns. This will be substantial as a part of the present study. The Federal Power Commission, for Michigan alone, lists $387 \mathrm{MW}$ "developed" and $279 \mathrm{MW}$ as "undeveloped" hydro sites. Almost all of the hydros in the Great Lakes region were built during the early decades of this century, or even before, and as mentioned in the foregoing, were built in "water-wheel" fashion, i.e., flow-through, no appreciable storage. Because of this, one can suspect that the water in the respective watersheds is materially underutilized, for the generation of electricity as is indicated in the Hart case.

Energy conversion by these hydro plants, because they are old, is probably less efficient than it could be. If the facilities were to be enlarged when converting to energy storage systems, as that they can be used in combination with wind-power systems, an efficiency gain of perhaps ten percentage points could be expected. At the same time, water utilization could be increased, perhaps by more than $50 \%$ as appears to be the case for the Hart hydro.

Assuming a 50-50 match of wind-power and hydro-power, one can visualize more than $1.000 \mathrm{MW}$ derived from such a combination in Michigan. This could be all baseload generation, obviously requiring no fuel. The energy would be consumed near where it is produced, thereby reducing transmission losses and in some cases transmission facilities costs.

The hydro possibilities in Michigan have been neglected for many years. The relatively low cost of fossil fuels made it so. During the 1920's, 14 river systems in Michigan were studied for their hydro potential. ${ }^{(*)}$ This type of work was abandoned for the same reason.

(*) Hydroelectric Power Resources of the United States, Developed and Undeveloped, Federal Power Commission, Washington, December 1972.

(**) Unpublished studies by Wisler et al, University of Michigan, for the Michigan Conservation Department. Copies are in the State Library. 
Some of these studies could possibly form a basis for a broader examination of the potential.

The Hart study outcome with respect to hydro storage alone should not be construed as being applicable to other systems without similar tests covering a few. other representative locations. Hart is one of the small systems. Each and every system is different, as is the local availability of wind power. Therefore, broadened study, beyond what is indicated for Hart, is called for before solid conclusions can be drawn.

The Hart hydro situation will be reported on as definitively as is possible. It is expected that the information so provided will permit a judgment with respect to further study of the potential for wind-power/ hydro-power systems in the Great Lakes region, to determine whether it is one viable alternative.

\section{RESULTS OF PRELIMINARY ECONOMIC ANALYSIS 6.1. Introduction}

This section concerns itself with the preliminary economics of using WECS to supply energy to the Hart electric system. Developed here is a crude estimate, not necessarily a viable proposal to the city of Hart. It is merely an indication of whether wind power is a cost effective option for Hart or similar situations. This estimate, when refined by the end of the first year grant-period, is expected to be an assessment to determine whether going into a year II effort is worthwhile in terms of providing definitive information, information which would be used by the city of Hart and others to make decisions concerning their future energy supply with a reasonable degree of confidence.

The economics of using WECS as a fuel saver is presented below. These results are specialized to the boundary conditions, i.e., interest rates, wind energy, fuel prices, etc., in this case applied to the city of Hart and its electric system. A rough estimate of the cost of a baseload wind-hydro system is also presented. Additionally, other energy alternatives known to be available for the city of Hart are also reviewed. 


\subsection{Fuel Saver Economics}

A general equation, which includes all the economic variables such as initial capital investment, interest rate, amortization period, etc. was derived using basic mathematics of finance. ${ }^{7}$ This equation is given as:

$$
\begin{aligned}
& S=\left(1+r_{1}\right)^{n} a A+\frac{\left(1+r_{1}\right)^{n}-1}{r_{1}} \beta\left(1+r_{2}\right)^{n} P 8760 A \\
& -\frac{\left(1+r_{1}\right)^{n}-1}{r_{1}} \cdot\left(1+r_{3}\right)^{n} \text { y P 8760A }
\end{aligned}
$$

where the following are defined

$a=$ total capital cost of WECS expressed in $\$ / \mathrm{m}^{2}$ (per $\mathrm{m}^{2}$ of swept area $\mathrm{A}$ )

$n$ = amortization period

$r_{1}=$ interest rate on the initial capital investment

$A=$ swept area of the wind turbine in $\mathrm{m}^{2}$

$\beta=$ operating and maintenance costs expressed in $\$ / k$ Wh at time $n=0$

$\mathbf{r}_{2}=$ percent increase per year of the operating and maintenance costs.

$\mathrm{P}=$ average wind power $/ \mathrm{m}^{2}$ produced by a specific wind turbine given a region's wind characteristics

$y=$ fuel costs in $\$ / \mathrm{kWh}$ at time $\mathrm{n}=0$.

$\mathbf{r}_{3}=$ percent increase per year of the fuel cost in $\$ / \mathrm{kWh}$

$S=$ balance left of the initial capital investment after $n$ years

The left hand side of equation (1), the balance $S$ of the initial capital investment after $\mathrm{n}$ periods, is equal to three separate terms. The first term represents the initial capital investment compounded at an interest rate $r_{1}$ for $n$ periods. The second term represents the operation and maintenance costs added to the initial capital investment each period and the last term represents the amount of money returned each period for the energy generated during that period. $P$, the average wind power $/ \mathrm{m}^{2}$, is a function of the region's wind characteristics and of the specific wind turbine. That is, it is proportional to the area under the region's wind power duration curves which is 
defined by specifying the wind turbines cut-in, rated, and cut-off wind speeds.

Equation (1) is a general equation which can be solved several different ways. For example, given wind power densities, fuel costś, amortization period, interest rate, etc. the maximum allowable capital investment per wind turbine swept square meter, can be deter mined. Sensitivities of the economics to base fuel cost, to percent increases in fuel costs, etc., can also be calculated.

The example of wind turbines as a fuel saver for the city of Hart is worked out below. In this example, $P$ was determined for the G.E. and Kaman wind turbines using Muskegon, Ludington, or 1975 MSU measured wind characteristics. The other variables were determined by using the best information available from the city of Hart and REA co-ops in Michigan. Specifically, these assumptions are:

1. A $7 \%$ interest rate, $r_{1}$. This is the interest rate that the city of Hart pays on its municipal bonds. REA interest rates generally vary between 7 and $8 \%$.

2. The amortization period $n=30$ years

3. The operating and maintenance cost, $\beta$, were assumed to be $\$ .0066 / \mathrm{kWh}$

4. For this first case, $r_{2}=r_{3}=0$

5. P 8760A was taken from the energy valculations for the different machines. (See Tables 6, 7, and 8)

Using these assumptions and the machine characteristics of the four different NASA machines, equation (1) was solves for $y$, the energy cost required to amortize the initial capital investment in 30 years. The results of these calculations are shown in Table 13. It was assumed that the energy produced by the wind turbines has a value independent of the time of day, month or year it is consumed. This is a simplification since for most applications, energy prices for fuelsaver wind turbines must be priced with electrical demand and other methods for generation of power. In later reports, more sophisticated economic models will account for user demand, competitive peaking power, etc. 
The economics of the fuel saver mode become more attractive, if the assumption is made that costs of fossil fuels and operating and maintenance increase each year. That is, if in addition to the above assumptions 1, 2, 3 and 5, the following assumption is also made:

1. Private and government speculative studies of energy costs for Michigan have projected increases in fossil fuel costs from 7 to $9 \%$ per year for the next 10 years. Thus, a rate corrected for inflation $r_{3}=3 \%$ over the amortization period was assumed.

Equation (1) was resolved by incorporating this additional assumption and solving for $y$, the allowable fossil fuel cost at $n=0$ required to amortize the initial capital investment in 30 years. Computer calculations are shown in Figure 27 where the base $(n=0)$ fossil fuel costs y vs. average power censity are plotted for a number of assumed capital investment costs $a$. These curves can be used to determine the fossil fuel costs for a given wind turbine if the average power density $P$ available to the wind turbine and the capital investment is known. For example using Muskegon 1972 wind data, the P for the G. E. $500 \mathrm{~kW}$ is $.106 \mathrm{~kW} / \mathrm{m}^{2}$ while the $P$ for the $1,500 \mathrm{~kW}$ machine is .118 $\mathrm{kW} / \mathrm{m}^{2}$ respectively. The intersection between these capital costs and the respective power densities are shown in Figure 27 along with the resulting fossil fuel costs. These fossil fuel costs are $\$ .0145 / \mathrm{kWh}$ for the $500 \mathrm{~kW}$ wind turbine and $\$ .015 / \mathrm{kWh}$ for the $1.5 \mathrm{MW}$ wind turbine. Thus, wind turbines located on the lakeshore will be economic if they are used to replace energy from diesel oil or coal fired generating plants where the fuel costs are in excess of $1.5 \notin / \mathrm{kWh}$.

The present energy cost of operating the diesel plant when burning oil are $2.65 \notin / \mathrm{kWh}$ for fuel and $1 \not k / \mathrm{kWh}$ for operating and maintenance costs. Thus, even though the economics shown in Table 14 are tentative and approximate, they demonstrate that wind turbines located on the lakeshore could be employed economically as fuel savers by operating in parallel with the present diesel system. 


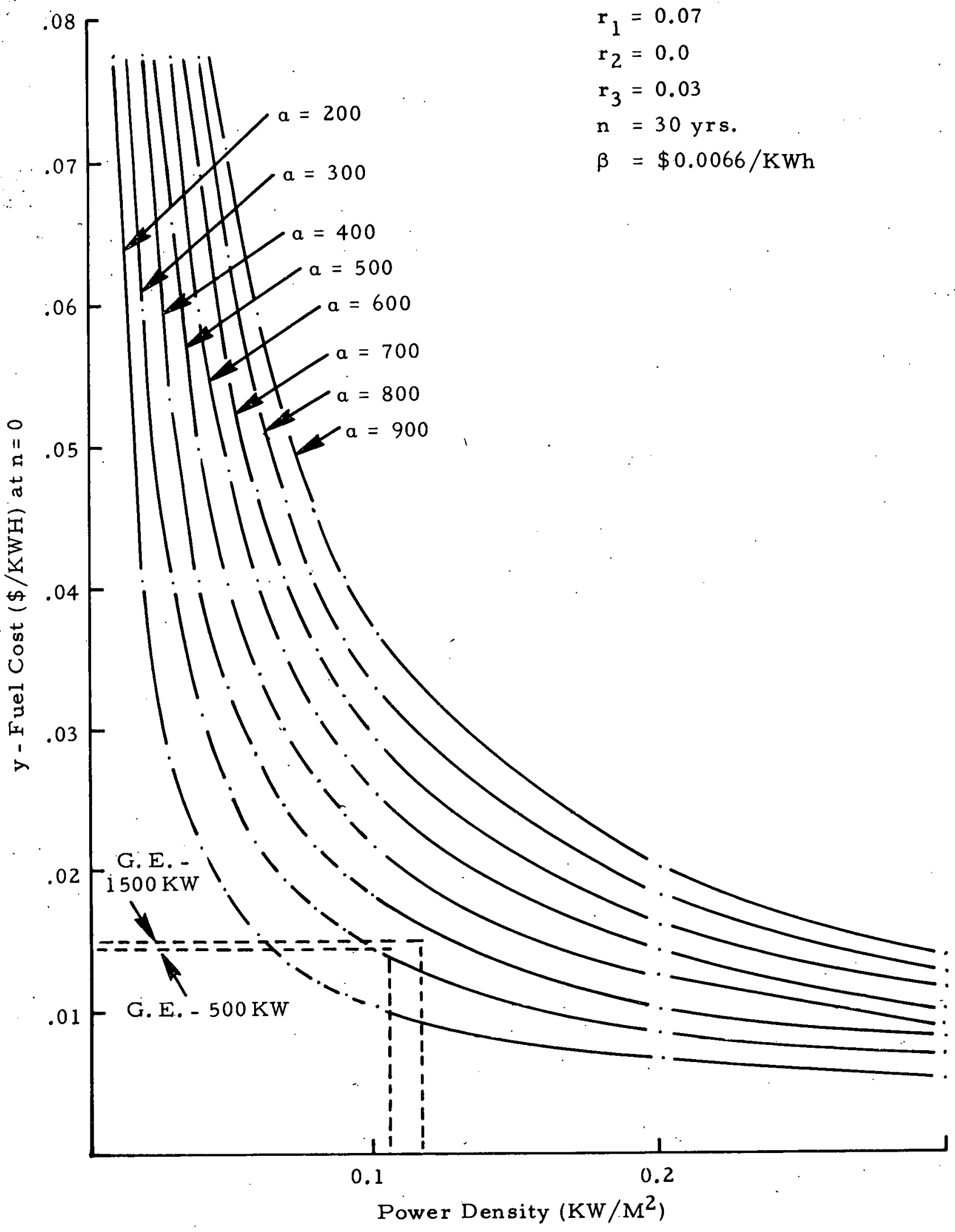

Figure 27. Fuel cost vs. average power density for different capital investment. 


\section{TABLE 14}

$\Varangle . / \mathrm{kWh}$ for the G.E. and Kaman Wind Turbines Operated as Fuel Savers

$$
\mathbf{r}_{\mathrm{i}}=.07 \quad-\mathrm{n}=30 \text { years } \quad-\mathbf{r}_{2}=\mathbf{r}_{3}=0 \quad-\beta=\$ .0066 / \mathrm{kWh}
$$

\begin{tabular}{|c|c|c|c|}
\hline Machine & $\begin{array}{l}\text { Initial Capital } \\
\text { Investment* } \\
\text { a A } \\
\end{array}$ & $\begin{array}{l}\text { Wind Region } \\
1972 \\
\text { Muskegon-Ludington } \\
\text { Shore Line } \\
\end{array}$ & $\begin{array}{l}\text { Wind Region } \\
\text { City of Hart } \\
(1975)\end{array}$ \\
\hline G. E. $500 \mathrm{~kW}$ & $\$ 523,000$ & $2.7 \not / \mathrm{kWh}$ & $4.9 \notin / \mathrm{kWh}$ \\
\hline Kaman $500 \mathrm{~kW}$ & $\$ 536,000$ & $3.9 \not / \mathrm{kWh}$ & $8.5 k / \mathrm{kWh}$ \\
\hline G.E. $1.5 \mathrm{MW}$ & $\$ 709,500$ & 2. $35 \notin / \mathrm{kWh}$ & $5.6 \notin / \mathrm{kWh}$ \\
\hline Kaman $1.5 \mathrm{MW}$ & $\$ 786,000$ & 3. $1 \notin / \mathrm{kWh}$ & $9.7 \mathrm{k} / \mathrm{kWh}$ \\
\hline
\end{tabular}

*Includes $\$ 36,000$ for site costs. 
Other general conclusions a re:

(1) the economics strongly favor lakeshore locations over the city of Hart locations.

(2) The cost $(\$ / \mathrm{kWh})$ differences between the $500 \mathrm{~kW}$ and the 1. $5 \mathrm{MW}$ machines are not substantial. Thus, when considering that the $500 \mathrm{~kW}$ machine has the technical advantage of producing more uniform power over the year, i.e., it has less down time, than a $1.5 \mathrm{MW}$ machine, it appears that a system of $500 \mathrm{~kW}$ machines may be the most useful solution for wind turbines in the G. L. region.

6.3. The Economics of a Base-load Wind Turbine-Hydro System

A crude estimate of the costs of using wind turbines in conjunction with the city of Hart hydro facility to generate baseload electric energy is presented here. An energy delivery system supplying a base load demand of $600 \mathrm{~kW}$ is assumed. This system consists of two $500 \mathrm{~kW}$ G.E. wind turbines located on the shore of Lake Michigan, about 8 miles west of Hart Lake. Each wind turbine will provide an average power per $\mathrm{hr}$ of 235 to $250 \mathrm{~kW}$ over an entire year.

Table 1.5 summarizes some further assumptions and the economics of the system. If the wind turbines cost $\$ 1,000 / \mathrm{kW}$ installed and the hydro facility $\$ 800 / \mathrm{kW}$ installed, then electric energy can be generated at a cost of $3.2 \phi / \mathrm{kWh}$. This is not an optimum design. However, it demonstrates that the wind and hydro combination shows economic promise for base-load or load-following operations. It is emphasized that more detailed study is required to provide more exact design. For example, it is expected that the baseload capacity will vary from season to season since the availability of wind and water varies with the seasons. Further study of the wind-hydro applications will be proposed as part of a year II research effort.

\subsection{Benchmark Economics}

Two cost-benefit projections will be prepared with the support of this project. The first one, reported on in this section, is near ly complete and uses estimated $\mathrm{kWh}$ costs of total demand including wind-generated energy using average monthly wind-velocity projections based upon our wind measurements. The second projection described 
TABLE 15

\section{Baseload Wind Hyd ro Generation Economics}

Two $500 \mathrm{~kW} \mathrm{G.E.} \mathrm{Machines} \mathrm{at} \$ 1,000 / \mathrm{kW}=$ $\$ 1,000,000$ $600 \mathrm{~kW}$ hydro facility at $\$ 800 / \mathrm{kW}$

$\frac{480,000}{\$ 1,480,000}$

Total initial capital investment

Other assumptions

interest rate $8 \%$

amortization period -wind - 25 years

hydro -30 years

Operating rate of combined wind -hydro system $=95 \%$ or $4,993,200 \mathrm{kWh} / \mathrm{yr}$

Money Costs per year

wind

$$
\frac{.08(1.08)^{25}}{(1.08)^{25}-1}\left(\$ 10^{6}\right)=
$$

Hyd ro

$$
\frac{.08(1.08)^{30}}{(1.08)^{30}-1} \$ 480,000=
$$

$\$ 136,338$

Money Cost $\mathrm{kWh}$

$$
\frac{\$ 136,338}{4,993,200}=\$ .027 / \mathrm{kWh}
$$

Operating and maintenance $\$ .005 / \mathrm{kWh}$

Total electric energy cost $\$ .032 / \mathrm{kWh}$ 
in Section 9 will be programmed next year and is based upon hourly wind velocity and demand, and thus; recognizes the random character of wind and demand variations. The goal of both projections is to prepare estimated operating statements for the Hart utility using wind generation at feasible sites. In order to evaluate these estimates, it is necessary to compare them with a projection where wind is not used. This reference of "benchmark" projection must account for expected load growth, estimated increases in the cost of oil, gas, and purchased energy, and for generation additions to the Hart system calised by expected load growth.

The MSU research team began with a 5 -year monthly projection; using 1974 and 1975 operating data as a base, with the output to be a sequence of predicted energy costs for the Hart utility. The daily operating logs, fuel invoices, and monthly operating statements of Hart were used to find the $\mathrm{kWh}$ produced by each diesel, the hydro facility, and to account for energy purchased from Wolverine. Wolverine was consulted to give expected purchase costs and dispatch strategy. The direct costs for each energy source are listed so that a production cost per $\mathrm{kWh}$ can be calculated.

Using such historical data as a base, the load is increased on a monthly basis equivalent to a yearly $7 \%$ growth, as is the fuel cost and the cost of purchased power. The cost of oil is assumed to increase $8 \%$ per year and natural gas $25 \%$ per year while Wolverine direct or energy charges are increased $19 \%$ per year. When the load minus existing capacity exceeds the average margin (spinning reserve factor) an extra generator is added. A $4 \mathrm{MW}$ generator was added in April 1975 and is assumed to be a diesel operating with the same efficiency as the existing large diesel and with the same annual fuel mix which is $20 \%$ oil and $80 \%$ natural gas. Part of this table of calculations is shown in Table 16 indicating predicted demand and energy costs for three months per year for five years. This table was abstracted from a large table including each month from 1974 to 1980 and operating data for each energy source. It is too large to put into this report. The assumptions used to generate the data shown are as follows: 
TABLE 16

SELECTED RESULTS OF BENCHMARK OPERATING COST PROJECTION - - ENERGY ONLY

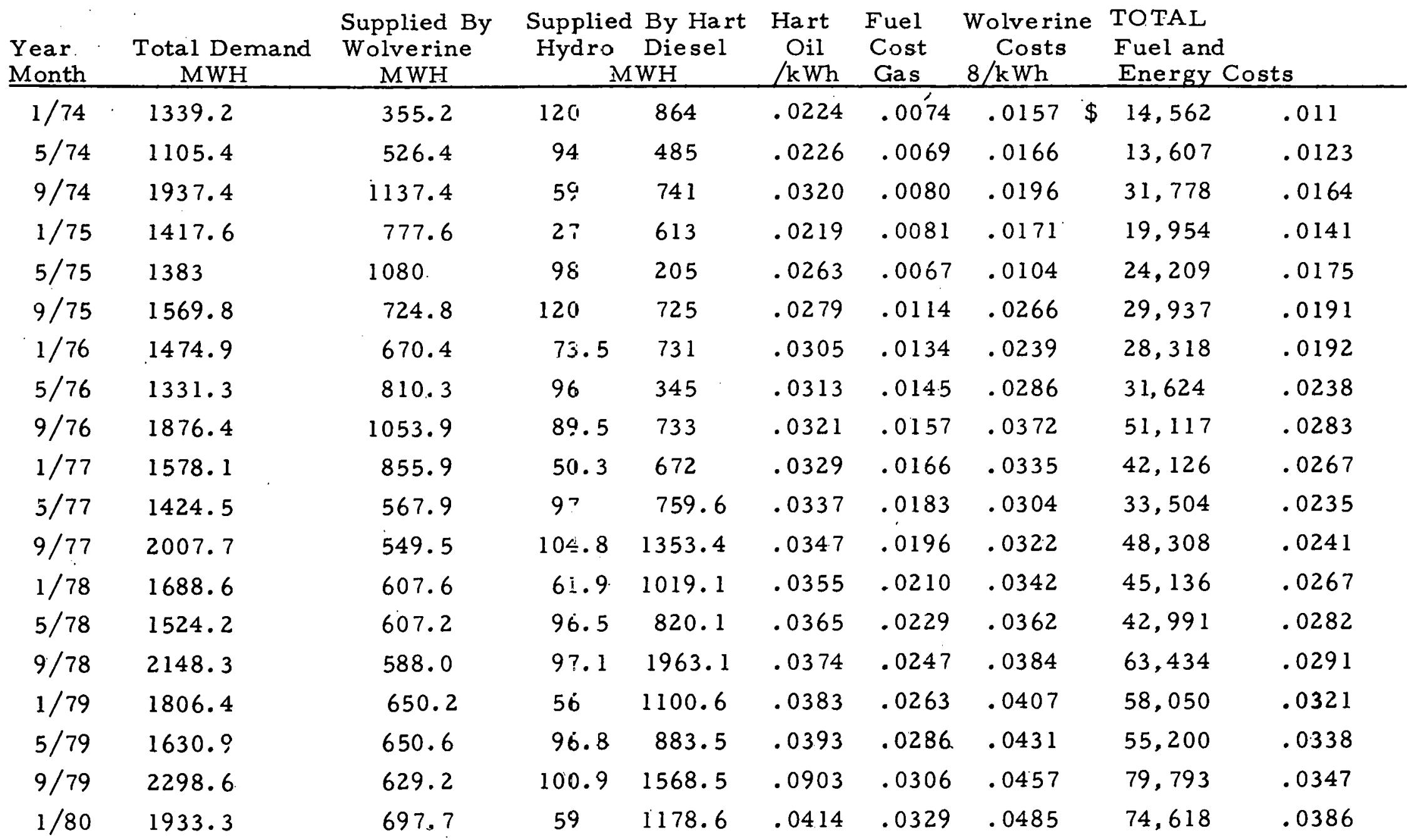


1) Load diversity is preserved by increasing total demand in, say January 1977, by multiplying January 1976 demand by 1.07. Some first-order smoothing of demand data was done from 1974 - 1976.

2) Hydro energy periodicity maintained by smoothed predic tion without growth.

3) Diesel-generated energy provided by a $20 \%$ oil and $80 \%$ gas mixture to reflect current and expected operating practice.

4) Wolverine costs, after new generator added in April 1977, adjusted to remove demand charges because Hart can then provide daytime spinning reserve for Wolverine.

5) The addition of the new generator will not change the Hart policy of using Wolverine to provide energy from $11 \mathrm{p} . \mathrm{m}$. to $7 \mathrm{a} . \mathrm{m}$. After A pril 1977, the added generator (which Hart is already considering) will provide all of Hart's daytime and evening demand.

6) No labor, overhead, lubricating oil, repair, or capital costs are included so the hydro energy is costless for this projection.

Inspection of Table 15 indicates that Hart's September energy peak is predicted to increase to 2, $298 \mathrm{MWh}$ in September 1979 from an actual 1,570 in September 1975. The energy costs (fuel costs) per KWh are predicted to increase from $1.91 \notin / \mathrm{KWh}$ in September 1975 to $3.86 \not /$ $\mathrm{KWh}$ in January 1980. This may indicate a positive potential for wind power in a fuel-saving mode.

In addition to serving as a reference for this study, the projection will also be of use to Hart and Wolverine in their future planning. Since the help given by the involved utilities has been substantial, we wish to provide information which will aid them also.

\subsection{Energy Alternatives for the City of Hart}

Whether a WECS will be adopted by a small rural or municipal power system is dependent on the economics of alternatives. The construction of large oil, coal fired or nuclear plants is not a possibility for Hart or Wolverine REA by themselves. They can cooperate with 
either a group of small companies like themselves or cooperate with a larger power company to gain access to bulk supply.

An option that has been recently made available to small power companies in Michigan by the Consumers Power Company is to offer for each company to buy a share in large power plants now under construction. Table 17 summarizes the various costs involved for the City of Hart if they were to choose this option. Research continuing with year II will compare these and other energy alternatives open to the City of Hart with the costs of "fuel saver" and baseload WECS.

\section{THE ENVIRONMENTAL IMPACT OF WIND TURBINES AND THEIR OPERATION IN THE HART, OCEANA COUNTY, MICHIGAN, AREA}

\section{1. Introduction}

The economic objective in selecting sites for wind turbines is to optimize energy output over time consistent with economic and environmental considerations. However, such optimum locations and configurations may be in conflict with human and ethical values such that the impact may preclude certain ventures, or that arrangements to mitigate the impact to a point of acceptability may be required.

Therefore, in planning wind turbine installations, an impact analysis is called for. Such an analysis may actually be required under the Environmental Protection Act or similar state legislation. If not otherwise provided, a full technology assessment of wind power operation could be required.

It is not practical for purposes of the present study to go into that much analysis and evaluation. In its place there is presented an overview of potential impact considerations, as they affect the study area, namely the Hart, Michigan, area including parts of Oceana County. This overview would probably hold true for most of the high winds areas along Lake Michigan.

Five provisional wind turbine sites in different environmental settings. were chosen for a comparative analysis and to indicate possible impact problems. These are some of the sites which were instrumented to gather wind data for the project. The location of these sites is shown in Figure 28. 


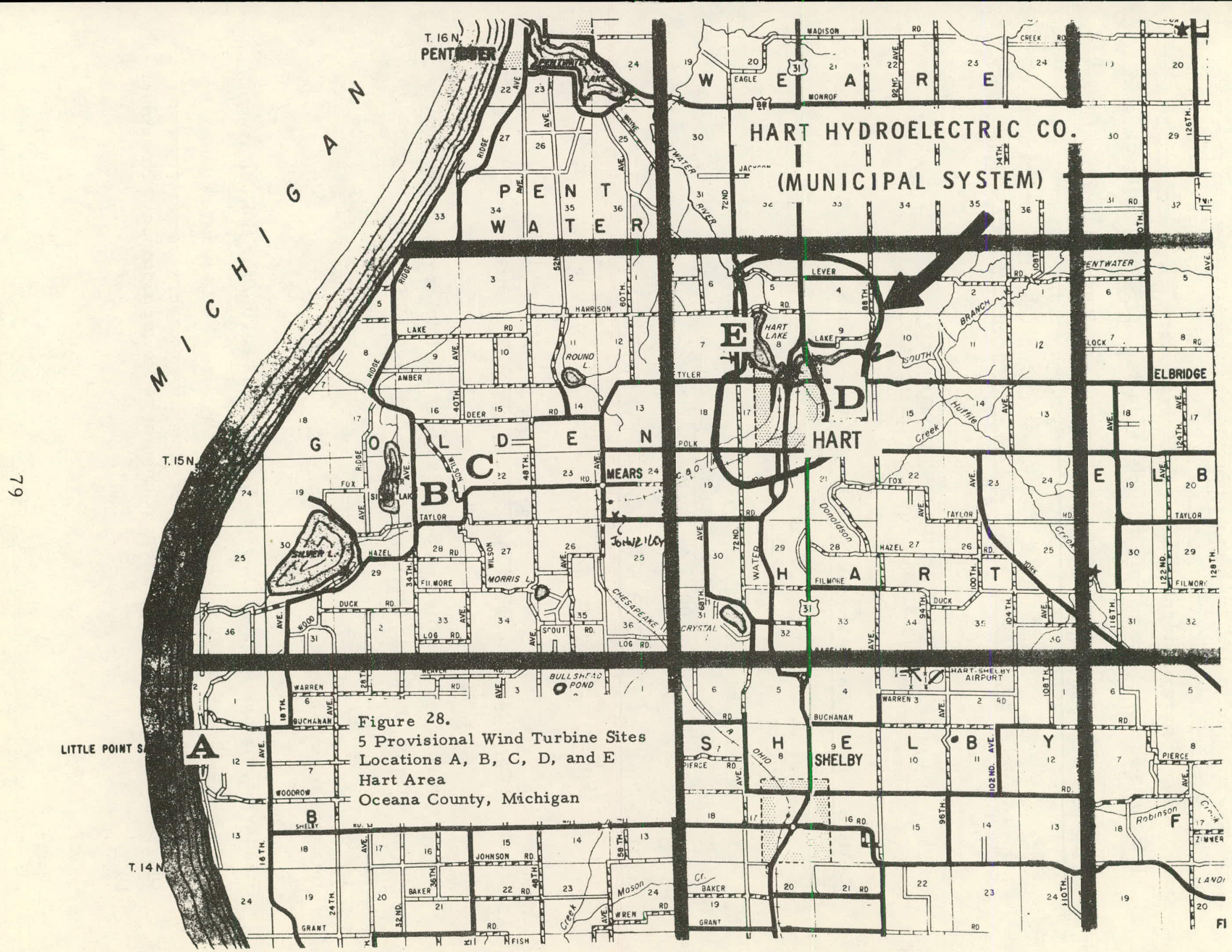




\section{TABLE 17}

Energy Alternatives for the City of Hart

All figures are adjusted to reflect 1980 estimates, 1982 for Midland.

KARN \#4 $663 \mathrm{MW}$ (oil) $\$ 188 / \mathrm{kw}$

Fuel $\frac{\$ 3.23 \text { (per M Btu) X 11,000 (heat rate in Btu) }}{1,000,000}=\$ .035 / \mathrm{kWh}$

$0+M \frac{\$ 1,191,016 \text { (estimated annual cost) }}{663,000 \times 24 \times 565 \times .7 \text { (plant factor) }}=\$ .0002 / \mathrm{kWh}$

\section{CAMPBELL \#3 $800 \mathrm{MW}$ (coal) $\$ 459 / \mathrm{kW}$}

$$
\begin{array}{ll}
\text { Fuel } & \frac{\$ 2.03 \times 9,200}{1,000,000}=\$ .019 / \mathrm{kWh} \\
0+\mathrm{M} & \frac{\$ 8,000,000}{800,000 \times 24 \times 365 \times .7}=\$ .0016 / \mathrm{kWh}
\end{array}
$$

MIDLAND \#1 and $2 \quad 1,271 \mathrm{MW}$ (nuclear) $\$ 673 / \mathrm{kw}$

Fuel \$.0066

$\begin{aligned} & 0+\mathrm{M}+ \\ & \text { Insurance }\end{aligned} \frac{\$ 12,000,000}{1,271,000 \times 24 \times 365 \times .7}=\$ .0015 / \mathrm{kWh}$

Add to the above Transmission Service based on $100 \%$ capacity factor:

Demand charge (varies with capacity factor) $\$ .0015 / \mathrm{kWh}$

$$
\$ .0018 / \mathrm{KWh}
$$

plus transmission losses estimated at $4 \%$.

Standby provisions (at cost) have to be made to provide for the contingency of the plant shared going down for any cause.

Source for the above information: Consumers Power Company, November 1975. 
7. 2. Five Provisional Wind Turbine Sites: A, B, C, D and E, Hart Area, Oceana County, Michigan

\subsection{Site A. Little Point Sable.}

This site is located in a low-profile sand dune area near the beach of Lake Michigan (elevation 578' asl). It is just south of the approximately $100^{\prime}$ high Little Point Sable lighthouse. The latter is not now operative, but is still under the control of the U. S. Coast Guard. The surrounding land is owned by the federal government, but is under the jurisdiction of the Michigan Department of Natural Resources. Silver Lake State Park is just to the north and east. There are some summer cottage settlements in the area located on private land, settlement density is relatively low. The dunes along Lake Michigan are considered environmentally sensitive, especially the large dunes between Silver Lake and Lake Michigan. Electric service to the area is single-phase, see Section 5, and would have to be changed to three-phase in order to connect to a large wind turbine. If too objectionable, the lines could be run underground.

7.2.2. Site B. Taylor Road and 34 th Street.

This site is in rural, but only partly farmed, surroundings. Elevation is $640^{\prime}$ asl. It is adjacent to a $69 \mathrm{kv}$ substation, terminus of a high-line from the Wolverine Cooperative and a distribution point for the Oceana Electric Cooperative. The site is attractive because of the proximity of the substation. There are only a few low-grade rural residences nearby. Land of the site itself has not been used for several years. Its ownership is in private hands.

7.2.3. Site C. Silver Hills Farms.

Setting is in a substantial commercial tree-fruit and asparagusgrowing enterprise. Elevation is approximately $800^{\prime}$ asl. This farm is professionally managed, has a number of large farm buildings in excellent condition. There are only a few scattered farm-type residences in the vicinity. This location is suitable for multiple land use, i.e., wind turbines and agricultural uses of the land. In practice, fruit trees are kept low for mechanical harvesting and spraying, and therefore should not materially interfere with wind turbine application. This is subject to verification. The owner would want assurance that the wind turbines would not interfere with crop production, which also would have to be verified. It could be the other way around. Manager is very cooperative and favorable toward 
wind power.

7.2. 4. Site D. Atop Hart Hill Just Off Tyler Road.

This site is at a relatively high elevation (740' asl) located in what may be called the commerical-rural fringe of the City of Hart. Wind turbines installed in this area would be prominent in that they could be seen from afar. Residential settlement is sparse enough to present no problem. Unlike the previously described sites, this site is within the Hart electric service area and adjacent to Hart three-phase distribution. Multiple land use potential is also applicable to this site. Owner is very cooperative and also favorable toward wind power.

7.2.5. Site E. 72nd Street North of Tyler Road.

This site is in a suburban-commerical-agricultural setting within the Hart electric service area. Elevation is about $680^{\prime}$ asl (Hart Lake is $622^{\prime}$ asl). This site is just west of Hart Lake.

\subsubsection{General Comments}

All of the owners of the sites described above indicated willingness to permit installation of one wind turbine. Everyone was very cooperative when asked for permission to install a wind data measuring tower. In other words, no negative attitude toward wind power could be detected. What would happen in the event where larger numbers of wind turbiries were to be erected, is a question one would have to research with perhaps different approaches. There appears to be little question that environmental impact effects would not be serious enough to prevent serving Hart and/or Oceana Electric Cooperative with wind power. This statement is tentative and subject to further analysis of the problem.

7.3. The Impact Rating of the Five Sites

The following Table 18, Impact Rating of Five Sites, is a rough appraisal of the situation as found in our investigation to date. Individual wind turbine sites were assumed to be approximately 10 acres in size. 
TABLE 18

Impact Rating of Five Sites

SITE

Nature of Impact

Air

Water

Soil and Land Use

Fish and Wildife

Vegetation

Noise

Safety

Vibration

Transmission

Visual

Aesthetics

Terrestrial

$E-M$ Wave Inter -

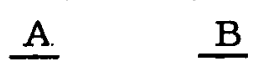

B

$\underline{\mathrm{C}}$

$\underline{\mathrm{D}}$

$\underline{\mathbf{E}}$

$\begin{array}{ccccc}N & N & N & N & N \\ N \text { to } L & N & N & N & N\end{array}$

L to $M \quad L$

L

L

L

N

N

$\mathrm{N}$

N

$N *$ *

N

L

$L$ to $M$

$\mathrm{L}$ to $\mathrm{M}$

$\mathrm{N}$

$\mathrm{N}$

$\mathrm{N}$

N

Vandelism Risks - technically belongs under public safety *Barring Major Disaster

$\mathrm{H}=$ Substantial impact, may raise objections

$\mathrm{M}=$ Nominal impact, probably can mitigate

$L=$ Negligible impact

$\mathrm{N}=$ No impact 
A discussion of these rankings follows:

Air

The construction and operation of large wind turbines will have no effect on air quality nor will it contribute to materially altering the existing macroscale wind patterns; for example, the wind drainage which is relevant to fruit orchards and other agricultural activities of Oceana County. Wake effects would have to be studied in detail.

Water

Soil and Land Use

Wildlife

Vegetation
An adverse impact to aquatic systems would not be created, if adequate measures were employed to prevent soil erosion in the right of way and along the access road, particularly during the construction phase.

Construction procedures should be maintained for the protection of the natural environment, in particular with respect to problems of soil erosion, i.e., ground surface should be left as natural as is practical. Damaged ground cover will have to be replaced.

There are no serious problems which can be foreseen as a result of construction on farm land. Once construction has boon completed, the surrounding area may easily recover assuming reasonable care. In fact, both economically and ecologically, multiple land use might be encouraged. Any disturbance to wildlife would be short lived, i.e., through the construction period. Due to the relatively low speed of the blades ( $40 \mathrm{mph}$ ), no serious threat to bird-life in the vicinity is assumed. This assumption will need to be subjected to empirical verification. After discussions with the State of Michigan Department of Natural Resources personnel, it was felt that bird kill due to wind turbines would be no greater than the bird kill on high voltage trans mission towers. However, an unknown variable is the effect of the rotating blade on the birds. The Michigan DNR official felt that the moving blade would chase the birds off. Whenever man changes the landscape, he modifies the microclimate by creating minor changes in the wind, 
Noi se

E-M Wave Interference (high-fre quency radio communications)

Safety

Trans mission temperature, humidity and soil moisture. Other manifestation are changes in earth surface roughness, changed reflectivity and altered heat and water storage capacity resulting from changes of trees, brushland, etc. Yet, whereas some of these changes are likely to occur during and after construction, they are not likely to be a serious enough problem warranting consideration.

The wind going through area of the windmill under load is expected to make no more noise than the wind going through a grove of trees, or through a high-tension power line.

The only interference results predominantly from the windmill tower and rotating blade in the immediate area of the windmill. The extent of this interference should be the subject of a more thorough investigation. Any other interference would be as the result of the transmission line, which would be the same as any transmission line. By comparison, properly designed, constructed and tested large wind turbine installations should be the near safest of all possible major energy conversion systems.

The study area is located on the northern fringe of the American mid-continent tornado path. Design and operating criteria would have to take this into account in any event. This would, at the same time, take care of risks posed by some of the vicious storms which are occasionally, but infrequently, experienced on Lake Michigan.

Unfortunately, not too much is known about safety risks associated with icing conditions.

Modern technology should be able to overcome the problem which caused one of the blades of the Grandpa's Knob to fail and travel a reported 70 feet.

No particular problem is foreseen. The area is well covered by transmission and distribution lines of the Hart electric system, the Oceana Electric Cooperative System, 
Visual

Aesthetics

Vandalism Risks the Wolverine Cooperative distribution system, as well as lines in substations of Consumers Power Company.

In fact, distributed wind turbine operation could help reduce transmission losses, which for these systems run up to about $12 \%$.

Whereas it may be desirable to keep towers off of hillcrests and out of open areas of high visibility, this is not too compatible with effective wind turbine operation. Moreover, it may be desirable to avoid "scenic" areas, yet often the best sites may also be the most "scenic." One is not sure of this, the many windmills in Europe which are still there are considered "scenic" treasures. Whether the visual impact of wind turbines in prominent locations is sufficiently objectionable to retard development of wind turbine systems is in the least unknown at this time. The issue is further beclouded by the fact that modern wind turbines initially are likely to be a novelty and therefore readily acceptable structures wherever they may be located.

Aesthetic design of wind turbine installation could do much to make them fit into ratural surroundings, considering observer positions and background patterns. Whether lattice towers or any other kind of a tower would have to be determined by the proposed location. Color schemes may be important. Non-reflective paints may be a must. Initially, wind turbine installations will bring with them potential disruption of the environment by curiosity seekers, tourists and vandals. There is the risk of litter and traffic jams. Such events would have to be carefully controlled from the very beginning. Properly handled, this could bring economic benefits.

Aside from environmental impact questions, the problem of vandalism has to be faced. For example, the electric utilities have been troubled for many years with damage from gun and rifle fire. Such damage could be aggravated 
if certain people or groups in this minority objected to wind turbine installation. (How does one keep marksmen from using rotating--or idle--turbine blades for practice targets?)

\section{4. Summary}

Questions of impact have been considered and discussed. Subject to much more detailed analysis and assessment, which would exceed the scope of the present study, it can be said with reasonable confidence that--from environmental, human and ethical values points of view-application of wind power to small electric systems, such as those which - serve the study area, is possible. Objections are likely to be quite limited. The exception could be installations on the beaches of Lake Michigan. The magnitude of that problem would have to be determined empirically.

Up to this point, this part of the study was able only to "scratch the surface." The investigation centered on only five sample sites which may be representative. More intensive study will undoubtedly bring to light more facts. Whether such facts turn out to be much less affirmative than what has been described herein appears to be doubtful. Yet, this should not discourage a more intensive treatment of the impact question which will continue to be a part of this study.

\section{SYSTEMS MODEL FOR THE HART POWER SYSTEM WITH WIND TURBINES}

\section{1. Need for Evaluation Model}

The cost-benefit analysis for the Hart system with wind-turbines discussed in Section 6 is based upon monthly average wind velocities and monthly energy consumption in kwh. In other words, this is a deterministic average estimate which does not account for fluctuations in wind and in power demand. When the proposal for this project was written, the investigators anticipated that an evaluation method, statistically accounting for the random nature of wind, water flow, fuel prices, and demand, would be needed for a definitive statement as to the economic feasibility of wind generation for the Hart and similar systems. It was contemplated that several different scenarios, involving several sizes of 
wind generators at several locations. would be evaluated against the benchmark scenario discussed in Section 7. The output of the se evaluations would be a probabilistic distribution of costs and benefits so that conclusions could be stated in statistical terms, i. e., : the probability that the benefits will exceed the costs will be, say, 0.9 for a certain configuration. Obviously, worst and best case scenarios can also be $r$ un but the investigators believe it is better to recognize explicitly the random nature of the wind as an energy source. The statistical approach allows for random fluctuations in demand, in fuel prices, and in water flow.

\section{2. Choice of Parameters in Evaluation Model}

The choice of exogenous variables into the model, the basic time interval of computation, and the level of detail (aggregation) within the model is limited by the time interval over which data is available, the desired output variables, and the accuracy of available information on the conversion behavior of the wind generators. A basic time interval of one hour was determined because the load or demand data from operating logs of the Hart system is available at hourly intervales, and also because the wind recorder output tapes are difficult to read at less than hourly intervals, and further because a five-year run would involve 720 times 12 times five $=43,000$ output points. This number of data points is large, but feasible, whereas intervals of one second would yield too much output. This decision evokes the question of short-term wind fluctuations and the inaccuracy induced by assuming the. wind to be constant over hourly intervals. The GE and Kaman prototype data available to the research team indicated that the various control systems in the wind stations have settling times on the order of one to two minutes implying a minimum time interval for a steady-state or static wind-generator model of one or two minutes. (It will be necessary for the MSU team to investigate gust statistics over the time scale from one minute to one hour to validate the assumption of accuracy of hourly wind averages.)

The choice of exogenous variables was immediate--rate variables (wind velocity, power in $\mathrm{kW}$, and water flow in cfs) are more fundamental than level variables (energy) which can be readily found by integrating the rate variables. The exogenous rate variables chosen were wind velocity 
$\mathrm{WV}$ at two or three sites, water flow into the hydro pond in cfs, and Hart load and losses in $\mathrm{kW}, \mathrm{PL}$. The other exogenous variable is cost of fuel--oil and natural gas. Other obvious variables such as temperature are included implicitly in PL.

\section{3. Model Structure}

From these choices, it then follows that model internal variables include power produced by wind $P W$, by Diesel PD, and purchased from Wolverine $\mathrm{PW}$.

Internal model structure (interactions of variables and processes relating them) follows from the static assumption that the Hart demand PL is met by using all available wind power and producing the remainder by diesel and hydro or by purchase from Wolverine. The remaining structure is for costing and energy accounting. The model, shown in preliminary block-diagram form in Figure 29 can be changed to sell excess energy to Wolverine. This model and its implementation is discussed further in our proposal for an additional year of funding. At present, it is in the conceptual stage and programming and refinements have not been attempted. 


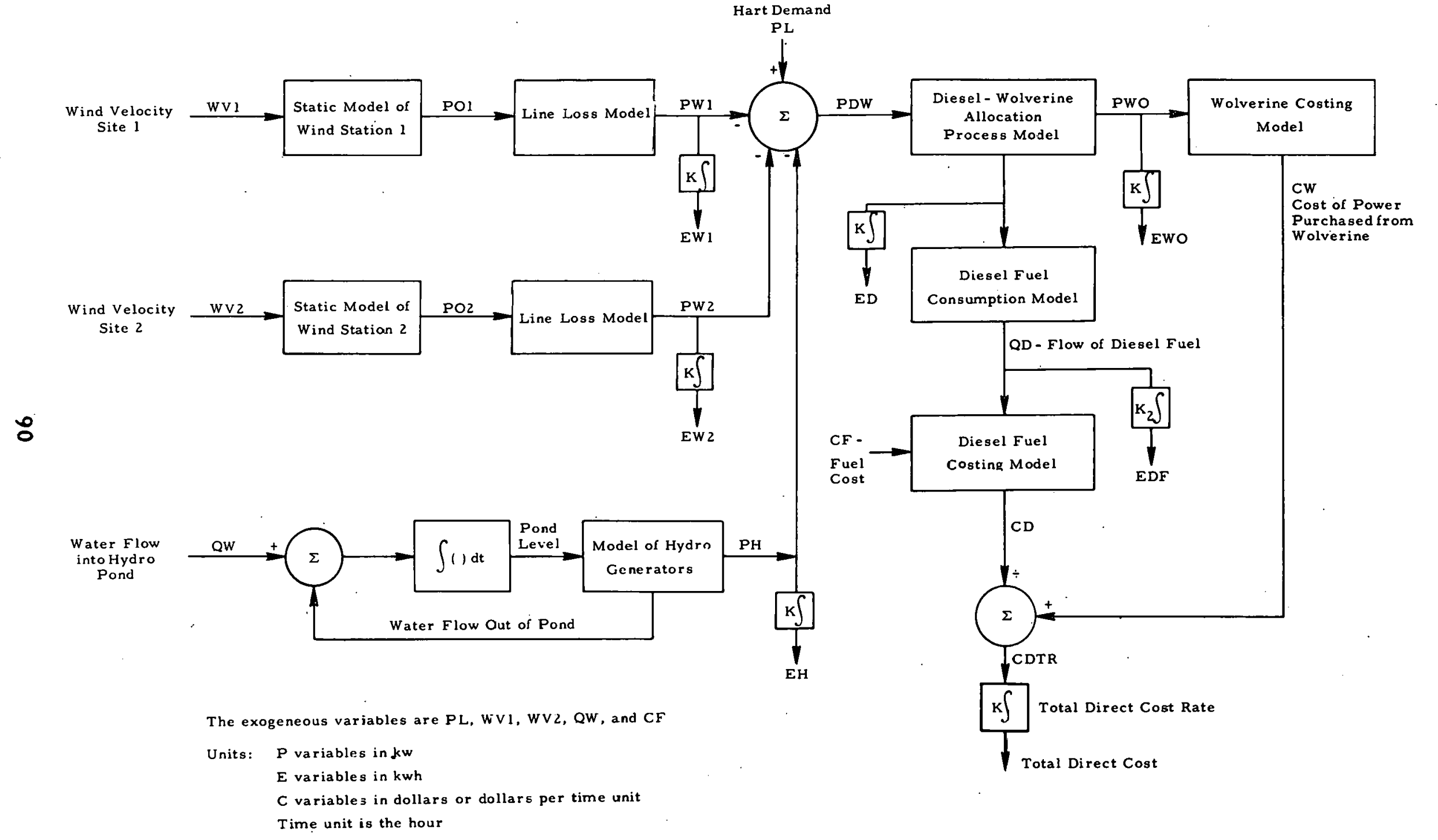

Figure 29. Evaluation model. 


\section{REFERENCES}

1. S. E. Rogers, "Environmental Effects of Wind Energy Conversion Systems, "Proceedings of the Second Workshop on Wind Energy Conversion Systems, Washington, D. C. ,. June 9-16, 1975.

2. M. J. Changery, "Initial Wind Energy Data Study," NSF-RANN75-020, May 1975.

3. A. G. Davenport, "The Relationship of Wind Structure to Wind Loading, " National Phy sical Laboratory, Symposium No. 16, Wind Effects on Buildings and Structures, pp. 54-102, Her Majesty's Stationery Office, London 1955.

4. "Climate of Michigan by Stations," Michigan Department of Agriculture and Michigan Weather Service, December 1971.

5. J. W. Reed, "Wind Power Climatology of the United States," SAND74-0348, Sandia Laboratories, Albuquerque, New Mexico, June 1975.

6. J. W. Reed, "Wind Climatulogy, " Proceedings of the Second Wurkshop on Wind Energy Conversion Systems, Washington, D. C. , June 911,1975 .

7. C. G. Justus, "National Wind Energy Statistics for Large Arrays of Aerogenerators, "Progress Report No. 1, School of Aerospace Engineering, Georgia Institute of Technology, Atlanta, Georgia 30332.

8. J. G. Kemeny, A. Schleifer, J. Lauri Snell and G. L. Thompson, Finite Mathematics with Business Applications, Prentice-Hall, Inc. (1962) Englewood Cliffs, New Jersey. 


\section{OTHER REFERENCES}

10. 1. Environmental Impact

Rogers, S. E., "Environmental Effects of Wind Energy Conversion Systems, "Proceedings of the Second Workshop on Wind Energy Conversion Systems, Washington, D. C., June 9-16, 1975.

Environmental Analysis for Federated Electric Cooperative, Inc. ; McLindon, G. J.; Louisiana State University, March 1972.

Power Line Environmental Analysis; Public Service Company of Colorado, Denver, Colorado, April 1974.

Ultra High Voltage Transmission System Assessment, R-1644; General Electric Company, Philadelphia, Pennsylvania; Commonwealth Associates, Jackson, Michigan.

Electric Power Transmission and the Environment, Federal Power Commission.

Evaluation of Power Facilities: A Reviewer's Handbook; Curran Associates, Inc., Northampton, Mass., April 1974.

Bradley, D. W. ; Conservation Planner, Bureau of Transportation Planning, Michigan Department of Highways and Transportation (verbal conversation).

\section{2. Energy Storage}

Hydroelectric Plant Construction Cost and Annual Production Expenses, Thirteenth Annual Supplement, 1969, Federal Power Commission, FPC S-211, Washington, April 1971.

Hydroelectric Plant Construction Cost and Annual Production Expenses, Fifteenth Annual Supplement, 1.971, Federal Power Commission, FPC S-211, Washington, April 1973.

Altman, M., Conservation and Better Utilization of Electric Power by Means of Thermal Energy Storage and Solar Heating, Report PB 210359 , UPTES-71-1, Phase I, University of Pennsylvania, Towne School of Civil and Mechanical Engineering, Philadelphia, October 1971.

Conservation and Better Utilization of Electric Power by Means of Thermal Energy Storage and Solar Heating, Report PB 210359 , UPTES-71-1, Phase II, Progress Report, University of Pennsylvania, Towne School of Civil and Mechanical Engineering, Philadelphia, December 1972.

Conservation and Better Utilization of Electric Power by Means of Thermal Energy Storage and Solar Heating, Report PB 210359 , UPTES$71-1$, Phase III, Progress Report, University of Pennsylvania, Towne School of Civil and Mechanical Engineering, Philadelphia, March 1973. 
Post, R. F. and S. F. Post, Flywheels, in Scientific American, 229 (6), 17-23, December 1973.

Decher, R., Compressed Air Energy Storage System Characteristics, Paper 739122 presented at the 8th Intersociety Energy Conversion Engineering Conference held at the University of Pennsylvania, Philadelphia, August 13-17, 1973, pp. 428-432 of Proceedings. Authors are connected with the University of California, Berkeley, Department of Civil Engineering.

C. C. Johnson, et al., Wind Power Development and Applications; in Power Engineering, pp. 50-53, October 1974.

Korsmeyer, R. B., Underground Air Storage and Electrical Energy Production, Oak Ridge National Laboratory, ORNL-NSF-EP-11, Oak Ridge, February 1972.

Denton, J. C. and H. G. Lorsch, Energy Conservation and Electric Load Leveling Through Thermal Energy Storage in Air Conditioning, in Proceedings of the Conference on Improving Efficiency in HVAC Equipment and Components for Residential and Small Commerical Buildings, Goldschmidt, V. W. (Ed. ), pp. 107-116, Purdue University, West Lafayette, 1974.

Stys, Z. S., New Energy-Storage Concept Sold, in Electrical World; 183: No. 12, pp. 46-47, June 15, 1975.

Staff Report on the Role of Hydroelectric Developments in the Nation's Power Supply, Federal Power Commission News; 7 : No. 24, pp. 17-22, June 14, 1974.

Robinson; A. L., Energy Storage, I. Using Electricity More Efficiently, in Science; 184: No. 4138, pp. 785-787, May 17, 1974.

Energy Storage, II. Developing Advanced Technologies, in Science; 184: No. 4139, pp. 884-887, May 24, 1974.

Thermal Storage Systems Aid Load Factor, in Electrical World; 184: No. 4, pp. 56-57, August 15, 1975.

Proceedings from the First National Symposium on Flywheel Technology sponsored by ERDA and Lawrence Livermore Laboratory, Berkeley, California, November 1975.

\subsection{Energy Utilization and Consumption}

Cargill, T. F. and B. A. Meyer, Estimating the Demand for Electricity by Time of Day, in Applied Economics, 3, pp. 233-246, Purdue University, West Lafayette, 1971.

Grot, R. A. and R. H. Socolow, Energy Utilization in a Residential Community, Working Paper W-7 presented at the NSF-RANN Symposium, Massachusetts Institute of Technology, February 14, 1973. Authors are at the Center of Environmental Studies, Princeton University. 
Tansil, John, Residential Consumption of Electricity, 1950-1970, ORNL-NSF-EP-51, Oak Ridge National Laboratory, Oak Ridge, July 1973.

A Study of Electric Space Conditioning in New York State, New York State, Department of Public Service, Albany, no date given.

Residential Energy Consumption--Phase I Report, HUD-HAI-1, Hittman Associates, Columbia, March 1972.

Residential Energy Consumption--Multi Family Housing Data Acquisition, HUD-HAI-3, Hittman Associates, Columbia, October 1972.

Residential Energy Consumption--Verification of the Time-Response Method for Heat Load Calculation, HUD-HAI-5, Hittman As sociates, Columbia, August 1973.

The Applicability of the Residential Energy Consumption Analyses to Various Geographic Areas, HUD-HAI-6, Contract H-1654, Department of Housing and Urban Development, Office of Policy Development Research, Washington, November 1973.

Kaufman, A. (Ed.), New York State Public Service Commission, Staff Report, Albany, August 1973.

Anderson, K. P., Residential Energy Use: An Econometric Analysis, Report R-1297-NSF, Rand Corporation, Santa Monica, October 1973.

Figley, K. A., The Residential User and the Electrical Load Factor, NSF/RANN/SE/Gl29729/TR/73/1, University of Pennsylvania, National Center for Energy Management and Power, Philadelphia, July 1973.

Galanis, N. and A. Delisle, Performance Evaluation of Wind-Driven Heating Systems, Paper 739065, presented at the 8th Intersociety Energy Conversion Engineering Conference held at the University of Pennsylvania, Philadelphia, August 13-17, 1973, pp. 376-381 of Proceedings. Authors are connected with the University of Sherbrooke, Department of Mechanical Engineering, Sherbrooke, Quebec, Canada.

Mor row, B., New Look at the Heat Pump, in Hydro News; 60: No. 5, pp $7-10,1973$.

Smith, W. T., Energy Use in Military Housing, in Airconditioning, Heating and Refrigeration News; vp, August 3, 1973.

Mutch, J. J., Residential Water Heating: Fuel Conservation, Economics and Public Policy, Rand Corporation, Santa Monica, 1974.

Jones, H. G. M. and N. Bhagat, Residential Energy Consumption and Income: A Methodology for Energy Policy Analysis Applied to the Greater New York Region, Brookhaven National Laboratory and State University of New York, Stony Brook, BNL - 18818, April 15, 1974. 
Jacobson, D. A., et al., A Model of Commercial Energy Use in Wisconsin, University of Wisconsin, Madison, December 1974.

Frey, D. A., A Model of Residential Energy Use in Wisconsin, University of Wisconsin, Madison, December 1974.

Tree, D. R. and J. F. Hamilton, Energy Requirements of Residential Homes, in Proceedings of the Conference on Improving Efficiency in HVAC Equipment and Components for Residential and Small Commercial Buildings; Goldschmidt, V. W., (Ed.) pp. 202-213, Purdue University, West Lafayette, 1974.

Dunning, R. L., Efficiency änd Cost of Various Residential Heating Systems, in Proceedings of the Conference on Improving Efficiency. in HVAC Equipment and Components for Residential and Small Commercial Buildings, Goldschmidt, V. W., (Ed.) pp. vp, Purdue University, West Lafayette, 1974.

Baughman, M. L. and P. L. Joskow; Energy Consumption and Fuel Choice by Residential and Commercial Consumers in the United States, LBL - 3635, pp. 101-119, Massachusetts Institute of Technology, Cambridge, 1974.

Dunning, R. I.; Electric-Resistance Heating Does Not Waste Fuel: In Fact, In Many Applications It Conserves Energy, in Electric Appliances; 28: No. 1, pp. 31-32, May 1975.

Newman, D. K. and D. Day, The American Energy Consumer, Ford Foundation Energy Policy Project, Ballinger Publishing Company, Cambridge, Mass. (This is the result of a national sample survey of 1500 households and another survey of the utility companies which serve them.) 
The rising cost of electricity is a problem for all of us. One long-range possibility for lower cost electricity is the utilization of wind power to produce it. The idea of using the wind to do this kind of work is not new, but whether it can reduce the cost of electricity has yet to be demonstrated.

Michigan State University researchers are doing a study of the application of wind power to benefit the Hart municipal electric system. As part of this study, they need some information from you -- a user of electricity. We hope that you will respond.

Enclosed with your monthly bill is a questionnaire. Please take a little time to answer it as well as you can. Then return it to the Hart Hydroelectric Company in the enclosed envelope. Your cooperation will indeed be helpful.

1. Name of person filling out this form:

2. Address:

3. Your phone number:

4. How many people live in the above residence?

5. Give the ages of each male living in the residence:

6. Give the ages of each female living in the residence:

7. This residence is (check one):
A house basement 1 story 2 story An apartment in a house An apartment in an a partment house A mobile home Other (explain)

8. Is this residence rented by you? Yes No If yes, to whom do you pay rent: Name Address 
Please answer the following questions only if you are reasonably sure of the answer.

9. About how many square feet of floor space are in this residence?

10. Is this home insulated? (Check all that apply)

In the ceiling 6 inches or less 8 inches or less In the walls

Under the floors (if there is no basement)

11. Does this residence have storm windows? Yes No

12. Home is heated by: (check one)

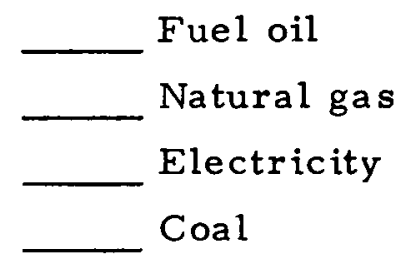

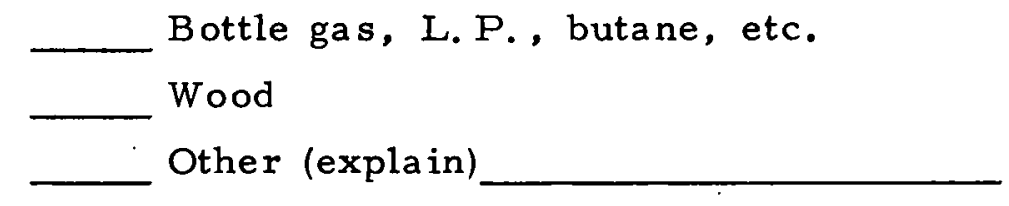
No How many?

13. This home has only space heaters: Yes Yes No

14. What type of air conditioning (check all that apply): Central air conditioning

Electric Natural gas
Size of central air conditioner:
BTU's Window How many? What size are the air conditioners? BTU's (See name plate for BTU size)

15. a. Water heater? Yes No Capacity Gallons

Electric
Natural gas
Oil
Yes No 
b. Range? Yes

Electric.

Natural gas
Wood
Coal

How many burners?

How many ovens?

Self-cleaning oven?

Microwave oven?

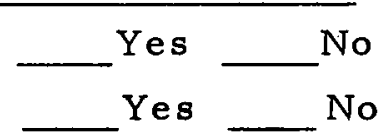

c. Refrigerator? Yes No Electric Gas

More than one? How many?

Frost-frec freezer compartment?

Frost-free food compartment?

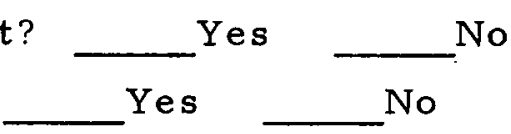

d. Freezer? Yes No Capacity cubic feet

Chest? Upright? Frost-free? Yes No

e. Televisions? Yes No

Black and white
Color

How many?

How many?

Does the color TV have instant-on? Yes No

16. Do you have a swimming pool? Yes No

17. Do you use an electric lawn mower?

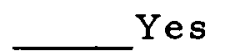
No Usually the lawn is mowed between: Early morning and 12 (noon) 12 (noon) and 4 p.m. 4 p.m. and sundown

Wind power availability is variable. When the wind blows, electricity can be generated; without sufficient wind, no electricity can be produced.

$R$ ight now we are measuring the wind power potential around Hart. In order to decide whether or not wind power will work for Hart, we must know when you use your appliances in your residence.

To the best of your knowledge, when do you use the following?

Dishwasher is used how many times weekly between:

4 a.m. and 12 (noon)

12 (noon) and 4 p.m.

4 p.m. and 8 p.m.
8 p.m. and 12 (midnight)

Have no dishwasher 
Clothes dryer is used how many times weèkly between:

$4 \mathrm{a}, \mathrm{m}$. and 12 (noon)

12 (noon) and 4 p.m.

4 p.m. and 8 p.m.

Is it a gas dryer?
8 p.m. and 12 (midnight)

Have no clothes dryer

Use coin laundry

Or an electric dryer?

Clothes washer is used how many times weekly between:

4 a.m. and 12 (noon)

12 (noon) and 4 p.m.

4 p.m. and 8 p.m.

I use cold water for washing:

Always

Sometimes

Never

How many showers are taken weekly between:

4 a.m. and 12 (noon)

12 (noon) and 4 p.m.

4 p.m. and 8 p.m.

8 p.m. and 12 (midnight)
8 p.m. and 12 (midnight)

Have no clothes washer

Use coin laundry

I use cold water for rinsing:

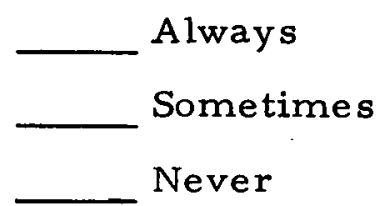

Average length of shower is:

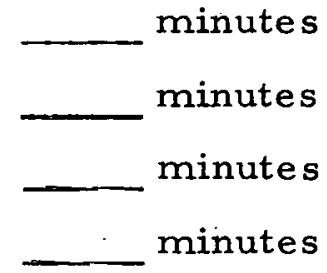

How many baths are taken weekly between:

4 a.m. and 12 (noon)

12 (noon) and 4 p.m.
4 p.m. and 8 p.m.

8 p.m. and 12 (midnight)

Thank you for the information and your time. Results of the study will be published when completed. 